Florida International University FIU Digital Commons

$11-10-2011$

\title{
Chloroperoxidase Catalyzed Enantioselective Epoxidation of Selected Olefins and Regiospecific Degradation of Dimethylsulfoniopropionate
}

Taiyi Chen

Florida International University, tchen003@fiu.edu

DOI: $10.25148 /$ etd.FI11120707

Follow this and additional works at: https://digitalcommons.fiu.edu/etd

\section{Recommended Citation}

Chen, Taiyi, "Chloroperoxidase Catalyzed Enantioselective Epoxidation of Selected Olefins and Regiospecific Degradation of Dimethylsulfoniopropionate" (2011). FIU Electronic Theses and Dissertations. 514.

https://digitalcommons.fiu.edu/etd/514 


\title{
FLORIDA INTERNATIONAL UNIVERSITY
}

Miami, Florida

\section{CHLOROPEROXIDASE CATALYZED ENANTIOSELECTIVE EPOXIDATION OF \\ SELECTED OLEFINS AND REGIOSPECIFIC DEGRADATION OF DIMETHYLSULFONIOPROPIONATE}

\author{
A thesis submitted in partial fulfillment of the \\ requirements for the degree of \\ MASTER OF SCIENCE \\ in \\ CHEMISTRY
}

by

Taiyi Chen

2011 
To: Dean Kenneth Furton

College of Arts and Sciences

This thesis, written by Taiyi Chen, and entitled Chloroperoxidase Catalyzed Enantioselective Epoxidation of Selected Olefins and Regiospecific Degradation of Dimethylsulfoniopropionate, having been approved in respect to style and intellectual content, is referred to you for judgment.

We have read this thesis and recommend that it be approved.

Kathleen Rein

Watson Lees

Xiaotang Wang, Major Professor

Date of Defense: November 10, 2011

The thesis of Taiyi Chen is approved.

$\begin{array}{r}\text { Dean Kenneth Furton } \\ \text { College of Arts and Sciences }\end{array}$
Dean Lakshmi Reddi
University Graduate School

Florida International University, 2011 
C) Copyright 2011 by Taiyi Chen

All rights reserved. 


\section{DEDICATION}

I dedicate this thesis to my husband Zhonghua Wang and my parents. The completion of this work would not have been possible without their love, support, and guidance. 


\section{ACKNOWLEDGMENTS}

I wish to thank many friends I have made here in Miami for helping me feel at home. First of all, I wish to express my sincerest and deepest gratitude to my major professor, Dr. Xiaotang Wang, for his incredible guidance, support, patience and encouragement over these years. I would also like to thank my committee members, Dr. Kathleen Rein and Dr. Watson lees, for their support and patience. Thanks to all the members of Dr. Wang's group, especially Zheng Wang, Lin Jiang, Hui Tian, Rui Zhang, Xiaofei Li, for their support, help, advice and friendship.

I thank my family and my friends for their support. I would not have survived this long journey from home without them. 


\author{
ABSTRACT OF THE THESIS \\ CHLOROPEROXIDASE CATALYZED ENANTIOSELECTIVE EPOXIDATION OF \\ SELECTED OLEFINS AND REGIOSPECIFIC DEGRADATION OF \\ DIMETHYLSULFONIOPROPIONATE \\ by
}

Taiyi Chen

Florida International University, 2011

Miami, Florida

Professor Xiaotang Wang, Major Professor

Chloroperoxidase (CPO), secreted by marine fungus Caldariomyces fumago, is the most versatile catalyst among known heme enzymes. Chloroperoxidase can catalyze epoxidation reactions with high enantioselectivity and high yield, which makes CPO an attractive candidate for both industrial and medicinal chiral synthesis. Toward this end, we have constructed two CPO mutants, F103A and N74V. Chiral HPLC was used to evaluate the enantioselectivity and yield of CPO and the mutants toward the epoxidation of styrene and its derivatives. Both of the mutants show dramatically changed epoxidation profiles compared to the parent protein. This information provided fresh insight into the mechanism through which $\mathrm{CPO}$ achieves its enantioselectivity. Furthermore, effort was made to understand the biological function of $\mathrm{CPO}$ through characterization of $\mathrm{CPO}$ catalyzed oxidation of dimethylsulfoniopropionate (DMSP), a secondary metabolite of many marine algal species that plays a pivotal role in marine ecology and global climate. 


\section{TABLE OF CONTENTS}

CHAPTER

PAGE

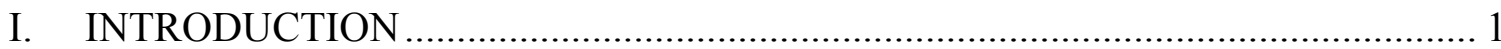

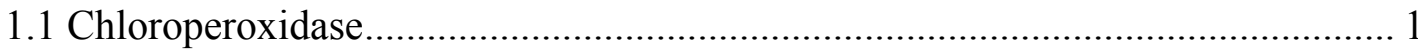

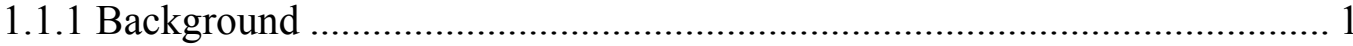

1.1.2 Mechanism of CPO catalytic cycle .......................................................... 1

1.1.3 CPO catalyzed enantioselective epoxidation reactions ............................... 2

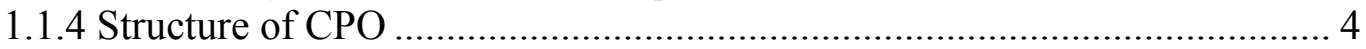

1.2 High Performance Liquid Chromatography ....................................................... 6

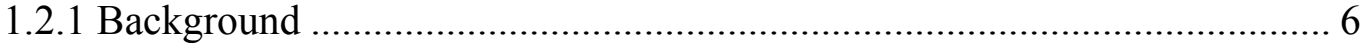

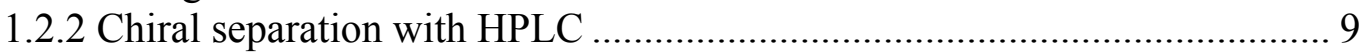

1.2.3 HPLC enantioseparation CSPs...................................................................... 11

1.2.4 Whelk-O 1 chiral stationary phase …………….................................... 13

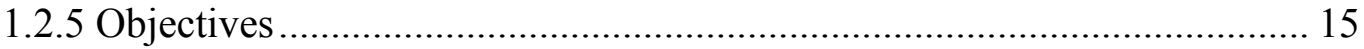

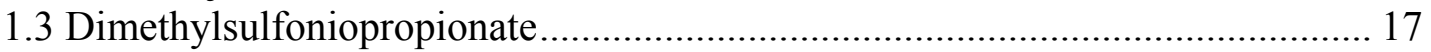

II. CHIRAL SEPARATION OF CPO AND ITS MUTANTS EPOXIDATION

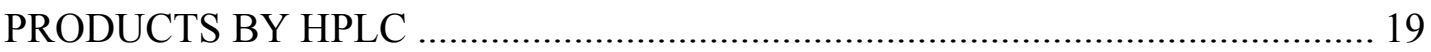

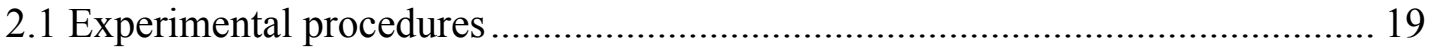

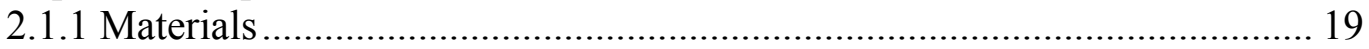

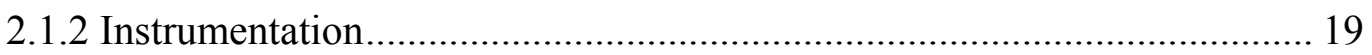

2.1.3 Expression and Purification of CPO F103A and N74V mutants ............... 20

2.1.4 Epoxidation of styrene and derivatives catalyzed by $\mathrm{CPO}$ and

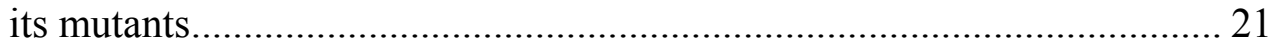

2.1.5 Chiral separation of styrene oxide and styrene oxide derivatives

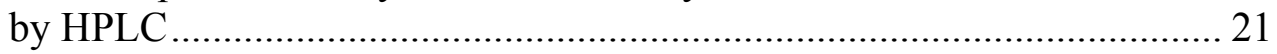

2.1.6 Identification of the enantiomers from CPO and its mutants catalyzed

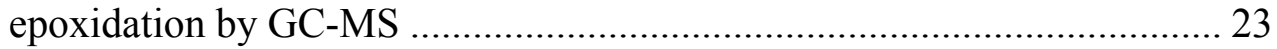

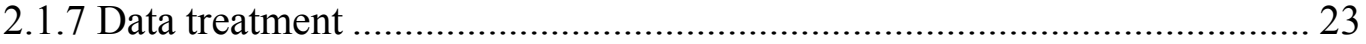

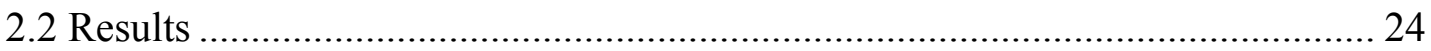

2.2.1 Development and optimization of HPLC method for the separation of styrene oxide and its derivatives ............................................................ 24

2.2.2 Identification of the epoxidation products of styrene and its derivatives catalyzed by WT CPO or its mutants ................................................... 32

2.3 Discussion and Conclusions ............................................................................ 36

2.3.1 Mobile phase modifier and temperature influence on Whelk-O 1

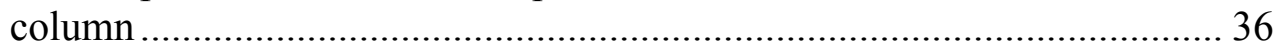

2.3.2 Elution order of styrene oxide and its derivatives ...................................... 55

2.3.3 Enantioselectivity and yield of CPO catalyzed epoxidation reactions....... 56

2.3.4 Enantioselectivity and yield of CPO mutants catalyzed epoxidation

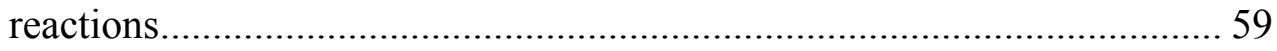

III. CPO CATALYZED REGIOSPECIFIC DEGRADATION OF DMSP ...................... 61

3.1 Experimental 
3.1.1 Materials

3.1.2 Instruments .................................................................................. 61

3.1.3 Oxidation of DMSP catalyzed by WT CPO and F103A ......................... 62

3.1.4 Identification of the products from CPO catalyzed oxidation of DMSP by GC-MS and LC-MS ....................................................................... 62

3.1.5 UV-vis absorption measurements of DMSO, DMS, 3-MPA and MSA .... 62

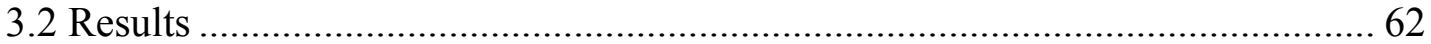

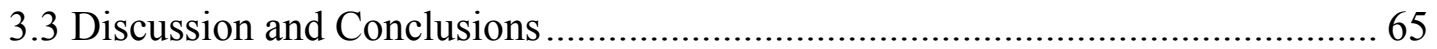

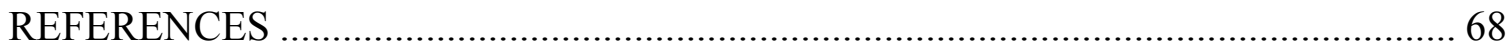

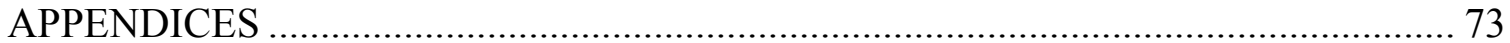




\section{LIST OF TABLES}

TABLE

PAGE

1.1 Major types of reactions catalyzed by CPO.................................................... 2

1.2 Structures of styrene and its derivatives and their epoxidation products................ 15

2.1 The influence of modifiers in mobile phase on the enantioseparation of styrene oxide, trans- $\beta$-methylstyrene oxide, and $\alpha$-methylstyrene oxide standards.

2.2 The influence of ethanol concentration in mobile phase and temperature on the enantioseparation of $\alpha$-methylstyrene oxide standard

2.3 The optimized HPLC conditions for the enantioseparation of styrene and its derivatives epoxidation products.

2.4 Enantioselective epoxidation results of styrene and its derivatives catalyzed by CPO, F103A and N74V 


\section{LIST OF FIGURES}

FIGURE

PAGE

1.1 Catalytic cycle of chloroperoxidase .................................................................. 3

1.2 The slice through a surface representation of CPO ......................................... 5

1.3 a. Diagram of the chromatographic process ................................................. 7

b. A chromatogram plotting the signal from a UV-vis detector ............................ 7

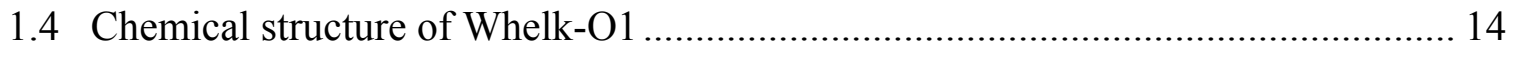

1.5 Routes for the degradation of DMSP by marine bacteria ................................ 18

2.1 Enantioseparation of styrene oxide standard on Whelk-O 1 column ..................... 26

2.2 Enantioseparation of trans- $\beta$-methylstyrene oxide standard

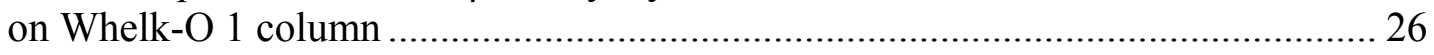

2.3 Enantioseparation of $\alpha$-methylstyrene oxide standard on Whelk-O 1 column......... 27

2.4 Effect of 2-propanol on separation of styrene oxide standard

on Whelk-O 1 column

2.5 Effect of ethanol on separation of styrene oxide standard on Whelk-O 1 column ... 28

2.6 Effect of 2-propanol on separation of trans- $\beta$-methylstyrene oxide standard on Whelk-O 1 column

2.7 Effect of ethanol on separation of trans- $\beta$-methylstyrene oxide standard on Whelk-O 1 column .

2.8 Effect of 2-propanol on separation of $\alpha$-methylstyrene oxide standard on Whelk-O 1 column .

2.9 Effect of ethanol on separation of $\alpha$-methylstyrene oxide standard on Whelk-O 1 column

2.10 Enantioseparation of $\alpha$-methylstyrene oxide standard on Whelk-O 1 column ......... 30

2.11 Enantioseparation of $\alpha$-methylstyrene oxide standard on Whelk-O 1 column ......... 31

2.12 Enantioseparation of $\alpha$-methylstyrene oxide standard on Whelk-O 1 column......... 31 
2.13 Enantioseparation of $\alpha$-methylstyrene oxide standard on Whelk-O 1 column .......... 32

2.14 Enantioseparation of styrene oxide catalyzed by CPO on Whelk-O 1 column ........ 37

2.15 Enantioseparation of styrene oxide catalyzed by F103A on Whelk-O 1 column..... 37

2.16 Enantioseparation of styrene oxide catalyzed by N74V on Whelk-O 1 column ....... 38

2.17 Enantioseparation of trans- $\beta$-methylstyrene oxide catalyzed by CPO

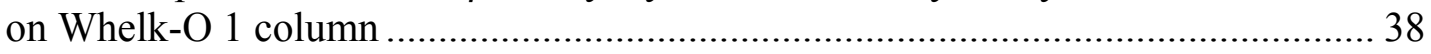

2.18 Enantioseparation of trans- $\beta$-methylstyrene oxide catalyzed by F103A

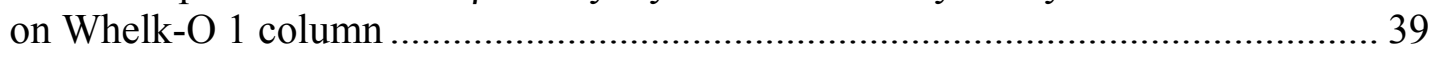

2.19 Enantioseparation of trans- $\beta$-methylstyrene oxide catalyzed by N74V

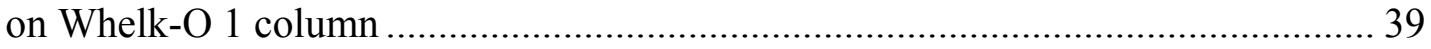

2.20 Enantioseparation of $\alpha$-methylstyrene oxide catalyzed by CPO

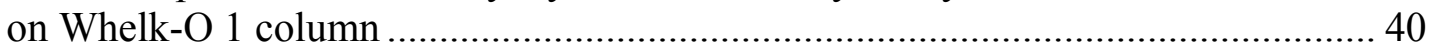

2.21 Enantioseparation of $\alpha$-methylstyrene oxide catalyzed by F103A

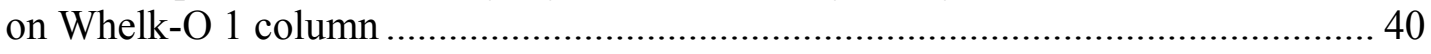

2.22 Enantioseparation of $\alpha$-methylstyrene oxide catalyzed by N74V

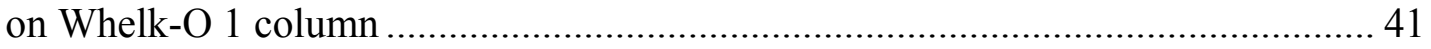

2.23 Enantioseparation of $\alpha$-methylstyrene oxide catalyzed by CPO spiked with racemic standard on Whelk-O 1 column

2.24 Enantioseparation of $\alpha$-methylstyrene oxide catalyzed by F103A spiked with racemic standard on Whelk-O 1 column

2.25 Enantioseparation of $\alpha$-methylstyrene oxide catalyzed by N74V spiked with racemic standard on Whelk-O 1 column

2.26 Enantioseparation of cis- $\beta$-methylstyrene oxide catalyzed by $\mathrm{CPO}$ on Whelk-O 1 column.

2.27 Enantioseparation of cis- $\beta$-methylstyrene oxide catalyzed by F103A on Whelk-O 1 column

2.28 Enantioseparation of cis- $\beta$-methylstyrene oxide catalyzed by F103A with $1 \mathrm{~S} 2 \mathrm{R}$ enantiomer on Whelk-O 1 column

2.29 UV-vis spectra of $(R)$-cis- $\beta$-methylstyrene oxide and $(S)$-cis- $\beta$-methylstyrene oxide 
2.30 Enantioseparation of cis- $\beta$-methylstyrene oxide catalyzed by N74V on Whelk-O 1 column

2.31 Enantioseparation of trans- $\beta$-ethylstyrene oxide catalyzed by CPO on Whelk-O 1 column.....

2.32 Enantioseparation of trans- $\beta$-ethylstyrene oxide catalyzed by F103A on Whelk-O 1 column

2.33 Enantioseparation of trans- $\beta$-ethylstyrene oxide catalyzed by N74V on Whelk-O 1 column. 46

2.34 Enantioseparation of $\beta$-dimethylstyrene oxide catalyzed by CPO on Whelk-O 1 column

2.35 Enantioseparation of $\beta$-dimethylstyrene oxide catalyzed by F103A on Whelk-O 1 column....

2.36 Enantioseparation of $\beta$-dimethylstyrene oxide catalyzed by N74V on Whelk-O 1 column

2.37 Mass spectrum of $(R)$ - trans- $\beta$-ethylstyrene oxide catalyzed by F103A 48

2.38 Mass spectrum of (S)- trans- $\beta$-ethylstyrene oxide catalyzed by F103A

2.39 Mass spectrum of $(R)$ - $\beta$-dimethylstyrene oxide catalyzed by F103A

2.40 Mass spectrum of $(S)$ - $\beta$-dimethylstyrene oxide catalyzed by F103A 50

2.41 Enantioseparation of $\alpha$-ethylstyrene oxide catalyzed by CPO on Whelk-O 1 column

2.42 Enantioseparation of $\alpha$-ethylstyrene oxide catalyzed by F103A on Whelk-O 1 column.

2.43 Enantioseparation of $\alpha$-ethylstyrene oxide catalyzed by N74V on Whelk-O 1 column.

2.44 Enantioseparation of $\alpha$-propylstyrene oxide catalyzed by CPO on Whelk-O 1 column...

2.45 Enantioseparation of $\alpha$-propylstyrene oxide catalyzed by F103A on Whelk-O 1 column.

2.46 Enantioseparation of $\alpha$-propylstyrene oxide catalyzed by N74V on Whelk-O 1 column. 
2.47 UV-vis spectra of $(R)$ - $\alpha$-ethylstyrene oxide and $(S)$ - $\alpha$-ethylstyrene oxide................ 53

2.48 UV-vis spectra of $(R)$ - $\alpha$-propylstyrene oxide and $(S)$ - $\alpha$-propylstyrene oxide........... 53

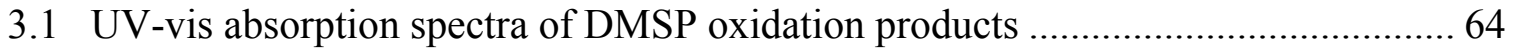

3.2 Activity assay of DMSP oxidation catalyzed by $\mathrm{CPO}$ at $25^{\circ} \mathrm{C}$ and $4{ }^{\circ} \mathrm{C} \ldots \ldots \ldots \ldots . . . . . .64$

3.3 Activity assay of DMSP oxidation catalyzed by F103A mutant ........................... 65 


\section{LIST OF ABBREVIATIONS}

ACRONYM

Ala

Asn

$\mathrm{CCN}$

$\mathrm{CPO}$

CSP

DEAE

DMS

DMSO

DMSP

ee

F103A

GC

Glu

HPLC

LC

MMPA

MPA

MS

MSA

N74V

P450
FULL NAME

Alanine

Asparagine

Cloud condensation nuclei

Chloroperoxidase

Chiral stationary phase

Diethylaminoethyl (cellulose)

Dimethyl sulfide

Dimethyl sulfoxide

Dimethylsulfoniopropionate

Enantiomeric excess

CPO with F103 to A mutation

Gas chromatography

Glutamic acid

High-performance liquid chromatography

Liquid chromatography

3-methiolpropionate

3-mercaptopropionate

Mass spectrometry

Methane sulphonic acid

CPO with N74 to V mutation

Cytochrome P450 
PDA

Phe

$\mathrm{Rz}$

TLC

UV-vis

WT
Photodiode Array

Phenylalanine

Reinheitzahl value

Thin layer chromatography

Ultraviolet-visible

Wild type 


\section{CHAPTER I. INTRODUCTION}

\subsection{Chloroperoxidase}

\subsubsection{Background}

Chloroperoxidase (CPO) is a $42-\mathrm{kDa}$ heme-containing glycoprotein secreted by the marine fungus, Caldariomyces fumago (C. fumago). ${ }^{1}$ It contains one ferriprotoporphyrin IX prosthetic group per protein molecule that is composed of 299 amino acid residues. ${ }^{2}$ CPO was originally found to catalyze halogenation reactions, and later on was discovered to catalyze a variety of one- and two-electron oxidations. ${ }^{3}$ As one of the most diverse and versatile heme peroxidases and a unique structure model for the study of heme peroxidase mechanisms, CPO has been extensively studied for half a century. However, the mechanism of CPO catalyzed enantioselective epoxidation is still not known with certainty and the biological function of CPO remains elusive.

In addition to catalyzing the typical peroxide-dependent halogenation reactions, $\mathrm{CPO}$ also catalyzes a variety of reactions, such as the classic one electron peroxidase reactions, catalase-type reactions, and P450-like oxidation reactions, as listed in Table 1.1. ${ }^{4-6}$ The reactions catalyzed by CPO can be divided into two categories based on whether or not the reactions require halide ions. The halide-dependent reactions are catalyzed by an acidic form of the enzyme, and the halide-independent reactions, such as epoxidation of alkenes and disproportionation of peroxides, are catalyzed by a neutral form of the enzyme. ${ }^{7}$

\subsubsection{Mechanism of CPO catalytic cycle}

The catalytic cycle of CPO, as shown in Figure 1.1, is initiated with $\mathrm{H}_{2} \mathrm{O}_{2}$ activation. The iron bound $\mathrm{H}_{2} \mathrm{O}_{2}$ is heterolytically cleaved to form a highly reactive oxo-ferryl 
Table 1.1. Major types of reactions catalyzed by CPO.

\begin{tabular}{|c|c|}
\hline $\begin{array}{l}\text { Halogenation } \\
\text { (normal function) }\end{array}$ & $\mathrm{RH}^{\mathrm{a}}+\mathrm{H}_{2} \mathrm{O}_{2}+\mathrm{X}^{-}+\mathrm{H}^{+} \longrightarrow \mathrm{R}-\mathrm{X}+2 \mathrm{H}_{2} \mathrm{O}$ \\
\hline $\begin{array}{l}\text { Dehydrogenation } \\
\text { (heme peroxidases) }\end{array}$ & $2 \mathrm{RH}+\mathrm{H}_{2} \mathrm{O}_{2} \longrightarrow \mathrm{R}-\mathrm{R}+2 \mathrm{H}_{2} \mathrm{O}$ \\
\hline $\begin{array}{l}\mathrm{H}_{2} \mathrm{O}_{2} \text { decomposition } \\
\text { (catalase) }\end{array}$ & $2 \mathrm{H}_{2} \mathrm{O}_{2} \longrightarrow \mathrm{O}_{2}+2 \mathrm{H}_{2} \mathrm{O}$ \\
\hline $\begin{array}{l}\text { Oxygen insertion } \\
\text { (P450s) }\end{array}$ & $\mathrm{R}+\mathrm{H}_{2} \mathrm{O}_{2} \longrightarrow \mathrm{R}-\mathrm{O}+\mathrm{H}_{2} \mathrm{O}$ \\
\hline
\end{tabular}

${ }^{\mathrm{a}} \mathrm{RH}$ and $\mathrm{R}$ represent substrates. $\mathrm{X}^{-}$is the halide ions.

porphyrin radical cation intermediate, Compound I. The distal Glu183 residue, in contrast with the distal histidine in other heme peroxidase, was suggested to play an important role as a general acid-base catalyst in facilitating the reaction between the peroxidase and $\mathrm{H}_{2} \mathrm{O}_{2}$. Compound $\mathrm{I}$, which preserves both of the oxidizing equivalents from hydrogen peroxide, is a common reaction intermediate of heme peroxidases. ${ }^{8-11}$ All reactions catalyzed by $\mathrm{CPO}$ are ping-pong reactions, in which Compound I is formed first and subsequently reacts with a second substrate to return CPO to its resting state. ${ }^{7}$ The first oxidizing equivalent is transferred to the substrate through a one-electron reduction of the porphyrin radical and leads to the formation of a second active intermediate, Compound II. The second oxidizing equivalent stored in Compound II is then released via a second one-electron reduction to restore the enzyme to its resting state. ${ }^{12-13}$

\subsubsection{CPO catalyzed enantioselective epoxidation reactions}

$\mathrm{CPO}$ is an effective catalyst for enantioselective epoxidation giving high turnovers and high yield in concert with high enantiomeric excess (ee). The chiral epoxidation 


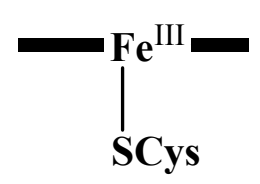

Resting state
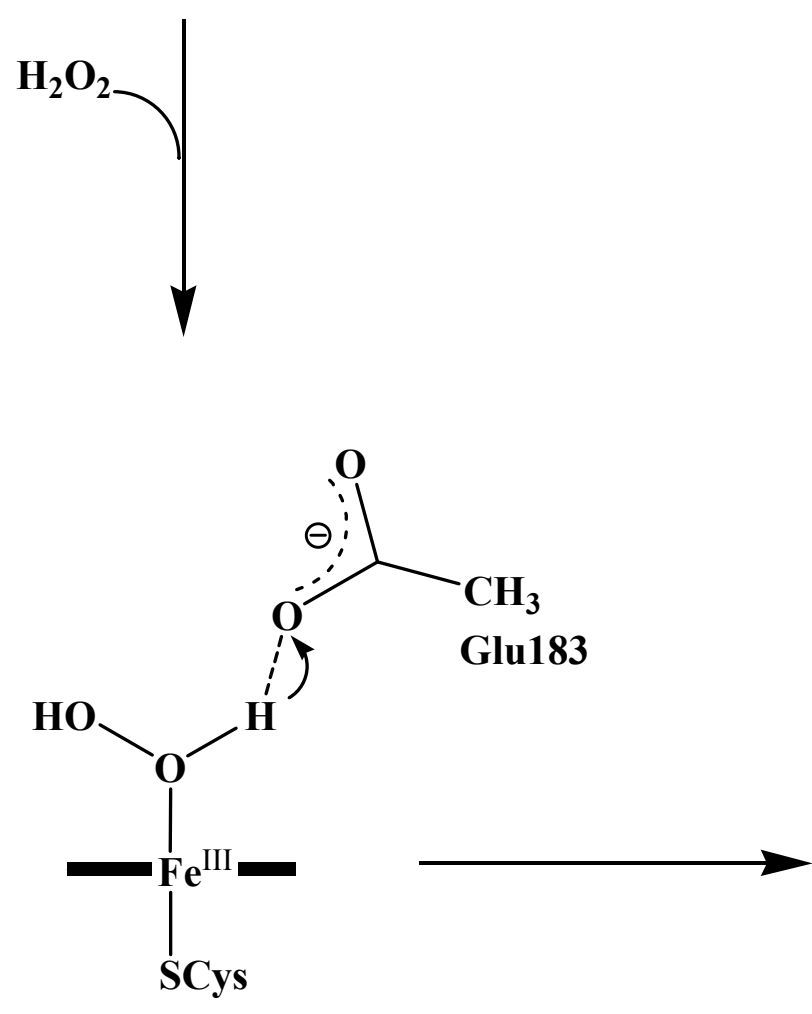

$\mathrm{Fe}^{\mathrm{III}}-\mathrm{HOOH}$
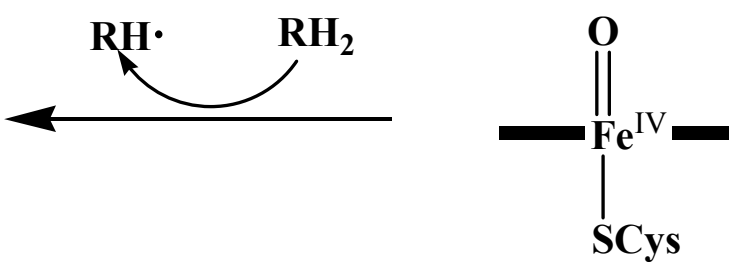

Compound II
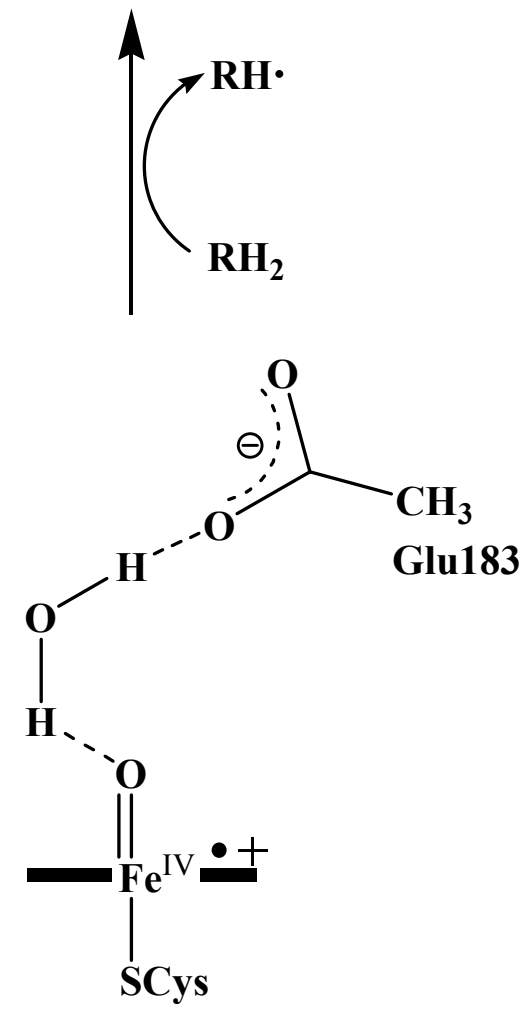

Compound I

Figure 1.1. Catalytic cycle of chloroperoxidase. $\mathrm{RH}_{2}$ and $\mathrm{RH} \cdot$ represent a reducing substrate and its radical product, respectively.

substrates of CPO include olefins, ${ }^{14-15}$ sulfides, and indole, ${ }^{16}$ and also chiral benzylic and propargylic hydroxylations. ${ }^{17}$ Remarkably, CPO catalyzed epoxidation products of styrene and its derivatives are widely used as intermediates in the synthesis of drugs, and agricultural and biological chemicals. ${ }^{18-20}$ Therefore, CPO has a great popularity and tremendous potential for industrial applications as a chiral catalyst. 


\subsubsection{Structure of CPO}

CPO shares many structural and catalytic features with both peroxidases and P450 enzymes. CPO has a cysteine ligand located on the proximal side of the heme, which is the same as in P450. Furthermore, the local hydrogen-bonding environment involving the cysteine sulfur in $\mathrm{CPO}$ is suggested to be similar to $\mathrm{P} 450 .^{21-22}$ On the other hand, $\mathrm{CPO}$ shares a polar distal side environment with peroxidases, which is different from $\mathrm{P} 450{ }^{23}$ $\mathrm{CPO}$ also has a unique structural feature by utilizing a glutamate residue as the acid-base catalyst that participates in the peroxide O-O bond cleavage mechanism, in contrast to the histidine residue in traditional peroxidases. ${ }^{24}$

The enantioselectivity of $\mathrm{CPO}$ has been attributed to the limited access of substrates to the heme active center. The heme edge of $\mathrm{CPO}$ is not as accessible as it is in other peroxidases, while the substrate pocket is directly adjacent to the oxo-ferryl center in Compound I via two access channels above the heme center, as shown in Figure 1.2..$^{23-24}$ The narrow channel contains several halides binding sites, and therefore was suggested as a pathway for access of halide anions to the active site. ${ }^{25}$ The second channel with a larger diameter (wide channel) which connects the surface to the heme active site is mostly hydrophobic near the heme and more polar at the top. ${ }^{26}$

The wide channel is thought to be the pathway for organic substrates to get into the heme active site. ${ }^{21}$ Therefore, the amino acids located in the wide channel must play an important role in directing and adjusting substrate binding. It is noticed that a pair of phenylalanines (Phe103 and Phe186) are situated at the bottom of the wide channel. The side chains of Phe186 and Phe103 are located almost parallel atop of the heme plane and shield the active site from solvent. ${ }^{24}$ In the crystal structures of CPO complexed with 
substrates, it is reported that most substrates are sandwiched between Phe103 and Phe186, with a distance of $3.5 \AA$ to both aromatic side chains. ${ }^{25}$ Compared to the substrate free form of $\mathrm{CPO}$, a small conformational change is observed, in which the side chain of Phe103 moves $0.5 \AA$ away from the active site for steric reasons upon substrate binding. ${ }^{24,27}$ Therefore, mutating Phe103 by removing its phenyl group may open the bottom of the wide channel to allow bulkier substrates to access the active site, and meanwhile may change the stereoselectivity of $\mathrm{CPO}$ catalyzed epoxidation reactions.

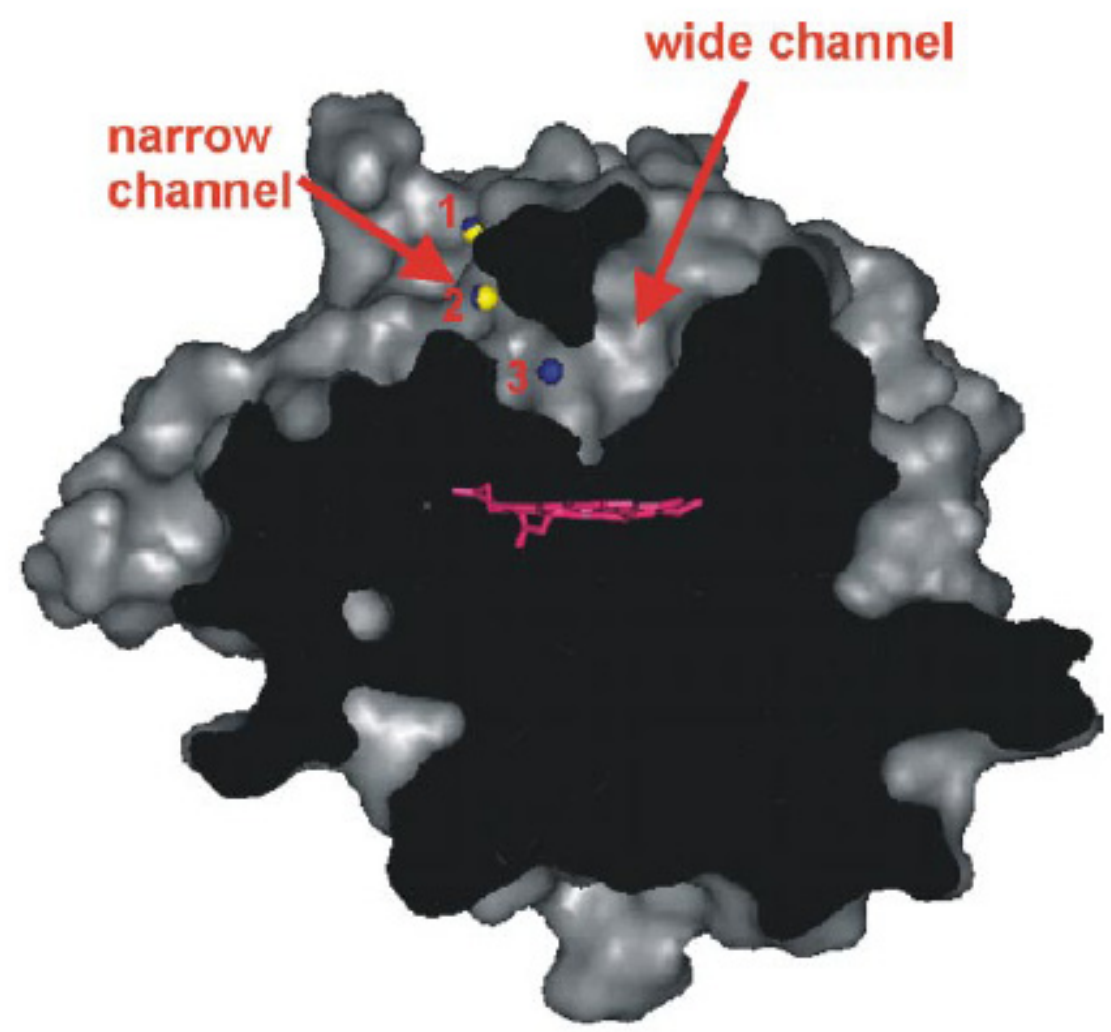

Figure 1.2. The slice through a surface representation of $\mathrm{CPO}{ }^{25}$ The two channels leading to the active site are marked by arrows, and the heme is shown in magenta. The sites 1,2 and 3 are the halide binding sites located within the narrow channel.

Another amino acid, located at the joint of the wide channel and the narrow channel, which attracted our attention is Asn74. Asn74 is the only hydrophilic amino acid along 
the wide channel, besides the proposed acid-base catalyst Glu183. It has been suggested that the amide group of Asn74 can form a hydrogen bond with halides and the polar moieties of substrates, and therefore controls the binding position and orientation of polar substrates. ${ }^{28}$ It is thus expected that changing Asn74 to a hydrophobic amino acid may greatly affect the stereoselectivity of CPO catalyzed halogenation and epoxidation/sulfoxidation reactions.

\subsection{High Performance Liquid Chromatography}

\subsubsection{Background}

Liquid chromatography (LC) was invented by Mikhail Tsvet, a Russian botanist who separated plant pigments in 1903, and has been used to separate mixtures of analytes into their constituent components for decades. ${ }^{29}$ Because of its powerful ability and diversity, it has been developed as one of the indispensable tools for academic research and industry.

In a liquid chromatographic technique, components in a mixture can be separated by distributing between the mobile phase and a stationary phase. The mobile phase can be any solvent or solvents mixture. The stationary phase consists of a matrix through which the solvent moves. A diagram of the chromatographic process is showed in Figure 1.3a, where the components of the sample (A and B in this example) are separated as they move through the column filled with packing. The separated components are continuously monitored by a detector as they are eluted from the column. The resulting detector signal generates the chromatogram, as shown in Figure 1.3b. The different motivating speeds of components $\mathrm{A}$ and $\mathrm{B}$ along the column are due to the different affinities of $\mathrm{A}$ and $\mathrm{B}$ for the stationary phase. 


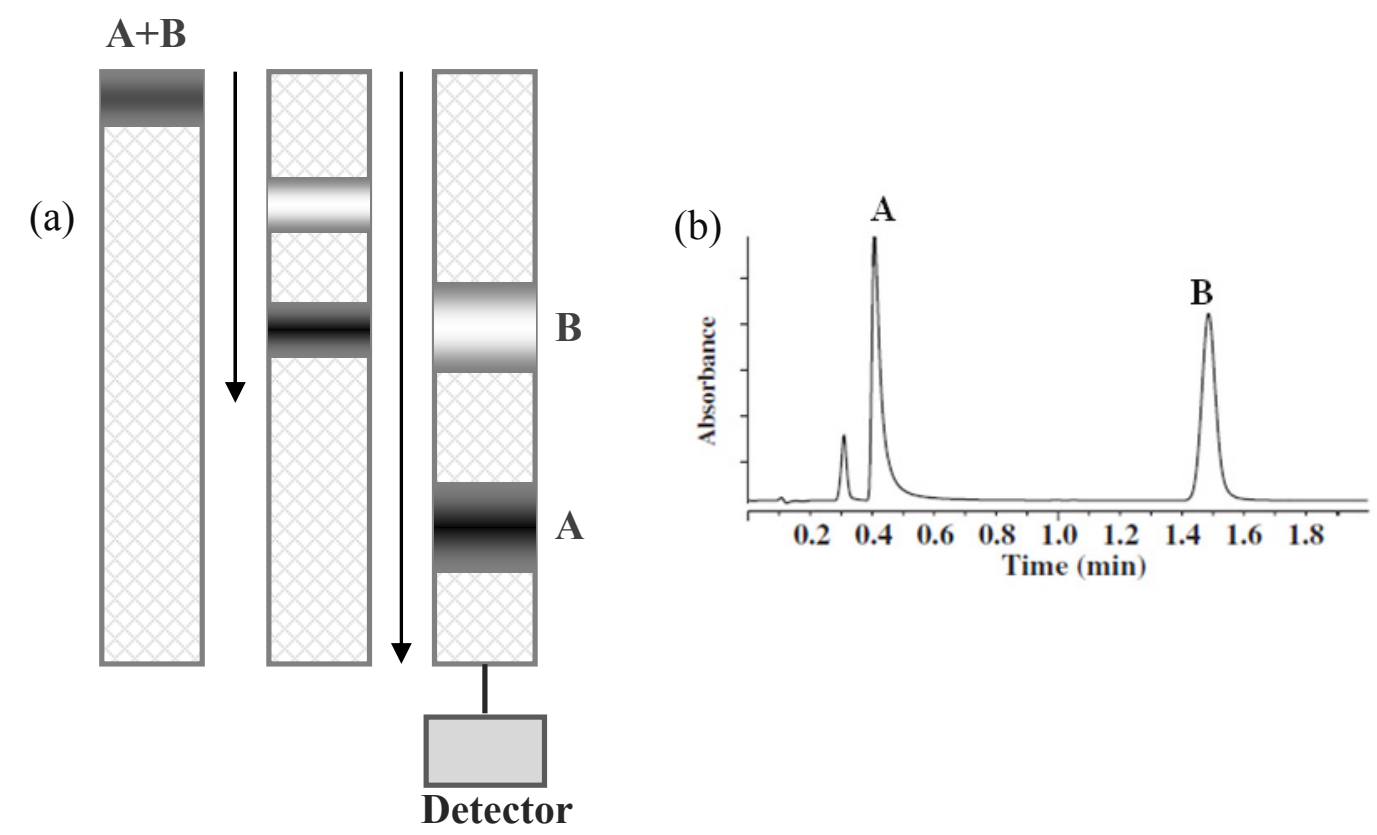

Figure 1.3. (a) Diagram of the chromatographic process showing the migration of two bands of components through a column. (b) A chromatogram plotting the signal from a UV-vis detector shows the elution of components A and B.

Few dependable chromatographic techniques were commercially available to scientists before the 1960s. The open-column methods, such as paper chromatography and thin-layer chromatography were used for most chemical separations during the 1960s. There were still serious limitations for the separation of similar compounds at that time. High-performance liquid chromatography (HPLC) arose in the late 1960s with the use of high pressure pumps and small particle columns. With the development of computers and in-line detectors, HPLC was quickly improved into a sensitive and quantitative technique. In the 1980s, HPLC had become an indispensable technique for the separation of chemical compounds in diverse industries. ${ }^{29}$ With the development of HPLC, the stationary phase materials used in LC become progressively diversified. Currently, a variety of types of columns can be selected based on different mechanisms for the separation of compounds, such as ion-exchange columns, adsorption columns, size- 
exclusion columns, and chiral columns.

High-performance liquid chromatography is the method of choice for the separation and analysis of non-volatile or thermally-unstable compounds. As an LC technique, compounds to be analyzed are dissolved in a suitable solvent and then forced through a chromatographic column under high pressure. These compounds elute at different times because of different migration speed, and are then passed through the detection system to yield qualitative and quantitative information.

Commercially available detectors include ultraviolet, mass-spectrometry, fluorescence, electrochemical, refractive index, and conductivity. ${ }^{29}$ By far the most commonly employed detectors in HPLC are ultraviolet (UV) detectors, which can provide adequate response for most analytes. UV detectors operate in the approximate wavelength range of 190-400 nm. If necessary, UV visible light detectors can expand this range up to $700 \mathrm{~nm}$ or more for the detection of colored analytes. It is imperative to select a wavelength at which the background absorbance of the mobile phase is minimal.

Much more rapid scanning can be achieved with the aid of a photodiode array (PDA) detector, which can scan a range of wavelengths every few milliseconds and record the LC Chromatogram simultaneously. The wavelength range can be programmed to detect all compounds absorption spectra in a single analysis. Photodiode array detectors can therefore determine the spectrum of each compound in the chromatogram and provide maximum sensitivity for all peaks. The assessment of peak purity can be provided by comparing the similarity of UV spectra at various points across the peak, in which a pure compound will produce a characteristic spectrum throughout the whole peak. Photodiode array detectors can also provide three-dimensional and two-dimensional contour plots, 
showing the relationship between wavelength, time, and absorbance. This feature can be used to detect whether there are overlapped peaks in a single chromatogram. Furthermore, the spectrum of each peak in the chromatogram can be collected and subsequently compared with those stored in a library, which facilitates the determination of peak homogeneity and identity. ${ }^{30-31}$

\subsubsection{Chiral separation with HPLC}

The pharmacological, pharmacokinetic, and toxicological behavior of the enantiomers of racemic drugs can differ widely. Therefore, separation of enantiomers has become very important in industrial fields, such as chiral synthesis, biochemistry, agricultural chemistry, pharmacology and medicine. ${ }^{32}$ However, efficient separation of enantiomers has been considered as one of the most difficult problems in chemistry. It is therefore important to develop enantioselective separation methods using chromatographic methods for evaluating the safety and the effectiveness of drugs containing chiral centers. Among the chromatographic methods currently used to achieve chiral separation of racemic mixtures, high resolution liquid chromatography methods based on chiral stationary phases (CSPs), are widely employed for the resolution of racemic mixtures of pharmacologically active chemical isomers. ${ }^{33-34}$

High-performance liquid chromatography is a versatile analytical technology widely used for the analysis of pharmaceuticals, biomolecules, and many ionic and organic compounds. ${ }^{30}$ During the past three decades, HPLC has been developed rapidly in the area of chiral applications. ${ }^{35}$ Compared with thin layer chromatography (TLC), HPLC can provide more rapid yet precise quantitative analysis, higher sensitivity and efficiency, better quantitative sample recovery and better reproducibility. Compared with gas chromatography 
(GC), HPLC is amenable to many more samples than GC. This is mostly because of the fact that the volatility and thermostability of the analyte are not a concern in HPLC. ${ }^{36}$

Briefly, chiral separation methods used for HPLC can be divided into two categories based on the use of chiral selectors: indirect enantioseparation and direct enantioseparation. In the indirect chiral separation method, the enantiomers are coupled with a derivatization agent to form diastereomers. Unlike enantiomers, diastereomers have different physical and chemical properties and therefore are resolvable in ordinary achiral environments. Original enantiomers are obtained from the rearrangement of the separated diastereomers after the chromatographic run. ${ }^{37}$ The indirect enantioseparation in HPLC has been used for many years and is still commonly performed for various purposes. The enantiomeric molecules frequently possess relatively easily derivatizable functional groups, such as alcohols, primary or secondary amines and carboxylic acids. The location of the functional group should be close to the chiral center in the molecule. ${ }^{38-39}$

In direct chiral separation methods, the enantiomers to be resolved are not amended. The enantiomers can interact with a chiral selector to form transient diastereomeric molecule associates. These diastereomers may have different behavior in the HPLC system, which result in the separation of the enantiomers. There are two different types of selectors that can be used: chiral additives in the mobile phase and chiral stationary phases. In the former type, the addition of chiral additives to the mobile phase may yield diastereoisomeric complexes with the analyte and different distribution ratios between the two diastereomers. The separation of the enantiomers can then be performed on an achiral stationary phase. $^{40-41}$ The main disadvantage of chiral chromatography using chiral additives is the detection problem because of their high UV absorption. Moreover, 
the recovery of the original enantiomers from diastereomers is necessary and requires extra steps compared with the CSPs method. As a result, the use of CSPs is preferred to the use of chiral additives because CSPs are easier to utilize and yield less complicated chromatographic systems. ${ }^{39}$

\subsubsection{HPLC enantioseparation CSPs}

Chiral liquid chromatography with CSPs has become one of the most versatile techniques for direct enantioseparation. It is a valuable tool in both analytical and preparative scales. Enantiomers can be resolved through the formation of transient diastereomeric complex between the solute and the chiral selector bound to the stationary phase. The discrimination of enantiomers on CSP is the result of different strengths and fitness between the two transient diastereomers. The enantiomer that fits better with the chiral selector can be retained longer in the chromatography column. ${ }^{39}$

The CSPs commonly used for enantiomeric separation can be classified as follows: polysaccharide-based CSPs, cyclodextrin-based CSPs, brush-type CSPs, protein-based CSPs, and ligand-exchange CSPs. ${ }^{42}$

The chirality of natural products, polysaccharides, makes them desirable candidates for optical resolution for enantioseparation. ${ }^{43}$ The most popular polysaccharide-based CSPs are cellulose and amylose carbamate derivertized CSPs. ${ }^{44}$ The most important interactions between the analyte and the CSP are hydrogen bonding, $\pi-\pi$ interactions and dipole interactions. ${ }^{32}$ The proposed chiral discrimination included formation of the diastereomeric solute-CSP complexes and the stabilization of these complexes through the insertion of part of the solute into a chiral cavity in the $\mathrm{CSP}^{45}$ Non-polar mobile phases, such as hexane with polar modifier, can be used with these columns. 
Cyclodextrins are cyclic oligosaccharides. The molecules with 6,7 and 8 glucose units are named $\alpha-, \beta-$, and $\gamma$-cyclodextrins, respectively. The cyclodextrins have the shape of a trunked cone with a diameter depending on the kind of cyclodextrin used. Cyclodextrins can therefore form inclusion complexes with various compounds of appropriate size. To separate the enantiomers, the hydrophobic moiety of the solute which is in close proximity to the solute chiral center, needs to penetrate into the cyclodextrin cone. The inclusion complexes are then stabilized by a number of interactions, including hydrogen bonding, dipolar interactions, hydrophobic interactions, and $\pi-\pi$ interactions with the polar groups on the edge of the cone. These interactions can function as the source of chiral discrimination for enantiomers separations. ${ }^{42,46}$ The formation of inclusion complexes with cyclodextrins in an aqueous system results mainly from hydrophobic interactions. Therefore, the mobile phase system generally can be used in a reversed phase mode, such as methanol or acetonitrile with water.

Brush-type CSPs are prepared by immobilizing small selectors on a chromatographic support, giving the appearance of a brush. The chiral selector usually contains a $\pi$ - donor and/or a $\pi$-acceptor molecule. The chiral discriminations with these CSPs are based on $\pi-\pi$ interactions, hydrogen bonding, dipole interactions and inclusion complexation between the solute and the CSP. ${ }^{47-48}$ The performance of the column can be affected by temperature. ${ }^{49}$ The covalently bonded versions of brush-type columns can be used with various mobile phases, including aqueous system. However, the non-polar mobile phase composed of hexane and an alcohol as an organic modifier is used more commonly because the CSPs stability and enantioselectivity are much greater in the non-polar solvent. ${ }^{50}$ 
All proteins have the ability for chiral recognitions, since the amino acids that make up proteins are chiral. Most commonly, the protein selectors are immobilized on a chromatographic support, usually silica. The chiral recognition mechanism for these CSPs is based on principles of bioaffinity towards the respective protein. The bioaffinity includes a combination of hydrogen bonding, hydrophobic interaction and electrostatic interaction. ${ }^{51}$ These CSPs can only be used in the reversed phase mode with aqueous buffers.

On ligand-exchange CSPs, the separation of enantiomers is achieved through the exchange of the chiral ligands and the enantiomers on specific metal ions via coordinated bonds. ${ }^{52}$ As a result, their range of applications is limited and only useful for the chiral resolution of enantiomers containing electron-donating atoms, such as oxygen, nitrogen, and sulfur. The reversed phase mode with aqueous buffers can be used with these columns.

\subsubsection{Whelk-O 1 chiral stationary phase}

Whelk-O 1 was selected in this study as the chiral stationary phase because it is versatile and robust for the separation of enantiomers of different compounds, including epoxides, amides, esters, etc. ${ }^{53-54}$ The brush-type CSP (Figure 1.4), based on 1-(3, 5dinitrobenzamido)-1, 2, 3, 4- tetrahydrophenanthrene, is attached to silica through a hydrocarbon tether and a siloxane linkage to the silica surface..$^{55}$

The basic selective mechanism of Whelk-O 1 is the "three point rule": three simultaneous interactions are required between the analyte and the CSP, and these interactions may be attractive or repulsive and they may be single point (e.g., hydrogen bonding) or multipoint (e.g., $\pi-\pi$ and dipole-dipole interactions). According to the rule, there should be at minimum three interaction sites required between the chiral selector 
and one enantiomer in a racemic mixture. At least one of these interactions is stereochemically dependent at the chiral center of the chiral selector and the enantiomer. Examples of the required "three point" interactions are hydrogen bonds, $\pi-\pi$ interactions, dipole-dipole interactions, and inclusion complexation. ${ }^{56-57}$

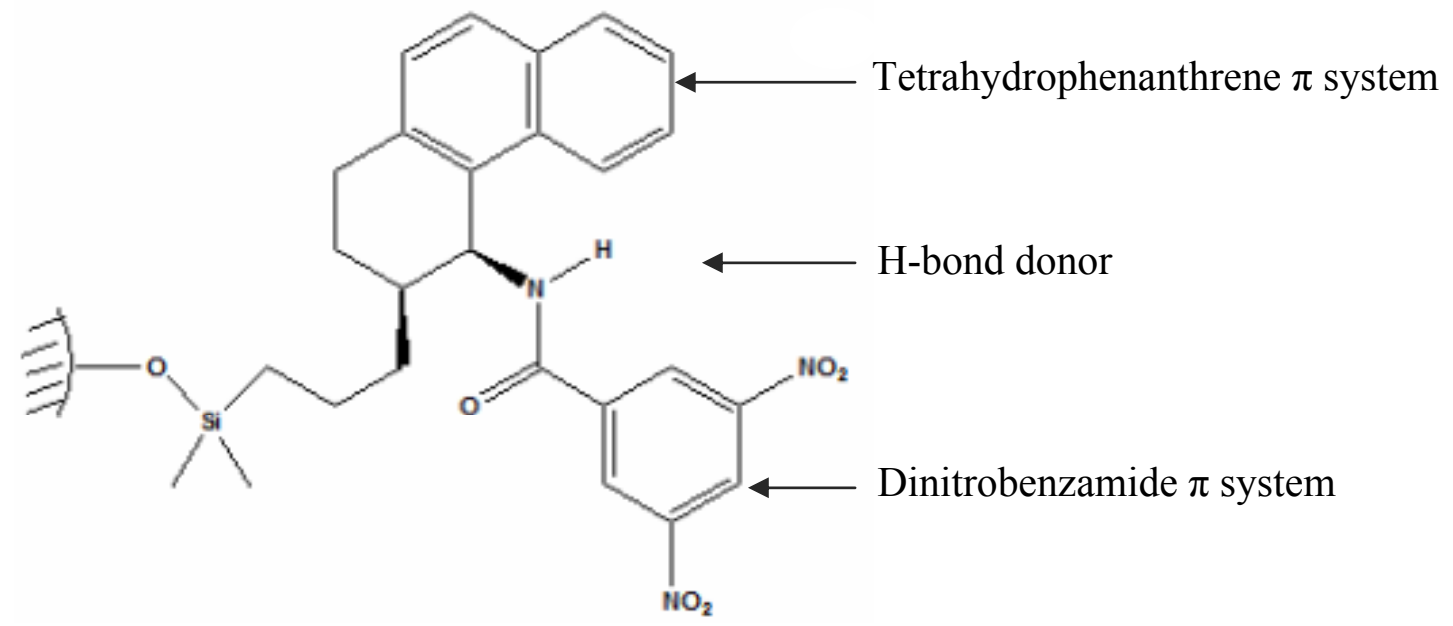

Figure 1.4. Chemical structure of Whelk-O1.

In Whelk-O 1 , the 3,5 -dinitrobenzamide $\pi$-system exhibits a stronger $\pi$-electron acceptor effect due to the presence of two electron-withdrawing nitro groups, whereas the $1,2,3$, 4-tetrahydrophenanthrene $\pi$-system functions as a $\pi$-electron donor in most cases. The $\pi$-electron acceptor/donor phase exhibits an extraordinary degree of generality. In addition, the hydrogen on the amide nitrogen is a typical hydrogen donor in forming a hydrogen bond. ${ }^{55}$

The broad versatility of Whelk-O 1 columns compares favorably with other chiral stationary phases. Moreover, the selector is covalently bonded to the support, so this CSP can readily tolerate the usual range of solvents, both organic and aqueous. ${ }^{50}$ Other advantages of Whelk-O 1 columns include column durability, excellent efficiency, ability to invert elution order and excellent preparative capacity. ${ }^{58}$ Our successful separation of 
the $(R)$ - and $(S)$-styrene oxide standards confirmed the chiral separation capability of Whelk-O 1 in differentiating the epoxidation products of styrene and its derivatives.

\subsubsection{Objectives}

The objective of this work is to develop a new method for chiral separation of epoxidation products of styrene, $\alpha$-methylstyrene, $\alpha$-ethylstyrene, $\alpha$-propylstyrene, cis- $\beta$ methylstyrene, trans- $\beta$-methylstyrene, trans- $\beta$-ethylstyrene, and $\beta$-dimethyl- styrene, from the epoxidation process with $\mathrm{CPO}$ or its mutant as catalysts. Table 1.2 shows the structures of styrene and its derivatives, and their epoxidation products. The other objective is to compare the enantioselectivity of CPO with its F103A and N74V mutants, through which, the function of the mutated residues can be elucidated.

Table 1.2. Structures of styrene and its derivatives and their epoxidation products.

Substrate Epoxidation products




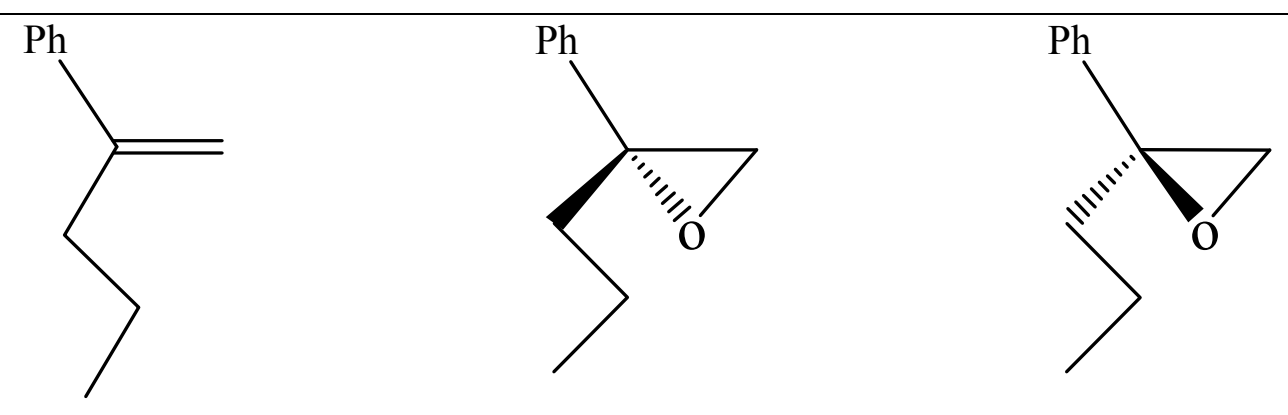

$\alpha$-propylstyrene

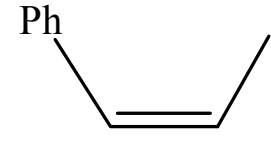

Cis- $\beta$-methylstyrene

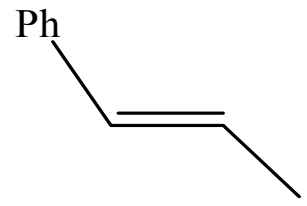

Trans- $\beta$-methylstyrene

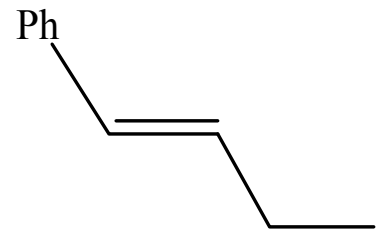

Trans- $\beta$-ethylstyrene

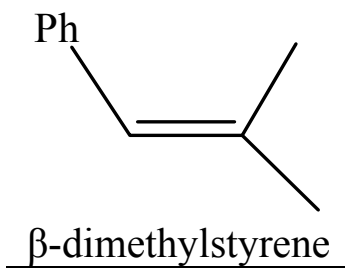

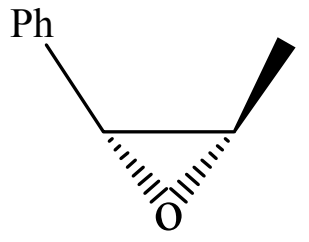

$(1 R, 2 S)$-isomer

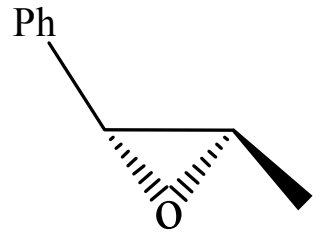

$(1 R, 2 R)$-isomer

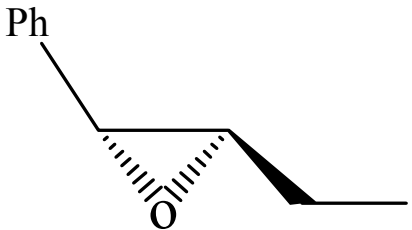

$(1 R, 2 R)$-isomer

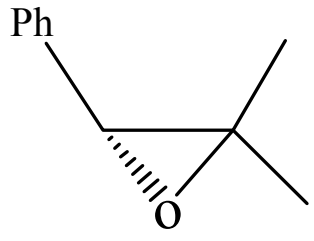

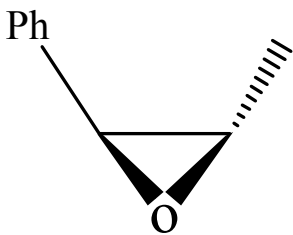

$(1 S, 2 R)$-isomer

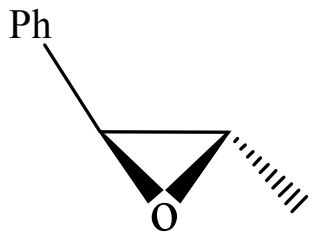

$(1 S, 2 S)$-isomer

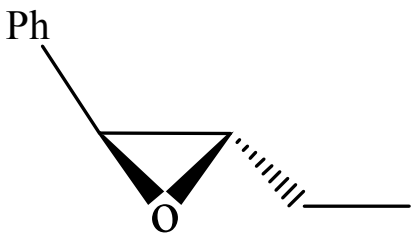

$(1 S, 2 S)$-isomer

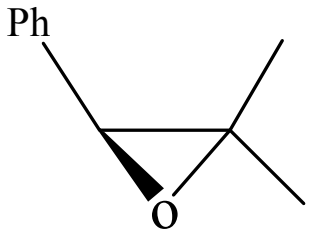




\subsection{Dimethylsulfoniopropionate}

The tertiary sulphonium compound dimethylsulfoniopropionate (DMSP) is a metabolite that is found in many marine phytoplankton, macroalgae, microalgae, and some species of aquatic vascular plants. ${ }^{59-61}$ Dimethylsulfoniopropionate has been studied intensively for its roles in oceanic sulfur cycles and global climate regulation. Biologically, DMSP has been shown to serve as a foraging cue for coralreef fish, sea urchins, penguins, procellariiform birds, and seals. ${ }^{62-64}$

Dimethylsulfoniopropionate tends to be released when cells senescence, most often the result of grazer attack by other organisms. ${ }^{65-66}$ Once released to the environment, DMSP can be degraded either by demethylation or by cleavage. ${ }^{67}$ Refer to Figure 1.5 of routes for the degradation of DMSP by marine bacteria. The DMSP demethylation product, 3-methiolpropionate (MMPA), can be further degraded by demethylation. The MMPA demethylation results in the production of methanethiol (MeSH) and 3mercaptopropionate (MPA). The latter pathway subsequently yields dimethyl sulfide (DMS) and acrylate. Dimethyl sulfide is a semivolatile compound and can be chemically oxidized to sulphur dioxide $\left(\mathrm{SO}_{2}\right)$ and methane sulphonic acid (MSA) in the atmosphere. These DMSP degradation products can form aerosol particles, which not only affect the radiation balance of the earth, but may additionally lead to the formation of cloud condensation nuclei $(\mathrm{CCN}) .{ }^{68-69}$

The DMSP-cleavage reaction was proposed as a grazing-activated defense system in marine macroalgae, microalgae and phytoplankton. ${ }^{70-72}$ The defense system can protect plants from grazers, since stored compounds in the plants are converted to more deterrent compounds upon damage to the plant tissues. ${ }^{73}$ In the DMSP-activated 
defense system, a non-toxic metabolite, DMSP, is rapidly converted to feeding deterrents on the scale of seconds when tissues are crushed. It is suspected that the damage results in contact between previously sequestered enzyme DMSP lyase and DMSP, with the resulting reaction yielding chemical deterrents, DMS and acrylate, against the grazers. Therefore, the sacrifice of tissues from the prey is a successful tactic to prevent loss of the whole plant. ${ }^{70-72}$

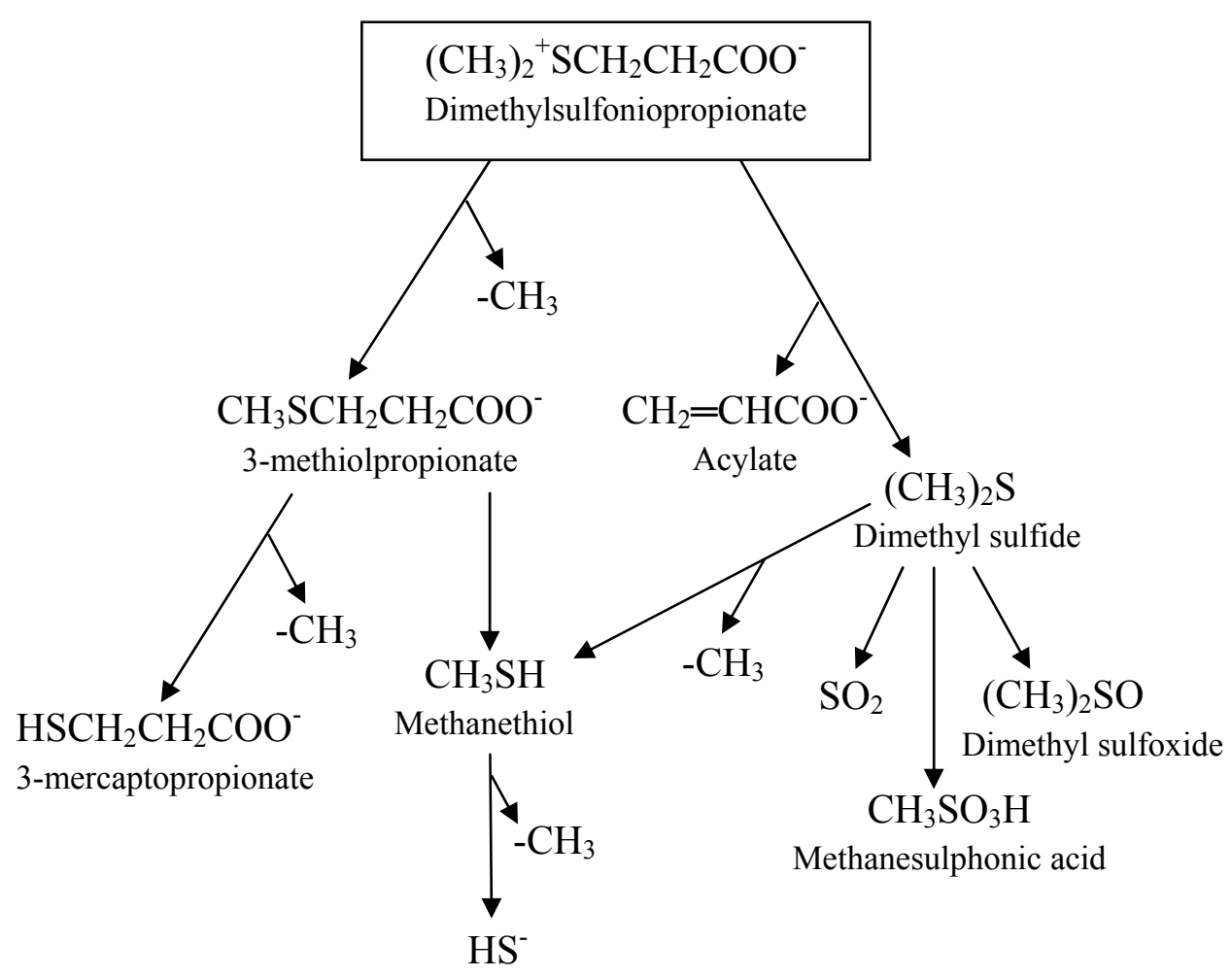

Figure 1.5. Routes for the degradation of DMSP by marine bacteria. 


\section{CHAPTER II. CHIRAL SEPARATION OF CPO AND ITS MUTANTS EPOXIDATION PRODUCTS BY HPLC}

\subsection{Experimental procedures}

\subsubsection{Materials}

Styrene, $\alpha$-methylstyrene, trans- $\beta$-methylstyrene, $\beta$-dimethylstyrene, $(R)$-styrene oxide, $(S)$-styrene oxide, $(1 R, 2 R)$-trans- $\beta$-methylstyrene oxide, $(1 S, 2 S)$-trans- $\beta$ methylstyrene oxide, and racemic $\alpha$-methylstyrene oxide standards were ordered from Sigma-Aldrich (St. Louis, MO). DEAE sepharose fast flow and Sephadex G-75 were purchased from GE Healthcare (Piscataway, NJ). Experimental used water with 18.2 megohm $\cdot \mathrm{cm}$ resistivity was freshly produced from a Milli-Q BioCel Water Purification System (Millipore, Billerica, MA). Pure wild-type (WT) CPO was prepared by our own lab with the Rz value over 1.50. CPO, F103A and N74V mutant stock cultures were provided by other members of our group. All other reagents and materials were purchased from Fisher Scientific (Pittsburgh, PA). Unless otherwise specified, all the chemicals and reagents were used without further purification.

\subsubsection{Instrumentation}

The HPLC analysis was carried out on a Waters 1525 instrument (Waters, Milford, MA), equipped with a photodiode array UV-detector. Waters Empower 2 software was used for instrument control and data analysis. The HPLC analysis of the organic phase on a Pirkle Concept Whelk-O 1 column $(250 \mathrm{~mm}$ x $4.6 \mathrm{~mm}$, Regis Technologies, Morton Grove, IL) was used to determine the ee value of epoxides formed in the reaction. The HPLC sample injection utilized a Rheodyne Model 7125 manual injection valve, consisting of a $20 \mu \mathrm{l}$ sampling loop. 
GC-MS analysis was performed by using a HP-6890 gas chromatograph interfaced with a HP-5973 mass detector (Hewlett- Packard, Palo Alto, CA) equipped with a DB5MS fused silica capillary column $(30 \mathrm{~m} \times 0.25 \mathrm{~mm}$ i.d., film thickness $0.25 \mu \mathrm{m}$, Agilent Technologies).

\subsubsection{Expression and Purification of CPO F103A and N74V mutants}

The CPO F103A mutant conidia from a whole Petri dish was inoculated into a 2-L Erlenmeyer flask containing $1 \mathrm{~L}$ of Aspergillus niger minimal growth medium with $5 \%$ maltose and $0.5 \%$ casein amino acids. The cell culturing was grown in a rotary shaker revolving at $225 \mathrm{rpm}, 25^{\circ} \mathrm{C}$ for $24 \mathrm{~h}$, followed by further growth at $22{ }^{\circ} \mathrm{C}$ for 6 days.

The CPO F103A mutant crude medium containing the secreted enzyme were collected by removing the fungal culture through filtration with Miracloth and consequently centrifuged at $9500 \mathrm{rpm}, 4{ }^{\circ} \mathrm{C}$ for $1 \mathrm{~h}$, followed by filtration though $0.8 \mu \mathrm{m}$ filters, to further remove mycelia debris. Unless otherwise specified, the whole procedure in the CPO mutant purification was performed at $4{ }^{\circ} \mathrm{C}$. The collected mutant crude culture medium was then concentrated with a high output ultrafiltration cell $(10 \mathrm{kDa}$ cut off membrane, Millipore) to about $50 \mathrm{~mL}$. The condensed medium was dialyzed against 25 $\mathrm{mM}$ potassium phosphate buffer at $\mathrm{pH} 5.9$ (4 liter) three times at $4{ }^{\circ} \mathrm{C}$ over a period of 24 hours to adjust the $\mathrm{pH}$ and to obtain the proper conductivity. The sample was further purified by passage through a DEAE Sepharose fast flow column $(2.6 \times 20 \mathrm{~cm})$. Proteins were eluted from the ion exchange column with a linear salt gradient consisting of 0 to $0.5 \mathrm{M} \mathrm{NaCl}$ in $25 \mathrm{mM}$ phosphate buffer at pH 5.9 in 15 bed volumes. The Reinheitzahl value (Rz, A398 nm/A280 nm) was used to check the purity of each fraction. Fractions 
with an $\mathrm{Rz}$ value higher 0.6 were collected and concentrated to about $5 \mathrm{~mL}$ using a Centriprep-YM30 concentrator (Amicon). The mutant was then further purified by gel filtration (sephadex G-75, $2.6 \times 100 \mathrm{~cm}$ ) using $50 \mathrm{mM}$ potassium phosphate buffer at $\mathrm{pH}$ 4.6. The resulted fractions with an $\mathrm{Rz}$ value greater than 1.3 were collected, concentrated and stored at $4{ }^{\circ} \mathrm{C}$ for future use.

The expression and purification procedures for CPO N74V mutant were identical to those of the F103A mutant. Concentrations of CPO mutants were determined using an extinction coefficient of $91200 \mathrm{M}^{-1} \mathrm{~cm}^{-1}$ at $400 \mathrm{~nm}$.

\subsubsection{Epoxidation of styrene and derivatives catalyzed by CPO and its mutants}

Styrene and its derivatives ( $\alpha$-methylstyrene, $\alpha$-ethylstyrene, $\alpha$-propylstyrene, cis$\beta$-methylstyrene, trans- $\beta$ - methylstyrene, trans- $\beta$-ethylstyrene, and $\beta$-dimethylstyrene) were used as the substrates to study the epoxidation enantioselectivity of the native $\mathrm{CPO}$ and its mutants. The reaction mixture for the epoxidation assay was prepared with a water solution of $100 \mu$ of tert-butyl hydroperoxide and $70 \mu 1$ of styrene or one of the styrene derivatives. The assay was initiated by adding $25 \mu 1$ of the above reaction mixture into $750 \mu \mathrm{l}$ of $100 \mathrm{mM}$ citrate buffer, $\mathrm{pH} 5.5$ containing 2 $\mathrm{mg}$ of WT or mutant CPO. After incubation at room temperature for $45 \mathrm{~min}, 50 \mu 1$ of $1 \mathrm{M} \mathrm{Na}_{2} \mathrm{~S}_{2} \mathrm{O}_{3}$ in a saturated solution of $\mathrm{NaHCO}_{3}$ was added to stop the epoxidation reaction. The resulted epoxidation products were extracted three times with a total amount of $300 \mu 1$ of isooctane.

\subsubsection{Chiral separation of styrene oxide and styrene oxide derivatives by HPLC}

The extracted products from the epoxidation reactions were separated by HPLC analysis using Whelk-O 1 as the chiral stationary phase. Enantiomers of all the CPO, 
F103A and N74V catalyzed epoxidation of styrene and derivatives were separated via optimized chiral HPLC methods, respectively.

For method development and optimization, the mobile phase composition, flow rate, and column temperature were the parameters taken into consideration to achieve separation of enantiomers. Resolution (Rs), analysis time, and pressure were used as criteria for method evaluation.

The HPLC mobile phase composition can be optimized by adding different solvents as modifiers. The type and concentration of the organic modifier have a key effect on chiral separation because the modifier can compete with analyte for the specific adsorption sites on the stationary phase. Since the Whelk-O 1 column can be used in normal-phase or reverse-phase, both phases were tested for the chiral separation of epoxides. First, the common reversed-phase solvent, water, was used as polar mobile phase with methanol or acetonitrile as the modifier. Mobile phases with water to methanol/acetonitrile ratios of 100:0, 75:25, 50:50, 25:75 and 0:100 were evaluated. For the normal-phase experiments, $n$-hexane, with 2-propanol or ethanol as an organic polar modifier, was used for the chiral separation. The effect of modifier concentration on the chiral separation was studied by varying 2-propanol or ethanol percentage in $n$-hexane from $0 \%$ to $1 \%$. The flow rate was set to $1.0 \mathrm{~mL} / \mathrm{min}$. The column temperature was maintained at either the ambient temperature or $4{ }^{\circ} \mathrm{C}$. The injection volume was $20 \mu \mathrm{L}$. Each of the analytes exhibit different UV absorption maxima, and thus the detector wavelength was tuned from $208.6 \mathrm{~nm}$ to $218.6 \mathrm{~nm}$.

In this method development strategy, there is a constant tradeoff between sensitivity, separation and resolution. In order to achieve the best separation quality of the epoxide 
enantiomers, retention time and peak shape were not optimized and often were sacrificed. Sensitivity or chromatographic conditions had to be compromised in order to get the best separation and resolution. Because of the existence of byproducts and excess substrates in the real samples, different methods were developed for different substrates to achieve the best separation results.

\subsubsection{Identification of the enantiomers from CPO and its mutants catalyzed epoxidation by GC-MS}

Identification of trans- $\beta$-ethylstyrene and $\beta$-dimethylstyrene was performed by GCMS qualitative analysis. Helium was used as the carrier gas with a flow rate of 1.2 $\mathrm{mL} / \mathrm{min}$. The injection port temperature was $280{ }^{\circ} \mathrm{C}$, and the interface was $250{ }^{\circ} \mathrm{C}$. The oven temperature was programmed as follows: initial temperature, $40{ }^{\circ} \mathrm{C}$; initial hold 1.0 min; temperature program rate, $10^{\circ} \mathrm{C} / \mathrm{min}$; final temperature, $300^{\circ} \mathrm{C}$; final hold, $5.0 \mathrm{~min}$.

\subsubsection{Data treatment}

The following parameters were calculated with the HPLC results:

$$
k^{\prime}(\text { retention factor })=\left(t_{R}-t_{0}\right) / t_{0}
$$

where $t_{R}$ represented the retention time and $t_{0}$ represented the void time;

$$
\alpha(\text { separation factor })=k_{2}, / k_{1},
$$

where $k_{1}$ ' and $k_{2}$ ' were the retention factors of the first and second eluted enantiomers, respectively;

$$
\text { Rs (resolution factor })=2\left(t_{R 2}-t_{R 1}\right) /\left(W_{1}+W_{2}\right)
$$

where $t_{R 1}$ and $t_{R 2}$ were the retention times of the first and second eluted enantiomers, respectively, and $W_{1}$ and $W_{2}$ represented their individual peak widths.

$$
\mathrm{ee}=\% \text { (major isomer) }-\% \text { (minor isomer })
$$




\subsection{Results}

\subsubsection{Development and optimization of HPLC method for the separation of styrene}

oxide and its derivatives

The aim of the method development and optimization was to develop a rugged and suitable HPLC method for the separation of styrene oxide and its derivatives by varying the mobile system and temperature. Both reversed and normal-phase chromatography methods were tested, but only the normal-phase type of the mobile phase was found to be appropriate for our selected compounds. For the normal-phase methods, the typical nonpolar organic solvent, $n$-hexane, was tested first as the mobile phase. Although acceptable separations were achieved for both styrene oxide and trans- $\beta$-methylstyrene oxide standards using the mobile phase of pure $n$-hexane, the analysis was very timeconsuming because of the long retention time, as shown in Figures 2.1 and 2.2. Moreover, the pure $n$-hexane mobile phase could not completely separate the $\alpha$-methylstyrene oxide standard, as shown in Figure 2.3. To optimize the analysis efficiency and achieve better separation, organic modifiers were applied to the mobile phase and the effect of different modifiers was studied.

Ethanol and 2-propanol are the two most commonly used mobile phase modifiers for Whelk-O 1. It was necessary to compare these two modifiers to evaluate which one can yield better enantioselectivity and resolution. Ethanol or 2-propanol was therefore introduced into the above mobile phase at the same concentration. Figure 2.4 through 2.9 show the effect of 2-propanol or ethanol on the separation of styrene oxide, trans- $\beta$ methylstyrene oxide and $\alpha$-methylstyrene oxide standards. It was found that the use of ethanol as a modifier in the mobile phase resulted in better peak shapes, shorter run 
times, and better selectivity and resolution compared to the use of 2-propanol, as shown in Table 2.1. Therefore, in the later experiments, ethanol was chosen as the mobile phase modifier.

Various combinations of $n$-hexane/ethanol ratios were examined to figure out the most optimum conditions for chiral separations. It is clear that with the increase of ethanol concentration from 0.1 to $0.5 \%$, the retention time decreased about $50 \%$, and the reduction of tailing was also observed. Refer to Figures 2.9 through 2.12 for enantioseparation of the $\alpha$-methylstyrene oxide standard with mobile phases at different ethanol concentrations. Therefore, the addition of ethanol to the mobile phase can save analysis time and solvent needs, and improve peak shapes by reducing tailing. However, excessive ethanol $(>0.5 \%)$ can lead to insufficient separation because the difference between the two enantiomer retention times is too small (Figure 2.12). In my experiments, $0.5 \%$ ethanol was a maximum for enantioseparation of styrene oxide and its derivatives to get proper separation. Table 2.2 shows the influence of ethanol concentration in mobile phase on the enantioseparation of the $\alpha$-methylstyrene oxide standard.

To achieve better enantioseparation of $\alpha$-methylstyrene oxide, the column temperature was set at ambient temperature and $4{ }^{\circ} \mathrm{C}$, respectively, because the temperature can affect both the retention and resolution of analytes on the column. ${ }^{74}$ Lowering the temperature of the column typically caused the peak broadening phenomenon and reduced sensitivity, but also led to an improved separation with larger selectivity factor and resolution factor, as shown in Table 2.2. Figure 2.13 shows the effect of the enantioselectivity of methylstyrene oxide separated on a Whelk-O 1 column under $4^{\circ} \mathrm{C}$. 


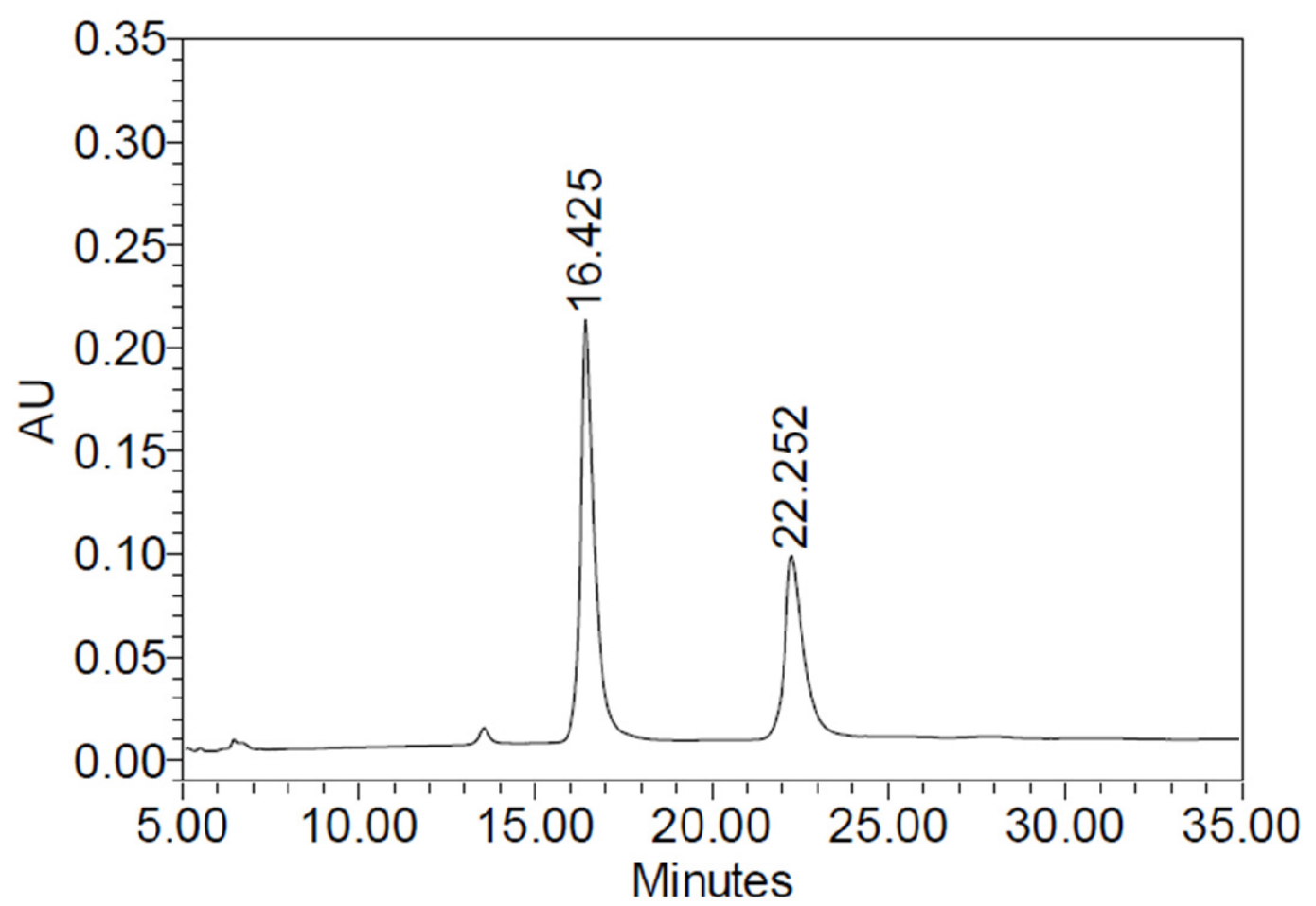

Figure 2.1. Enantioseparation of styrene oxide standard on Whelk-O 1 column. Mobile phase, pure $n$-hexane; monitoring wavelength, $215.7 \mathrm{~nm}$.

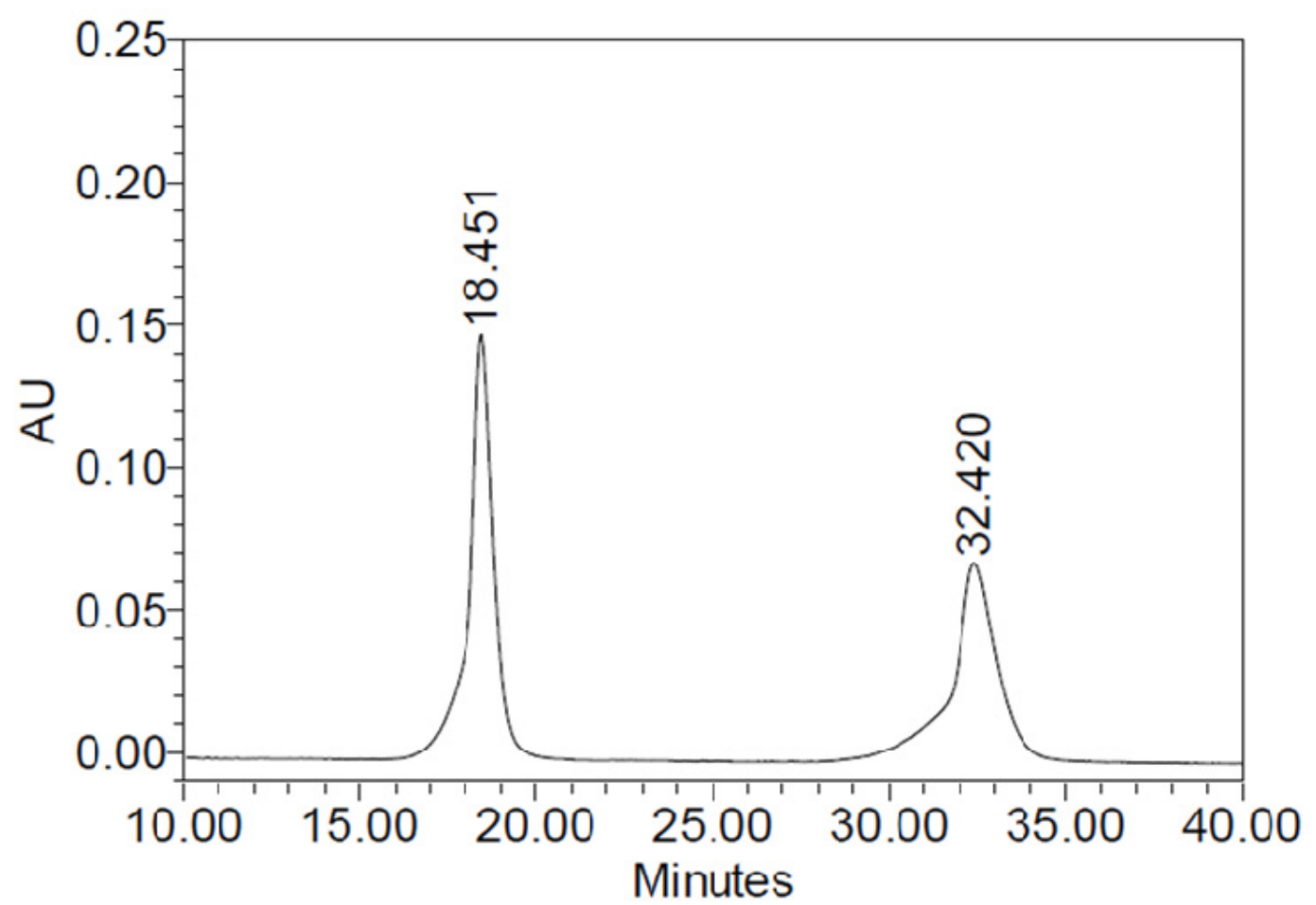

Figure 2.2. Enantioseparation of trans- $\beta$-methylstyrene oxide standard on Whelk-O 1 column. Mobile phase, pure $n$-hexane; monitoring wavelength, $216.8 \mathrm{~nm}$. 


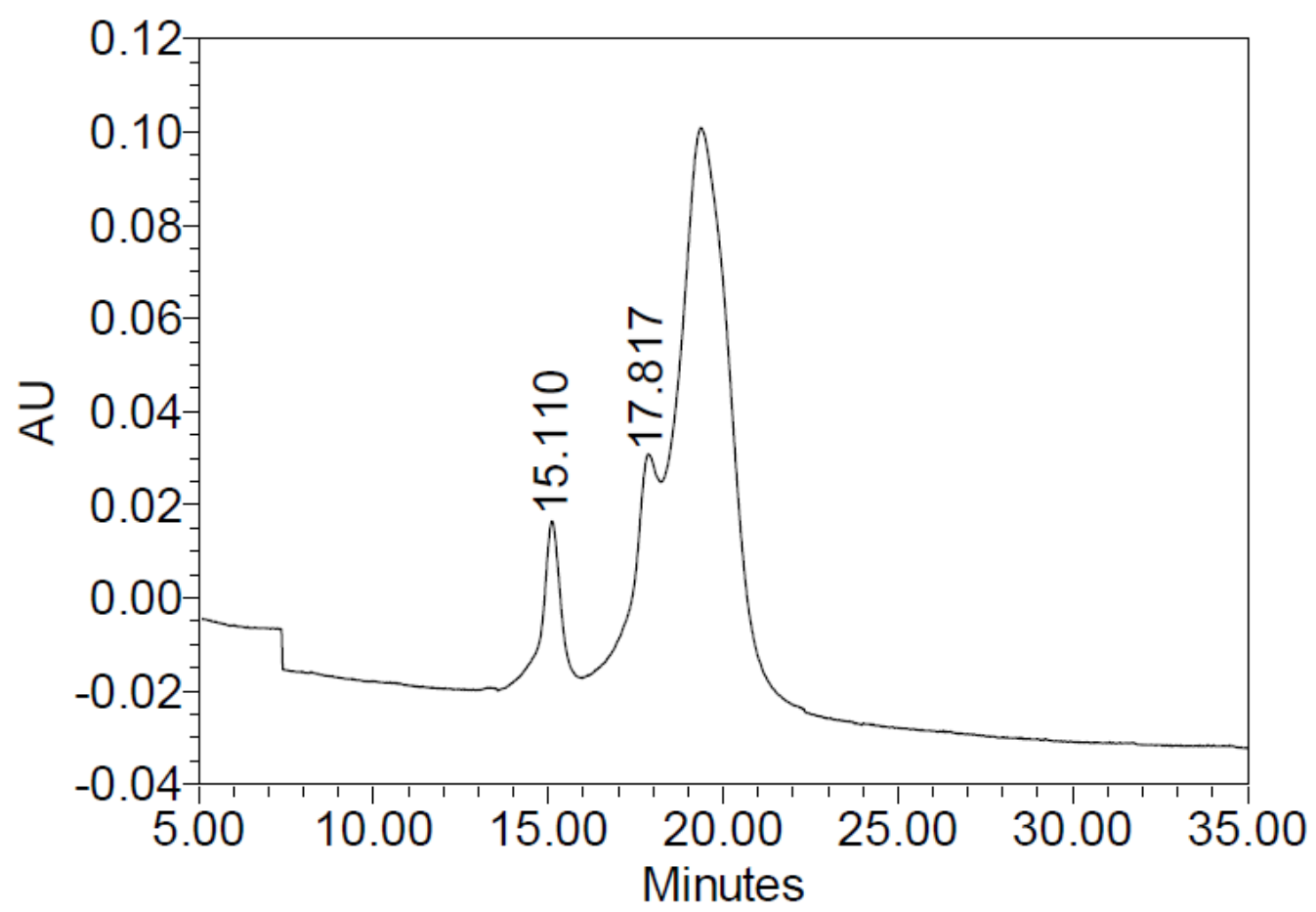

Figure 2.3. Enantioseparation of $\alpha$-methylstyrene oxide standard on Whelk-O 1 column. Mobile phase, pure $n$-hexane; monitoring wavelength, $208.6 \mathrm{~nm}$.

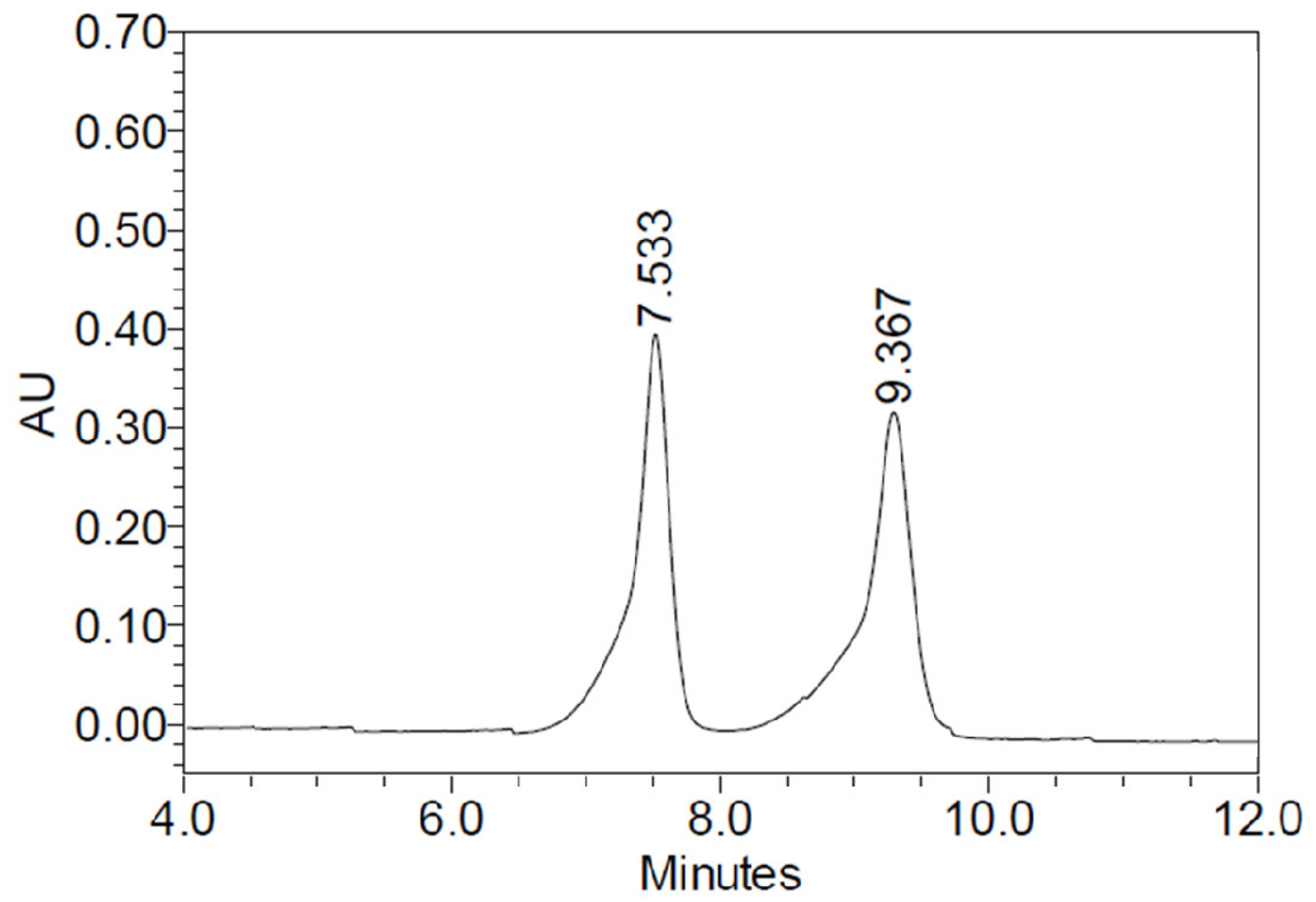

Figure 2.4. Effect of 2-propanol on separation of styrene oxide standard on Whelk-O 1 column. Mobile phase, $n$-hexane/2-propanol (99.8/0.2, v/v); monitoring wavelength, $215.7 \mathrm{~nm}$. 


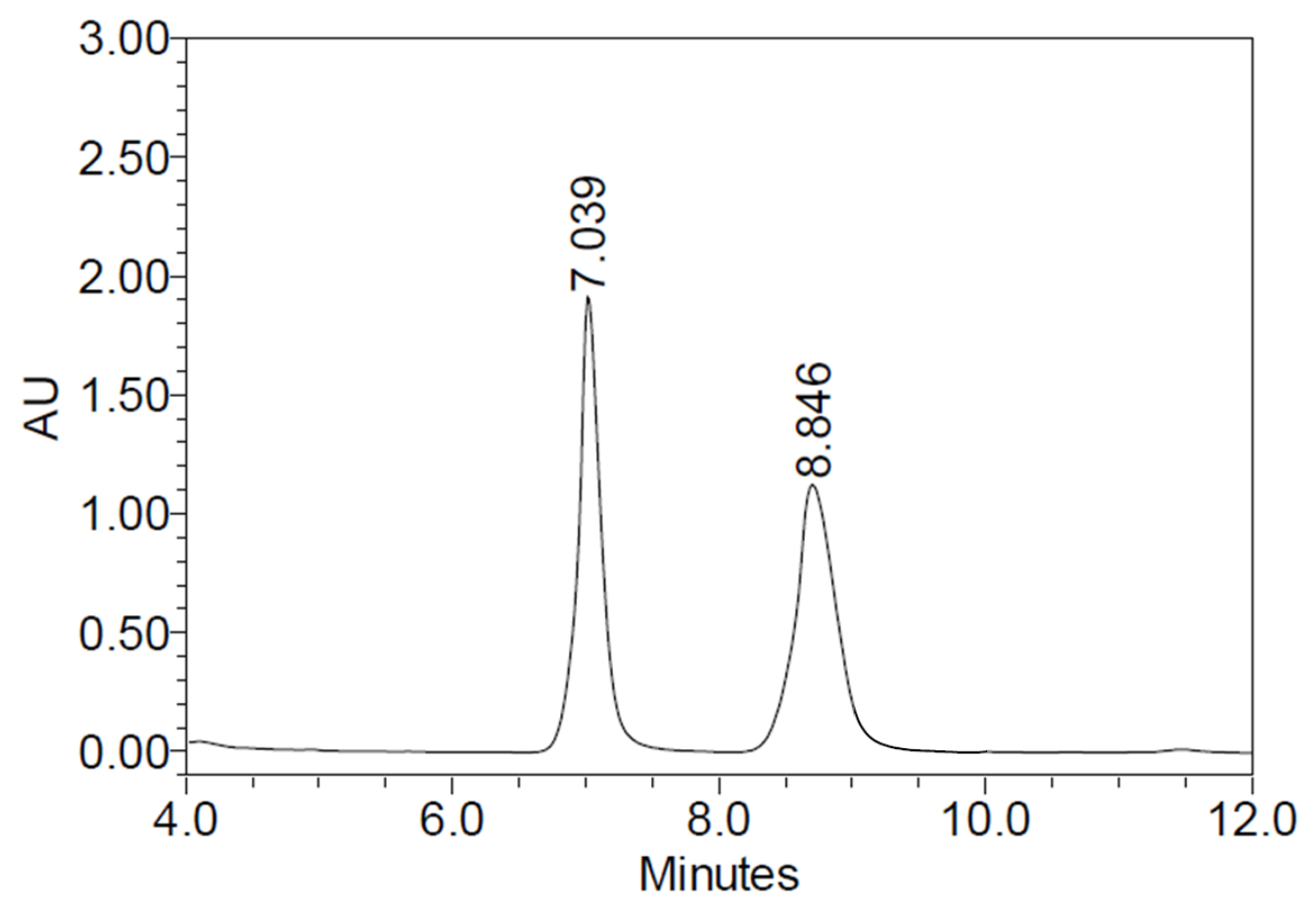

Figure 2.5. Effect of ethanol on separation of styrene oxide standard on Whelk-O 1 column. Mobile phase, $n$-hexane/ethanol $(99.8 / 0.2, \mathrm{v} / \mathrm{v})$; monitoring wavelength, $215.7 \mathrm{~nm}$.

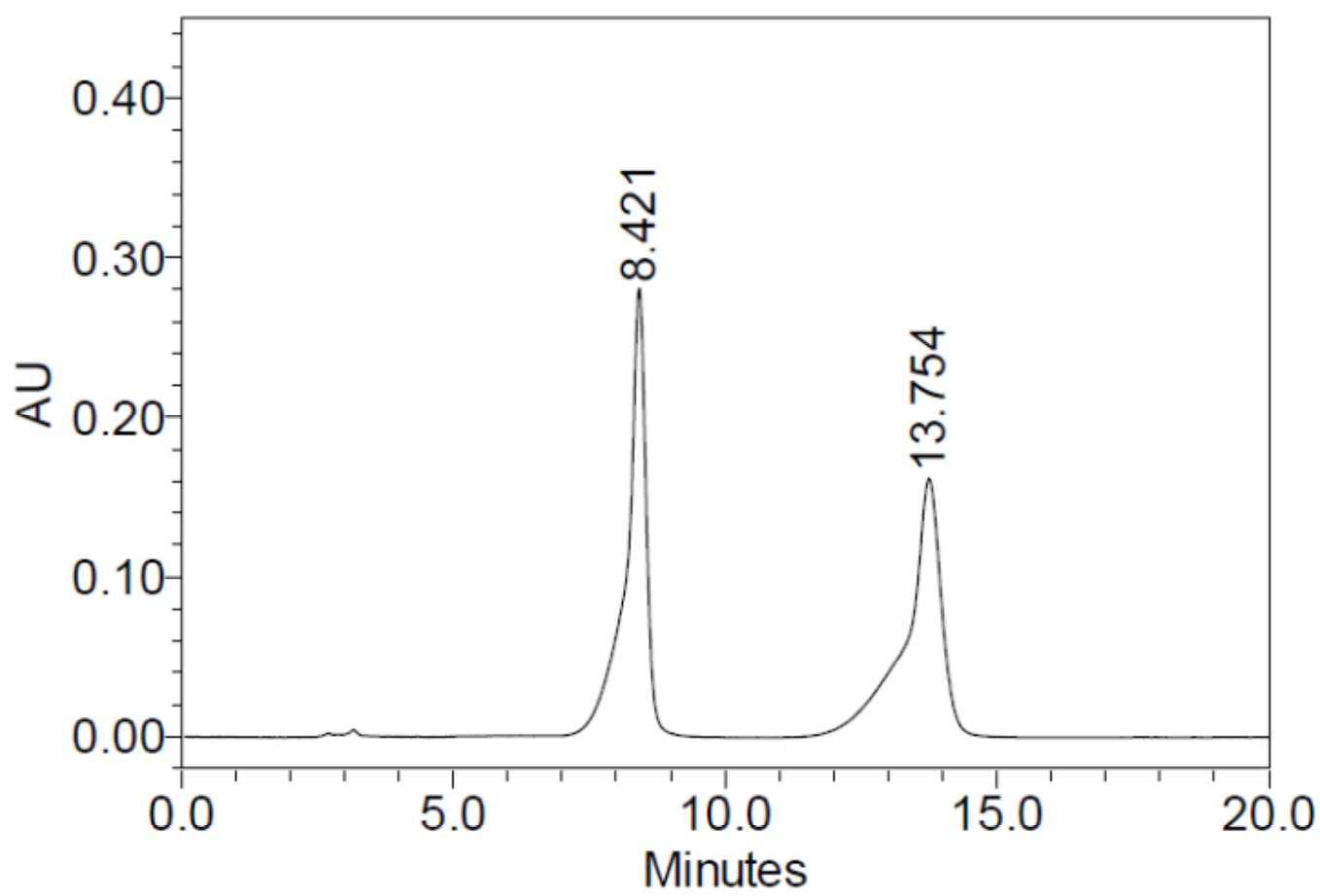

Figure 2.6. Effect of 2-propanol on separation of trans- $\beta$-methylstyrene oxide standard on Whelk-O 1 column. Mobile phase, $n$-hexane/2-propanol (99.8/0.2, v/v); monitoring wavelength, $216.8 \mathrm{~nm}$. 


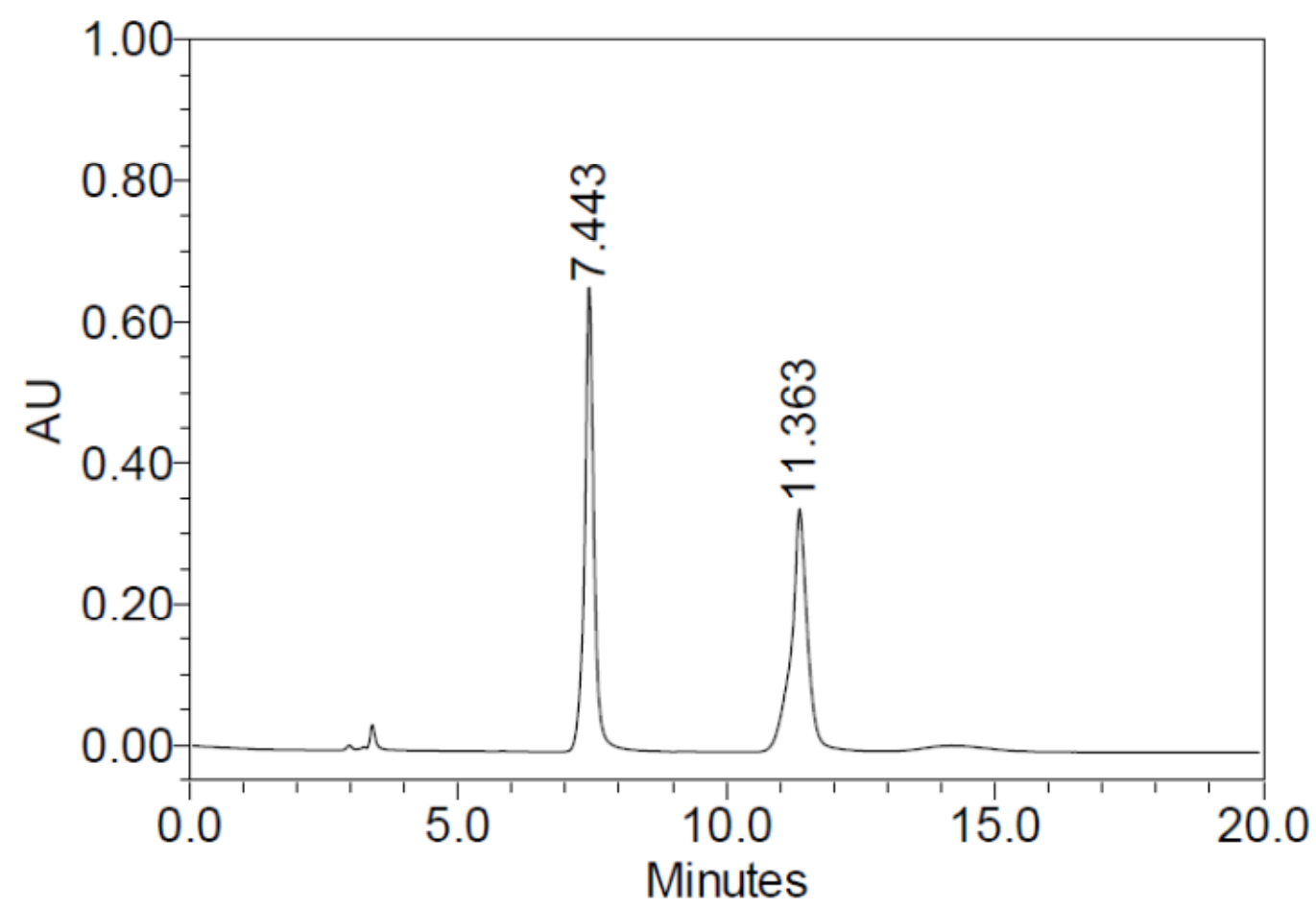

Figure 2.7. Effect of ethanol on separation of trans- $\beta$-methylstyrene oxide standard on Whelk-O 1 column. Mobile phase, $n$-hexane/ethanol (99.8/0.2, v/v); monitoring wavelength, $216.8 \mathrm{~nm}$.

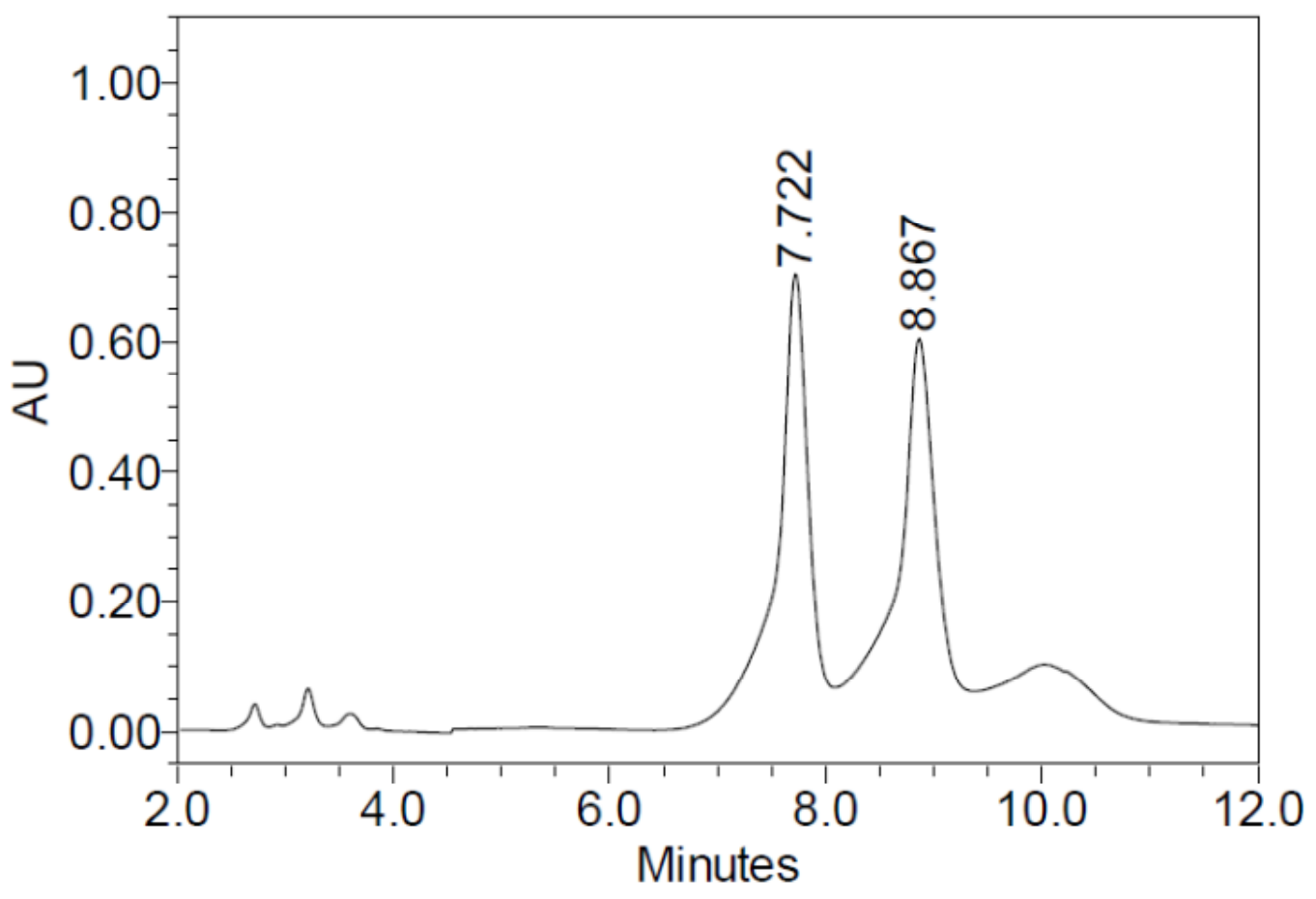

Figure 2.8. Effect of 2-propanol on separation of $\alpha$-methylstyrene oxide standard on Whelk-O 1 column. Mobile phase, $n$-hexane/2-propanol (99.8/0.2, v/v); monitoring wavelength, $208.6 \mathrm{~nm}$. 


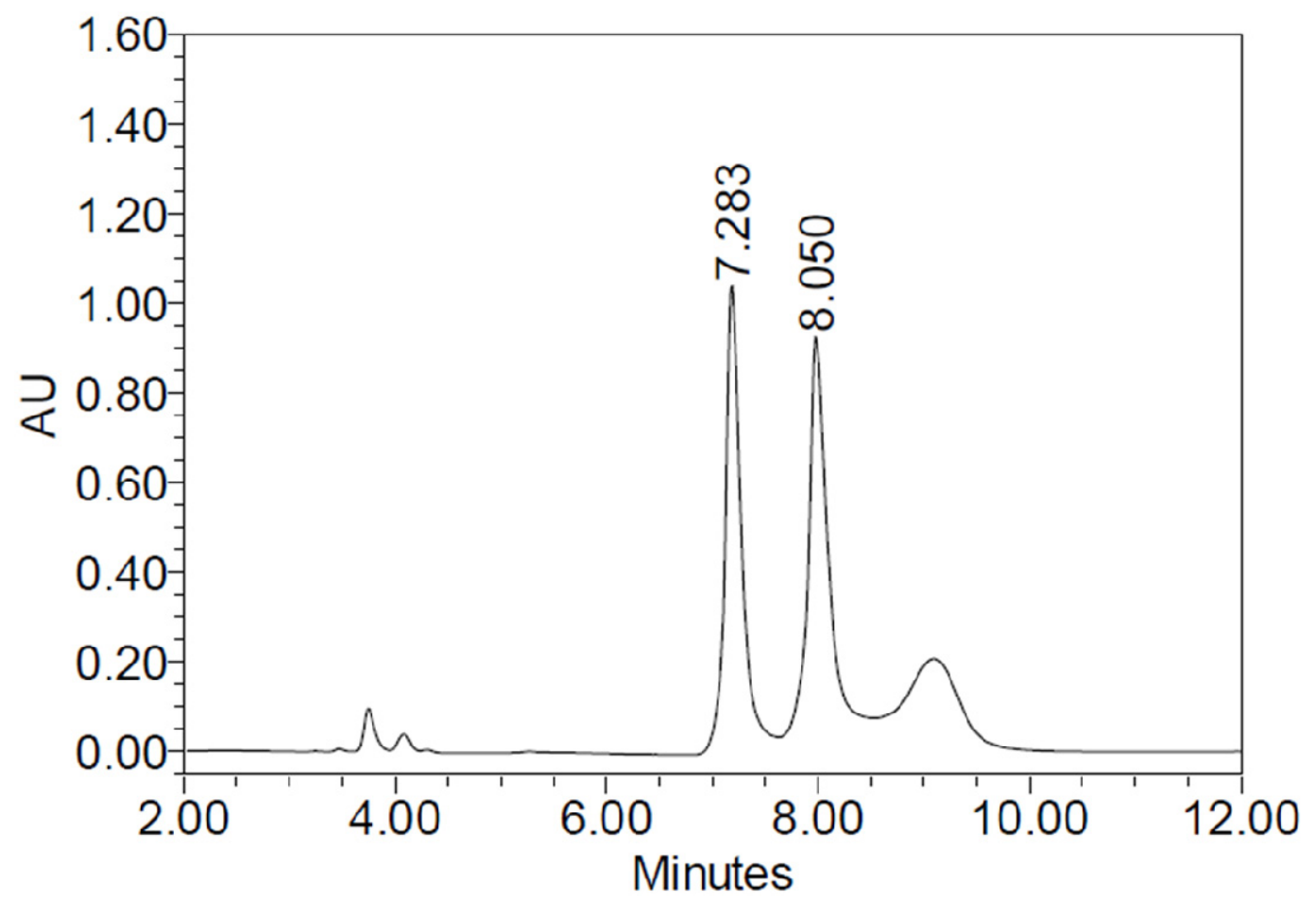

Figure 2.9. Effect of ethanol on separation of $\alpha$-methylstyrene oxide standard on Whelk-O 1 column. Mobile phase, $n$-hexane/ethanol (99.8/0.2, v/v); monitoring wavelength, $208.6 \mathrm{~nm}$.

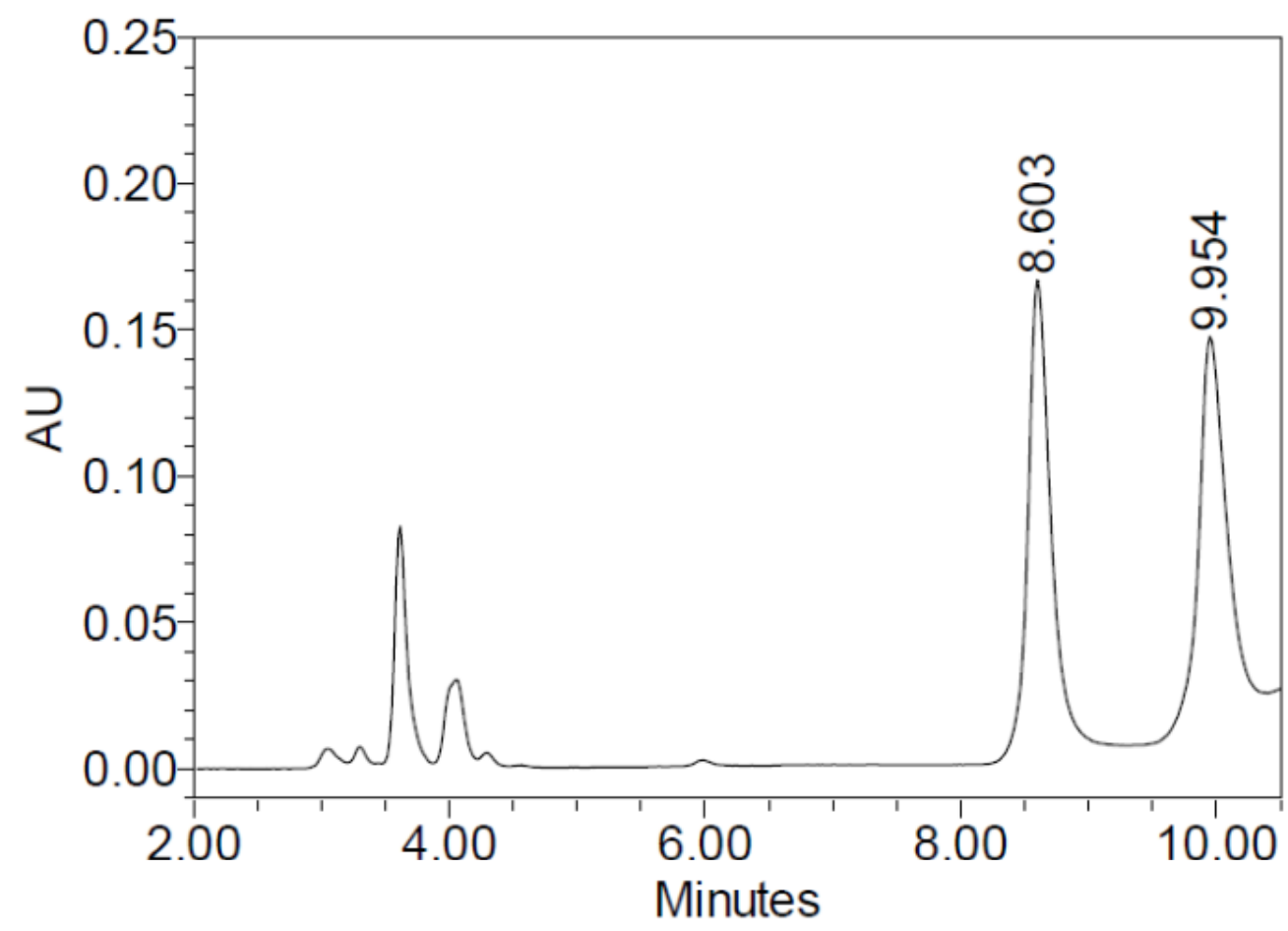

Figure 2.10. Enantioseparation of $\alpha$-methylstyrene oxide standard on Whelk-O 1 column. Mobile phase, $n$-hexane/ethanol $(99.9 / 0.1, \mathrm{v} / \mathrm{v})$; monitoring wavelength, $208.6 \mathrm{~nm}$. 


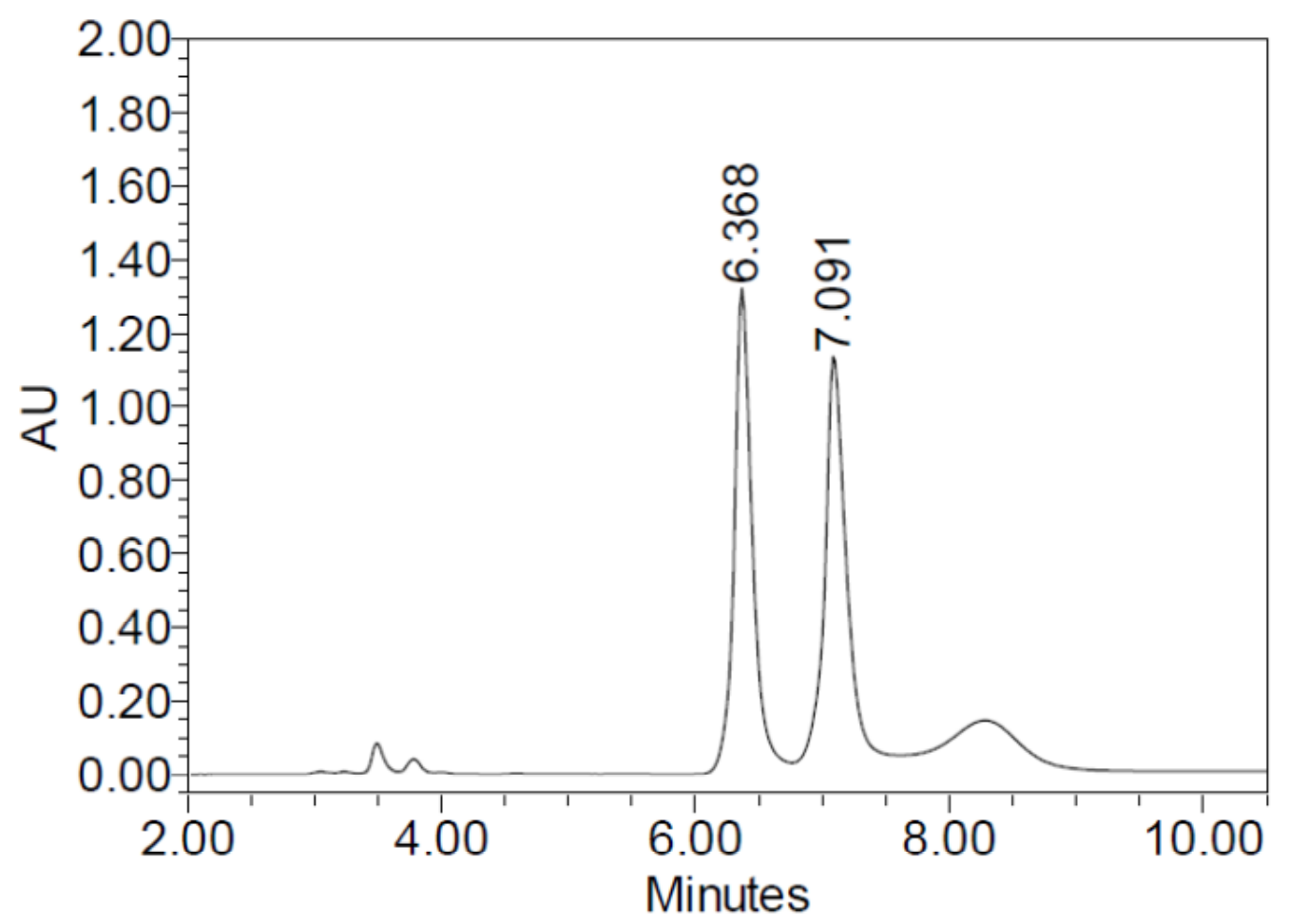

Figure 2.11. Enantioseparation of $\alpha$-methylstyrene oxide standard on Whelk-O 1 column. Mobile phase, $n$-hexane/ethanol $(99.7 / 0.3, \mathrm{v} / \mathrm{v})$; monitoring wavelength, $208.6 \mathrm{~nm}$.

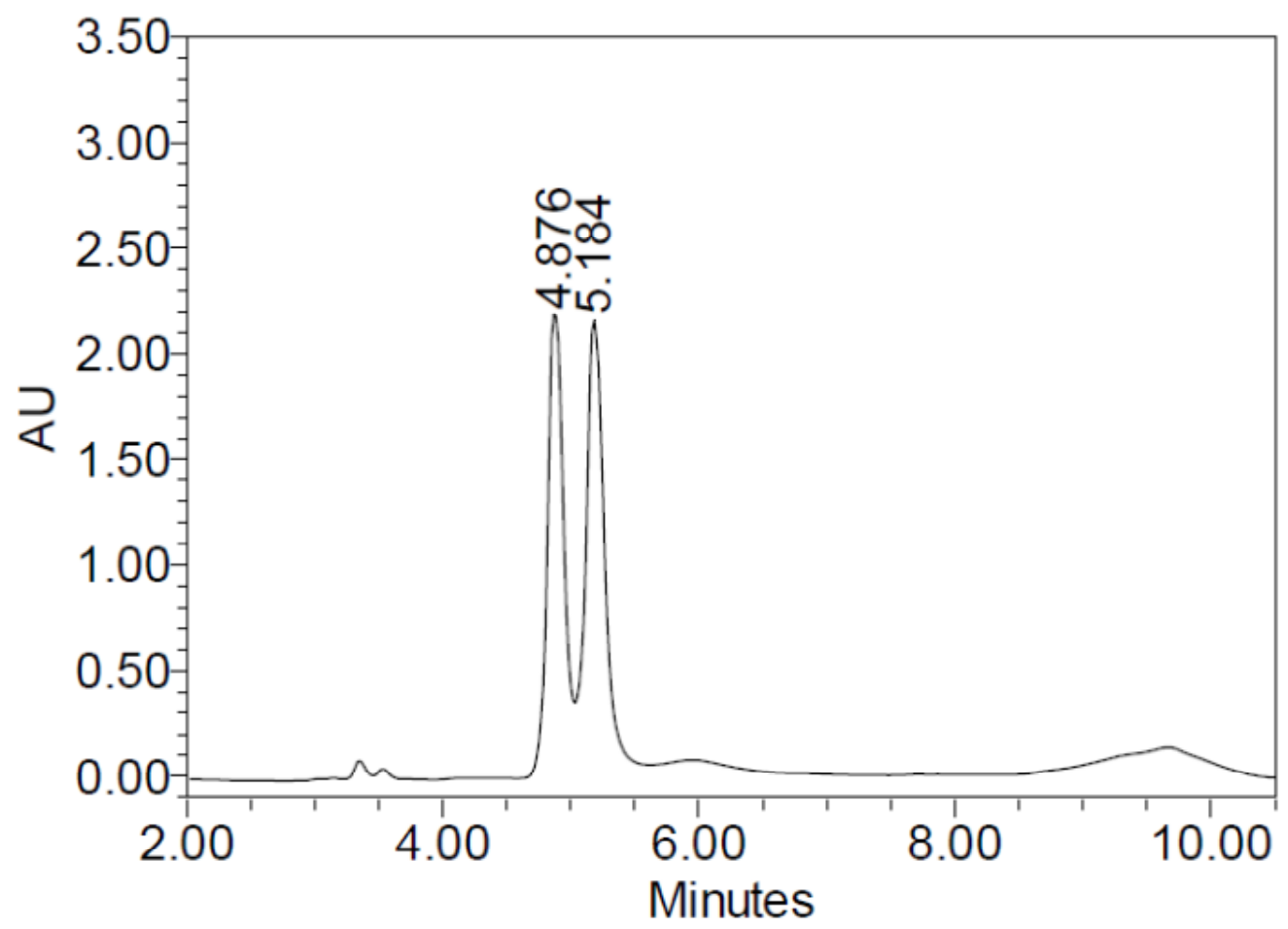

Figure 2.12. Enantioseparation of $\alpha$-methylstyrene oxide standard on Whelk-O 1 column. Mobile phase, $n$-hexane/ethanol $(99.5 / 0.5, \mathrm{v} / \mathrm{v})$; monitoring wavelength, $208.6 \mathrm{~nm}$. 


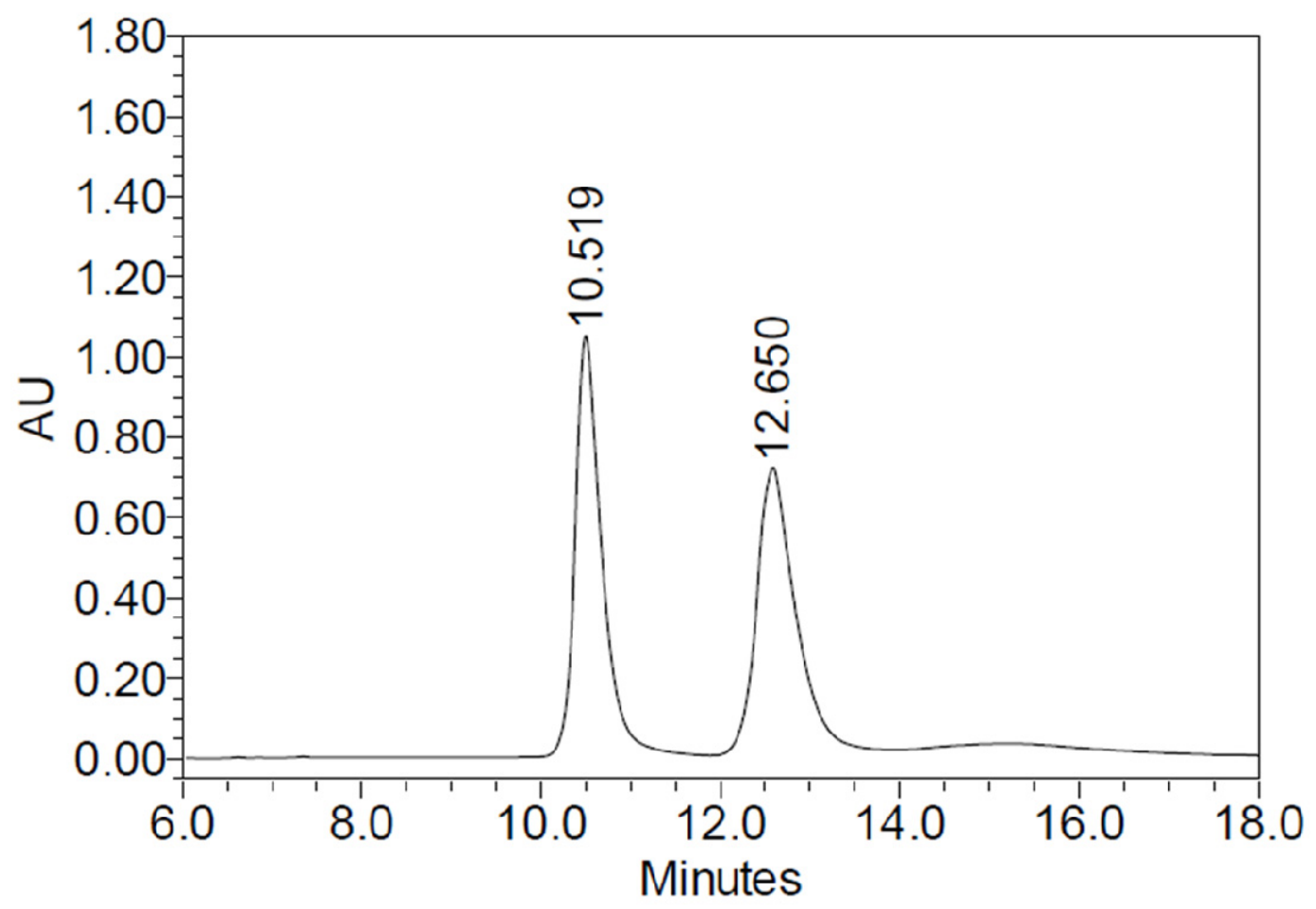

Figure 2.13. Enantioseparation of $\alpha$-methylstyrene oxide standard on Whelk-O 1 column. Mobile phase, $n$-hexane/ethanol (99.8/0.2, v/v); monitoring wavelength, $208.6 \mathrm{~nm}$; column temperature, $4{ }^{\circ} \mathrm{C}$.

\subsubsection{Identification of the epoxidation products of styrene and its derivatives catalyzed by WT CPO or its mutants}

The epoxidation products of styrene and its derivatives catalyzed by CPO or its mutants were identified from their HPLC spectra based on different strategies because of the limited availability of their corresponding standards.

By comparing the retention times of the products from the epoxidation process with the pure standards, the epoxidation products of styrene, trans- $\beta$-methylstyrene and $\alpha$ methylstyrene were identified. The enantioseparation results of styrene oxide catalyzed by WT CPO, F103A and N74V are shown in Figures 2.14, 2.15 and 2.16, respectively. The enantioseparation results of trans- $\beta$-methylstyrene oxide catalyzed by WT CPO, 
Table 2.1. The influence of modifiers in mobile phase on the enantioseparation of styrene oxide, trans- $\beta$-methylstyrene oxide, and $\alpha$-methylstyrene oxide standards. ${ }^{\mathrm{a}}$

\begin{tabular}{|c|c|c|c|c|c|c|c|c|c|c|c|c|}
\hline \multirow[t]{3}{*}{ Sample } & \multicolumn{8}{|c|}{ Mobile phase } & & & & \\
\hline & \multicolumn{4}{|c|}{ pure $n$-hexane } & \multicolumn{4}{|c|}{$\begin{array}{c}n \text {-hexane/2-propanol } \\
(99.8 / 0.2, \mathrm{v} / \mathrm{v})\end{array}$} & \multicolumn{4}{|c|}{$\begin{array}{c}n \text {-hexane/ethanol } \\
(99.8 / 0.2, \mathrm{v} / \mathrm{v})\end{array}$} \\
\hline & $k_{1}$, & $k_{2}$, & $\alpha$ & Rs & $k_{1}$, & $k_{2}$ & $\alpha$ & Rs & $k_{1}$, & $k_{2}$ & $\alpha$ & Rs \\
\hline Styrene oxide & 3.69 & 5.36 & 1.45 & 3.03 & 1.15 & 1.68 & 1.46 & 0.98 & 1.01 & 1.53 & 1.51 & 1.85 \\
\hline Trans- $\beta$-methylstyrene oxide & 4.27 & 8.26 & 1.93 & 3.08 & 1.44 & 2.93 & 2.03 & 2.08 & 1.1 & 2.25 & 2.04 & 3.16 \\
\hline$\alpha$-methylstyrene oxide & 3.32 & 4.09 & 1.23 & 1.04 & 1.22 & 1.53 & 1.25 & 0.77 & 1.06 & 1.32 & 1.25 & 0.94 \\
\hline
\end{tabular}

${ }^{\mathrm{a}}$ Chromatographic conditions: column: Whelk-O 1 column; flow rate: $1.0 \mathrm{~mL} / \mathrm{min}$; detection wavelength: styrene oxide, 215.7 $\mathrm{nm}$; trans- $\beta$-methylstyrene oxide, $216.8 \mathrm{~nm} ; \alpha$-methylstyrene oxide $208.6 \mathrm{~nm}$.

Table 2.2. The influence of ethanol concentration in mobile phase and temperature on the enantioseparation of $\alpha$-methylstyrene oxide standard. ${ }^{\mathrm{a}}$

\begin{tabular}{ccccc}
\hline$n$-hexane/ethanol (v/v) & $k_{1}$, & $k_{2}{ }^{\prime}$ & $\alpha$ & 1.26 \\
Rs & 1.31 \\
$99.9 / 0.1$ & 1.46 & 1.84 & 1.32 & 1.25 \\
$99.7 / 0.2$ & 1.06 & 1.03 & 1.22 & 0.92 \\
$99.5 / 0.5$ & 0.82 & 0.48 & 1.3 & 0.61 \\
$99.8 / 0.2\left(4^{\circ} \mathrm{C}\right)$ & 0.39 & 2.61 & 1.38 \\
\hline
\end{tabular}

${ }^{a}$ Chromatographic conditions: column: Whelk-O 1 column; flow rate: $1.0 \mathrm{~mL} / \mathrm{min}$; detection wavelength: $208.6 \mathrm{~nm}$. 
F103A and N74V are shown in Figures 2.17, 2.18 and 2.19, respectively. The enantioseparation results of $\alpha$-methylstyrene oxide catalyzed by WT CPO, F103A and N74V are shown in Figures 2.20, 2.21 and 2.22, respectively.

The epoxidation of $\alpha$-methylstyrene oxide catalyzed by CPO and its mutants produced several side products; thus the peaks caused by principal epoxidation products were hard to identify. Therefore, known substances ( $\alpha$-methylstyrene oxide standards) were added into the product mixture to determine the identity of the corresponding epoxidation products in the product mixture. If the known substance is present in the mixture, the peak for that substance will become larger in the spiked sample than in the unspiked sample. If the known substance is not present in the mixture, an extra peak will show up in the spiked sample compared to the unspiked sample. By analyzing the peak areas and the retention times required for peaks in the chromatogram, the principal products, $\alpha$-methylstyrene oxide enantiomers, catalyzed by CPO, F103A and N74V, were identified. Refer to the Figures 2.23, 2.24 and 2.25, which show the chromatograms of enantioseparation of $\alpha$-methylstyrene oxide catalyzed by CPO, F103A and N74V spiked with racemic $\alpha$-methylstyrene oxide standards. Their identical UV-vis absorption spectra also confirmed the identification results (data not shown).

Chloroperoxidase catalyzed epoxidation of cis- $\beta$-methylstyrene has a $96 \%$ enantiomeric excess, and the major product is the $(1 S, 2 R)$-enantiomer, according to previously published literature. ${ }^{75}$ Therefore, this major epoxidation product was used as the standard for latter experiments. Refer to Figure 2.26 for the enantioseparation of cis- $\beta$-methylstyrene oxide catalyzed by $\mathrm{CPO}$, which is in consistent with the literature. ${ }^{75}$ In order to determine the identity of the epoxidation products catalyzed by 
F103A, the known $(1 S, 2 R)$-enantiomer was added into the epoxidation products. The peak for the $1 S 2 R$ enantiomer became larger in the spiked analyte than in the unspiked analyte. Refer to Figure 2.27 for the enantioseparation of cis- $\beta$-methylstyrene oxide catalyzed by F103A and Figure 2.28 for the enantioseparation of cis- $\beta$-methylstyrene oxide catalyzed by F103A spiked with $1 S 2 R$ enantiomer. The matched UV spectra collected as each peak elutes further confirmed the identity of the enantiomers. Refer to Figure 2.29 for the UV spectrum of cis- $\beta$-methylstyrene from HPLC separation. The $\mathrm{N} 74 \mathrm{~V}$ catalyzed epoxidation of cis- $\beta$-methylstyrene was also identified by the same strategy as F103A. Refer to Figure 2.30 for the enantioseparation of cis- $\beta$ methylstyrene oxide catalyzed by N74V.

The enantioseparation results of trans- $\beta$-ethylstyrene oxide catalyzed by WT CPO, F103A and N74V are shown in Figures 2.31, 2.32 and 2.33, respectively. The enantioseparation results of $\beta$-dimethylstyrene oxide catalyzed by WT CPO, F103A and N74V are shown in Figures 2.34, 2.35 and 2.36, respectively. Because of the lack of standards for trans- $\beta$-ethylstyrene oxide and $\beta$-dimethylstyrene oxide, the separated epoxidation product enantiomers were identified with GC-MS. Using trans- $\beta$ ethylstyrene oxide as an example, the principle products confirmed by their matching UV spectra were collected for MS analysis. Refer to Figures 2.37 and 2.38 for mass spectra of $(R)$-trans- $\beta$-ethylstyrene oxide and (S)-trans- $\beta$-ethylstyrene oxide collected from HPLC separation. These two essentially identical mass spectra were found to be in good agreement with the epoxide structures. The largest peak at $\mathrm{m} / \mathrm{z}=148$ matched the molecular weight of trans- $\beta$-ethylstyrene oxide. The major ion fragments $\mathrm{m} / \mathrm{z} 133,119$ and 105 are also consistent with the structure of trans- $\beta$-ethylstyrene oxide. The $\beta$ - 
dimethylstyrene oxide was also identified by the same strategy as trans- $\beta$-ethylstyrene oxide. Figures 2.39 and 2.40 show the mass spectra of $(R)$ - $\beta$-dimethylstyrene oxide and $(S)$ - $\beta$-dimethylstyrene oxide.

The enantioseparation results of $\alpha$-ethylstyrene oxide catalyzed by WT CPO, F103A and N74V are shown in Figures 2.41, 2.42 and 2.43, respectively. The enantioseparation results of $\alpha$-propylstyrene oxide catalyzed by WT CPO, F103A and N74V are shown in Figures $2.44,2.45$ and 2.46 , respectively. The standards for $\alpha$-ethylstyrene oxide and $\alpha$ propylstyrene oxide were also commercially not available, yet the reaction yields of these products were too low to satisfy the sample amount required for MS analysis. Therefore, the UV spectra collected at each peak elutes were used to identify the enantiomers. Refer to Figures 2.47 and 2.48 for the UV spectra of $\alpha$-ethylstyrene oxide and $\alpha$-propylstyrene oxide from HPLC separation. Their essentially identical UV spectra confirmed their identity as enantiomers.

All the chromatographic conditions of the epoxidation product enantioseparation were shown in Table 2.3. After the successful identification of all the epoxidation products, the $k^{\prime}, \alpha$, Rs, ee value and yield for all the HPLC separation were calculated, as shown in Table 2.4.

\subsection{Discussion and Conclusions}

\subsubsection{Mobile phase modifier and temperature influence on Whelk-O 1 column}

The effect of the mobile phase modifiers and the effect of column temperature on chromatographic parameters, such as $k^{\prime}, \alpha$, Rs and elution order, were examined by the successful enantioseparation of styrene oxide, $\alpha$-methyl styrene oxide and trans- $\beta$-methyl styrene oxide standards. As shown in Table 2.1, the retentions of the solutes were weaker 


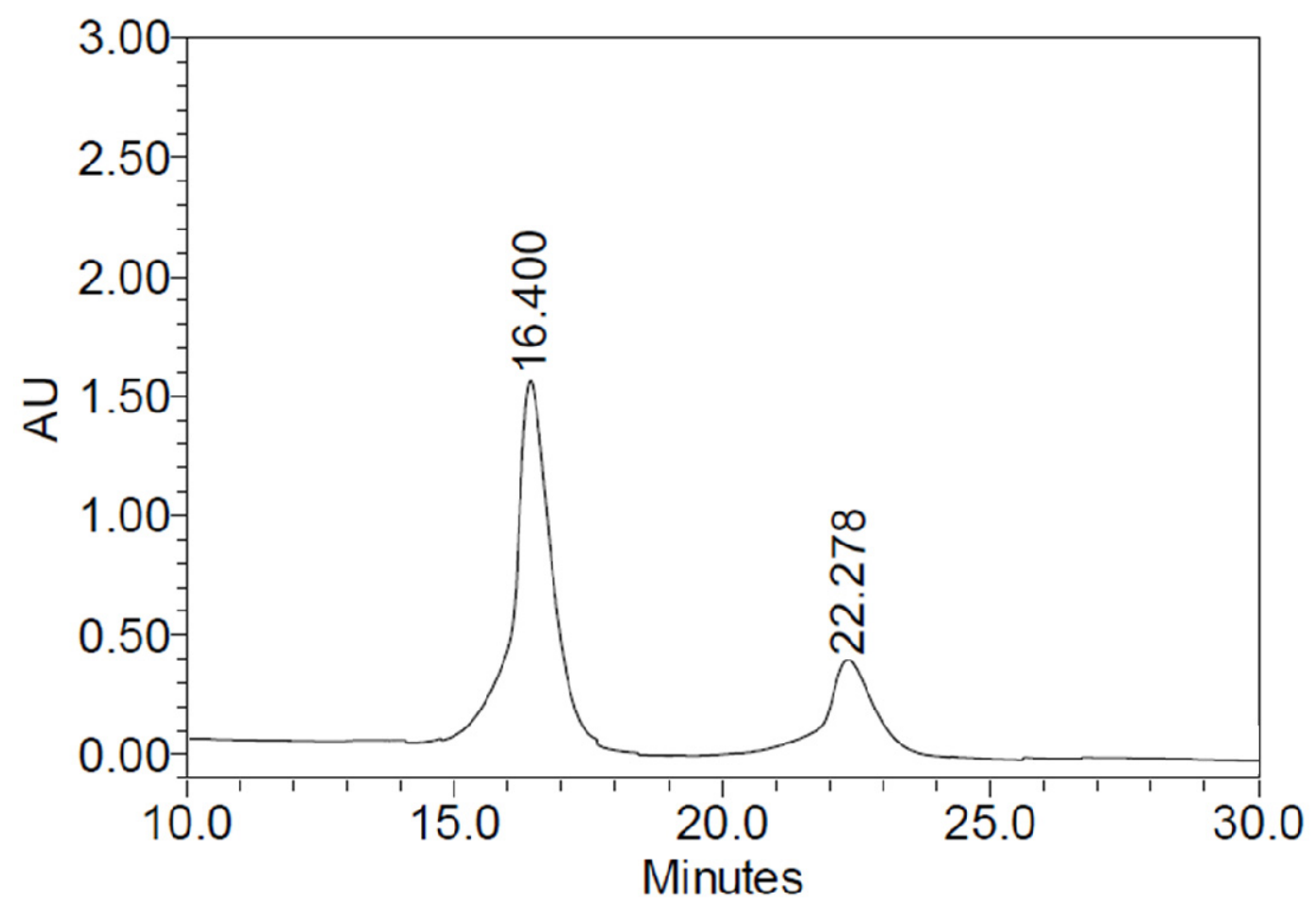

Figure 2.14. Enantioseparation of styrene oxide catalyzed by $\mathrm{CPO}$ on Whelk-O 1 column. Mobile phase, pure $n$-hexane; monitoring wavelength, $215.7 \mathrm{~nm}$.

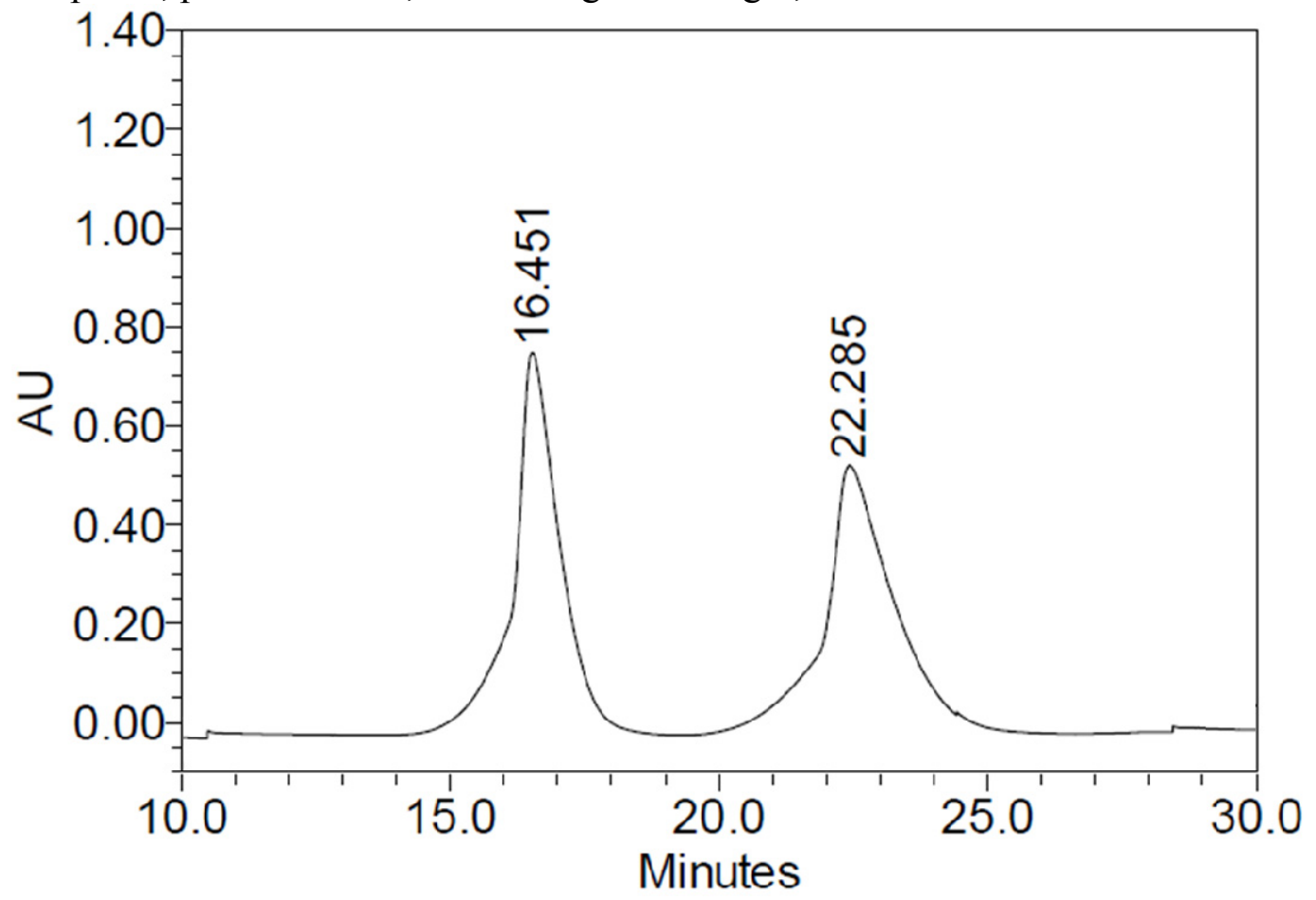

Figure 2.15. Enantioseparation of styrene oxide catalyzed by F103A on Whelk-O 1 column. Mobile phase, pure $n$-hexane; monitoring wavelength, $215.7 \mathrm{~nm}$. 


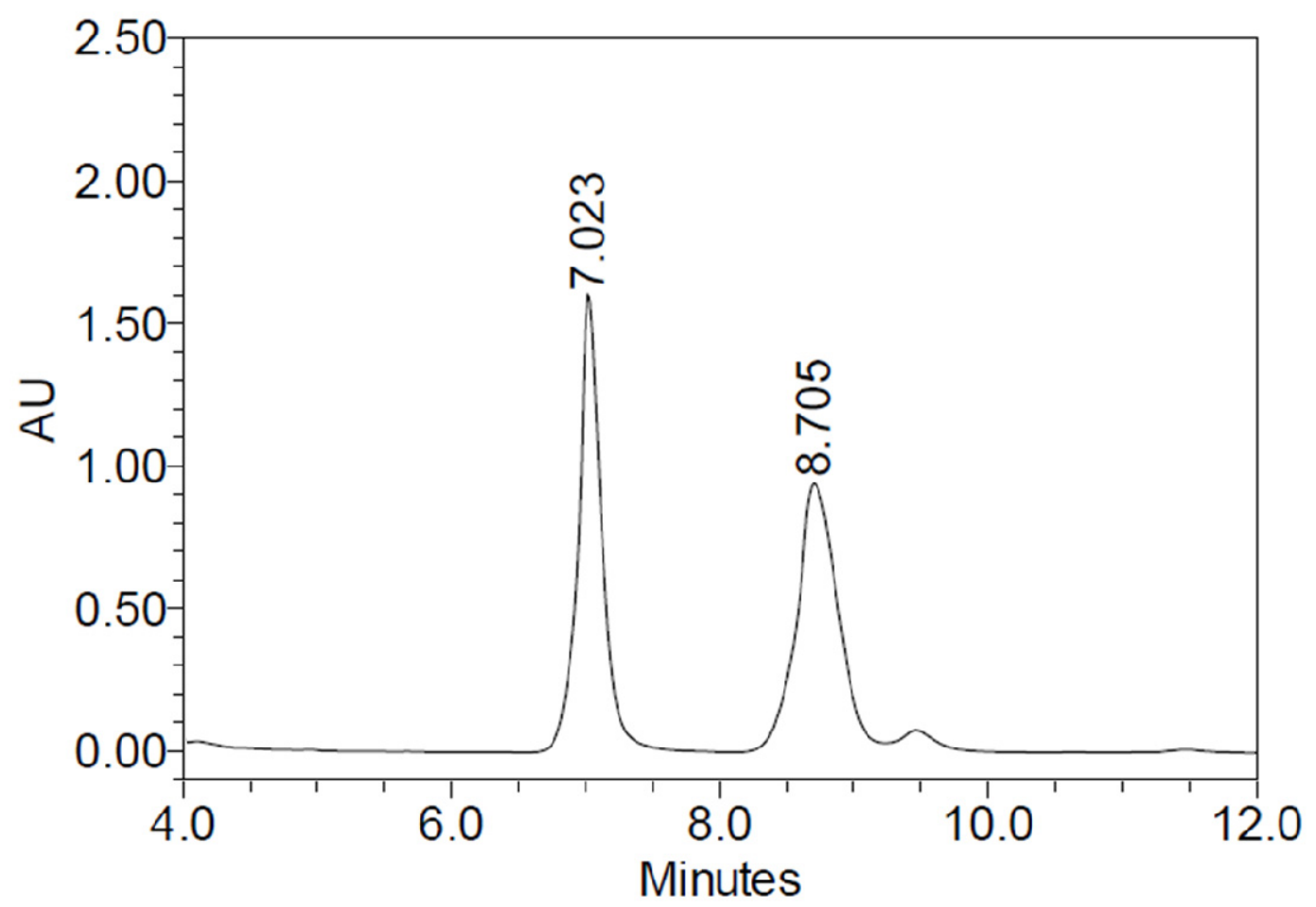

Figure 2.16. Enantioseparation of styrene oxide catalyzed by N74V on Whelk-O 1 column. Mobile phase, $n$-hexane/ethanol (99.8/0.2, v/v); monitoring wavelength, $215.7 \mathrm{~nm}$.

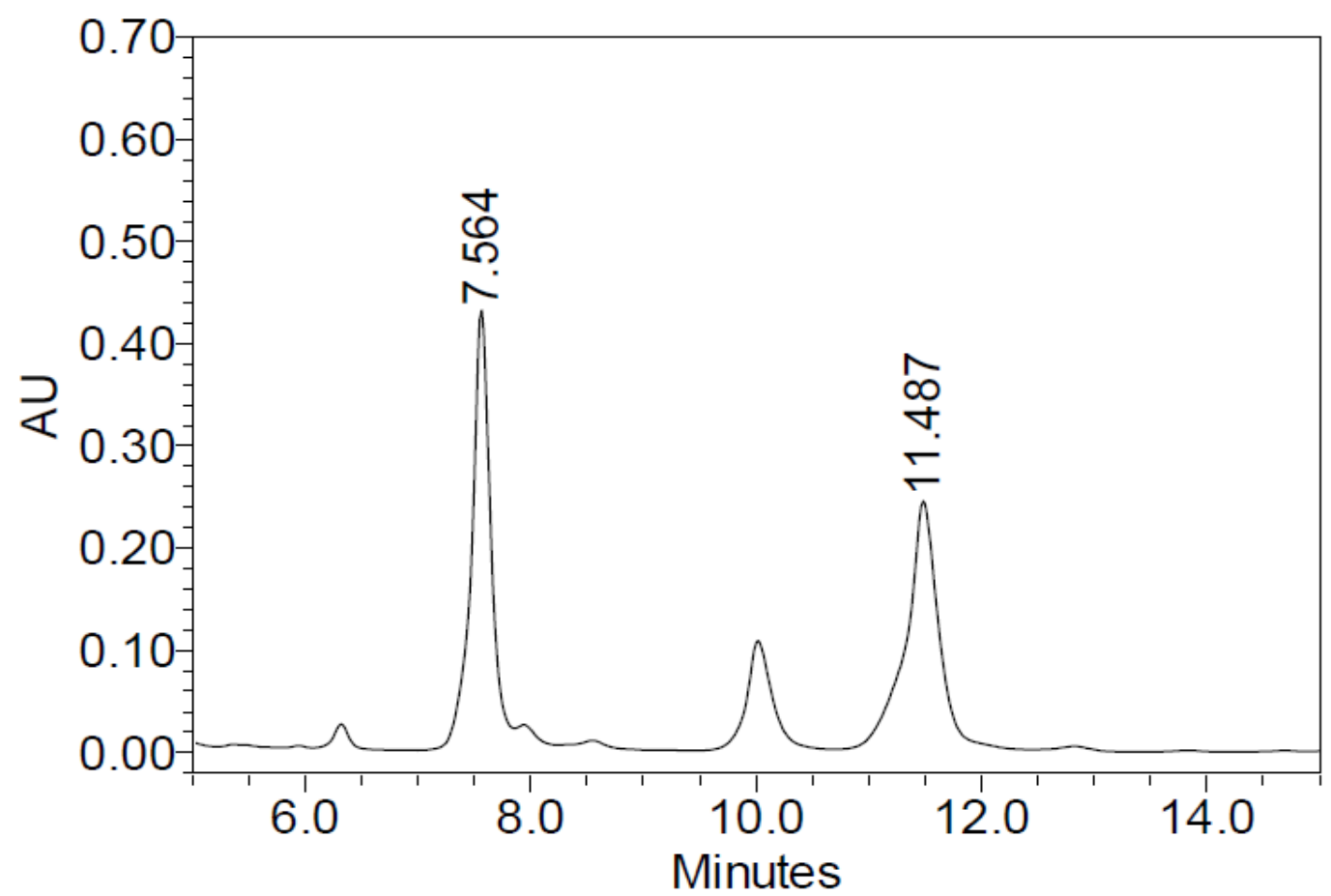

Figure 2.17. Enantioseparation of trans- $\beta$-methylstyrene oxide catalyzed by $\mathrm{CPO}$ on Whelk-O 1 column. Mobile phase, $n$-hexane/ethanol $(99.8 / 0.2, \mathrm{v} / \mathrm{v})$; monitoring wavelength, $216.8 \mathrm{~nm}$. 


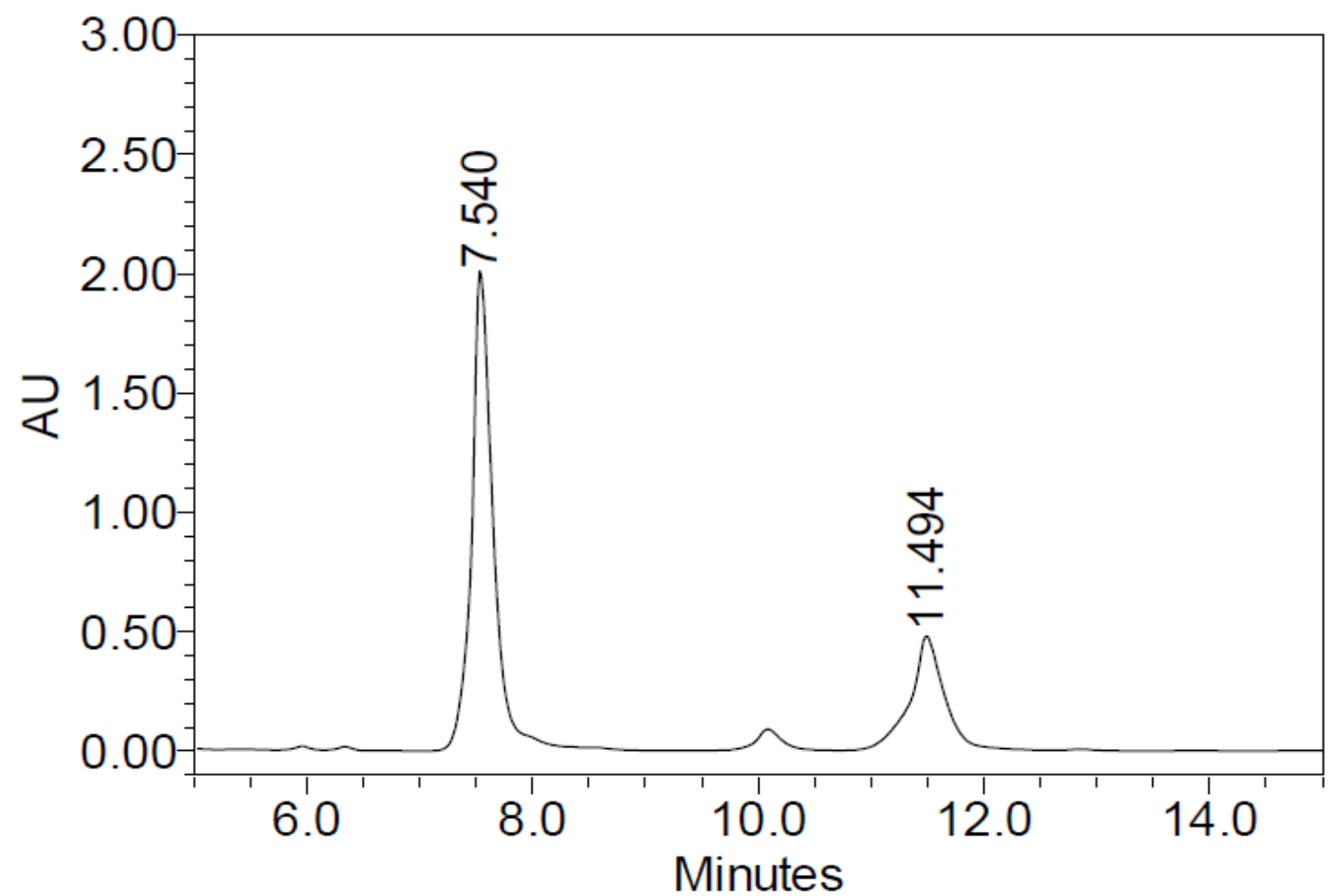

Figure 2.18. Enantioseparation of trans- $\beta$-methylstyrene oxide catalyzed by F103A on Whelk-O 1 column. Mobile phase, $n$-hexane/ethanol (99.8/0.2, v/v); monitoring wavelength, $216.8 \mathrm{~nm}$.

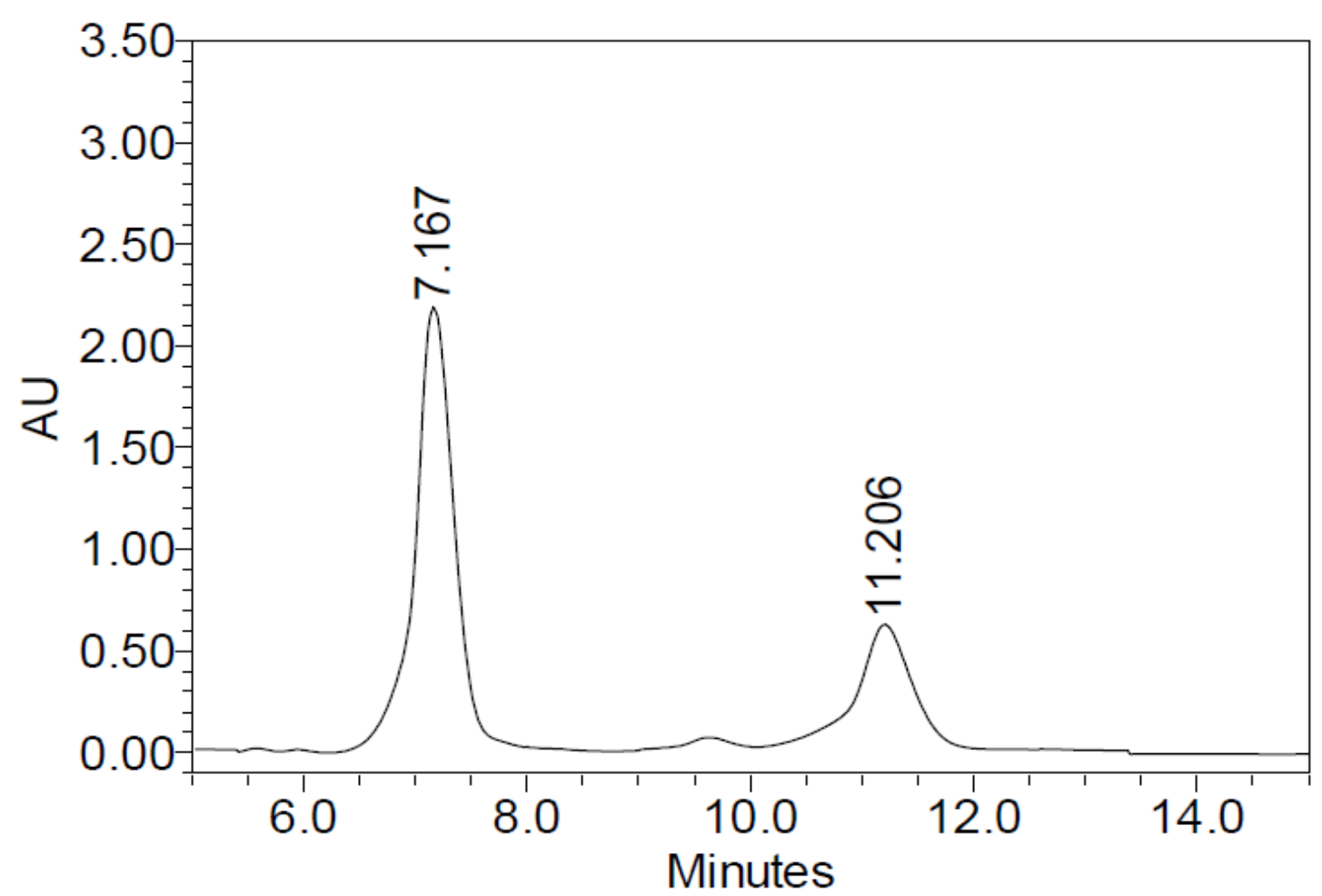

Figure 2.19. Enantioseparation of trans- $\beta$-methylstyrene oxide catalyzed by N74V on Whelk-O 1 column. Mobile phase, $n$-hexane/ethanol $(99.7 / 0.3, \mathrm{v} / \mathrm{v})$; monitoring wavelength, $216.8 \mathrm{~nm}$. 


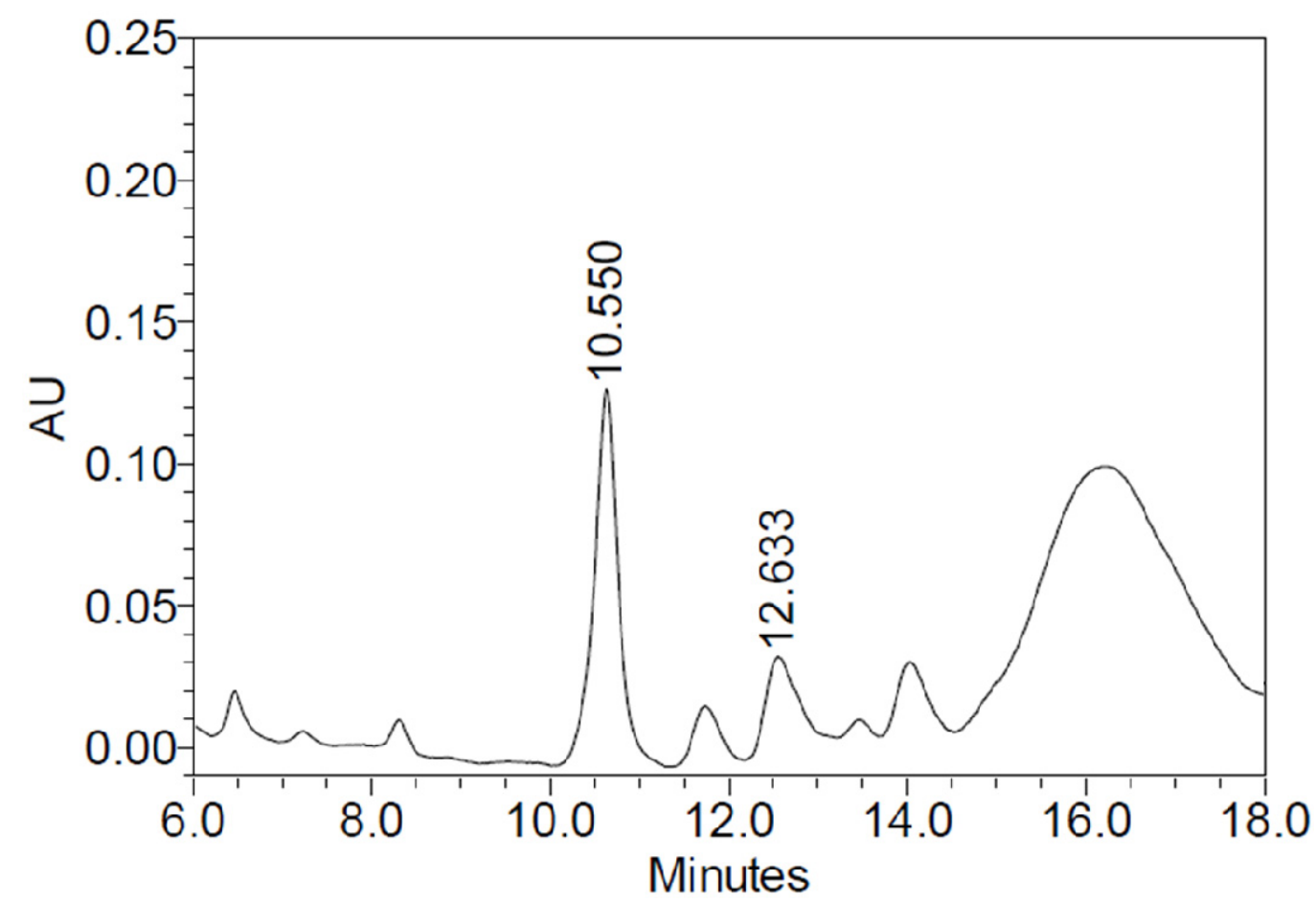

Figure 2.20. Enantioseparation of $\alpha$-methylstyrene oxide catalyzed by CPO on Whelk-O 1 column. Mobile phase, $n$-hexane/ethanol (99.8/0.2, v/v); monitoring wavelength, 208.6 $\mathrm{nm}$; column temperature, $4^{\circ} \mathrm{C}$.

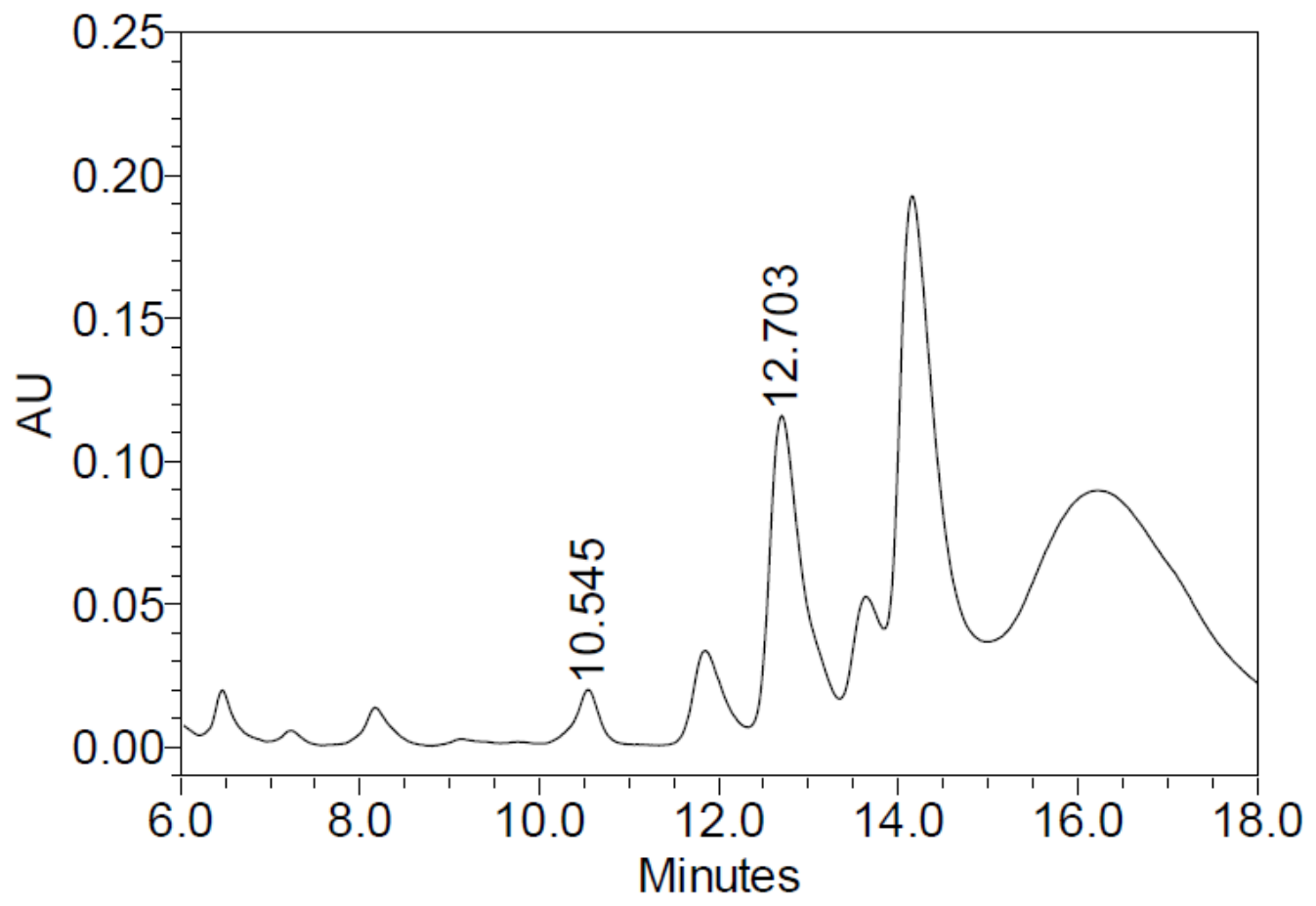

Figure 2.21. Enantioseparation of $\alpha$-methylstyrene oxide catalyzed by F103A on WhelkO 1 column. Mobile phase, $n$-hexane/ethanol $(99.8 / 0.2, \mathrm{v} / \mathrm{v})$; monitoring wavelength, $208.6 \mathrm{~nm}$; column temperature, $4^{\circ} \mathrm{C}$. 


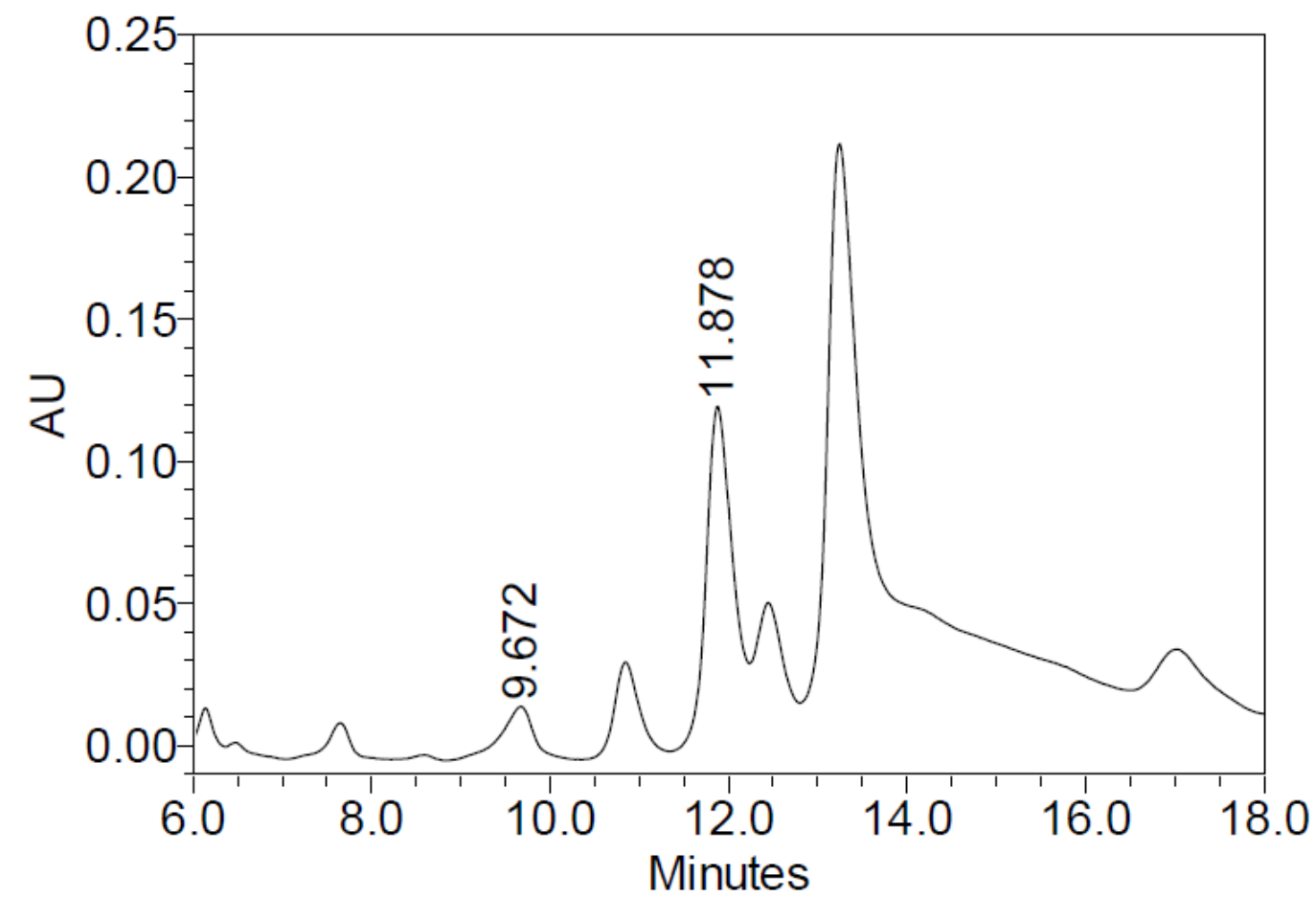

Figure 2.22. Enantioseparation of $\alpha$-methylstyrene oxide catalyzed N74V on Whelk-O 1 column. Mobile phase, $n$-hexane/ethanol (99.7/0.3, v/v); monitoring wavelength, 208.6 $\mathrm{nm}$; column temperature, $4^{\circ} \mathrm{C}$.

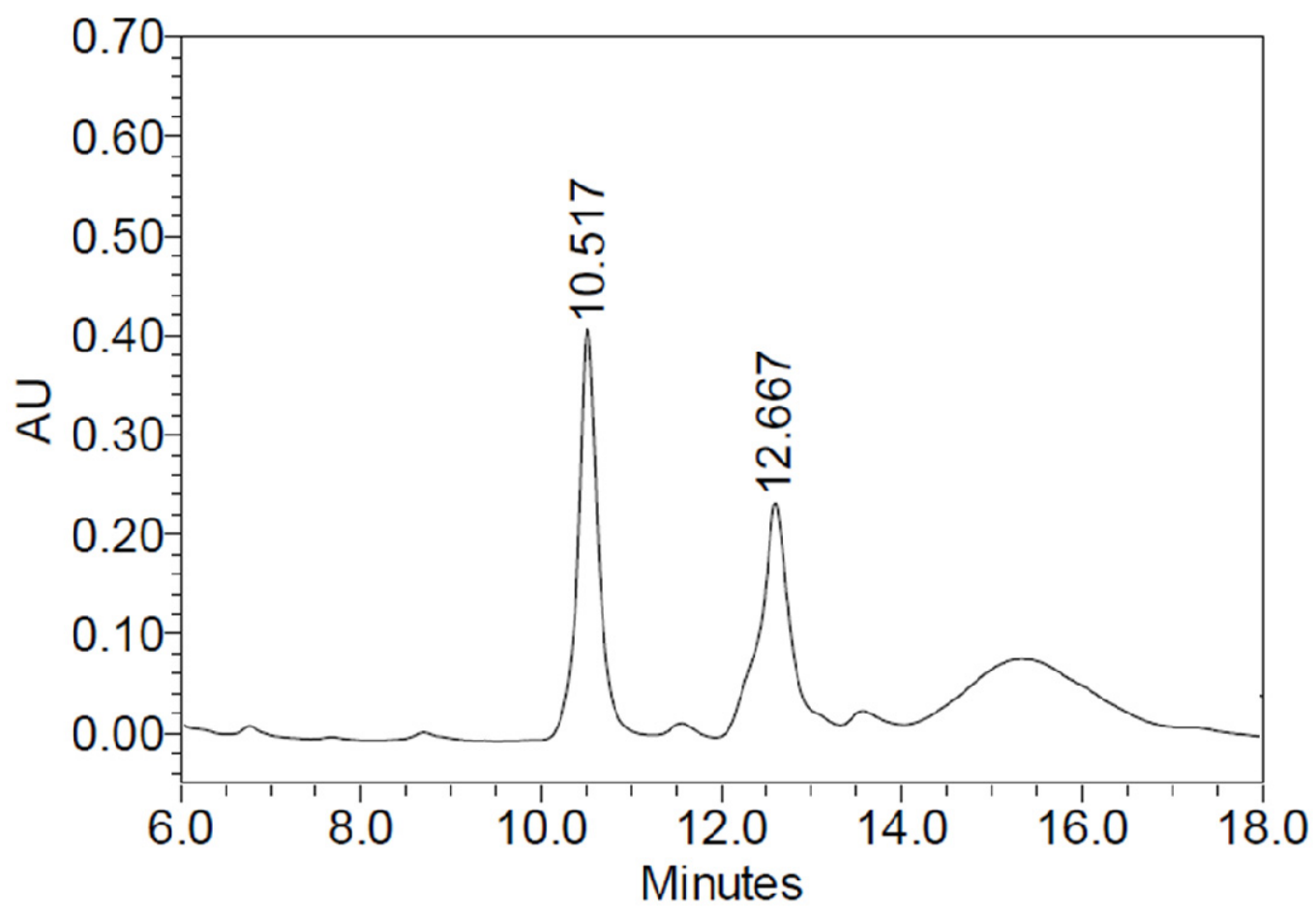

Figure 2.23. Enantioseparation of $\alpha$-methylstyrene oxide catalyzed by CPO spiked with racemic standard on Whelk-O 1 column. Mobile phase, $n$-hexane/ethanol $(99.8 / 0.2, \mathrm{v} / \mathrm{v})$; monitoring wavelength, $208.6 \mathrm{~nm}$; column temperature, $4^{\circ} \mathrm{C}$. 


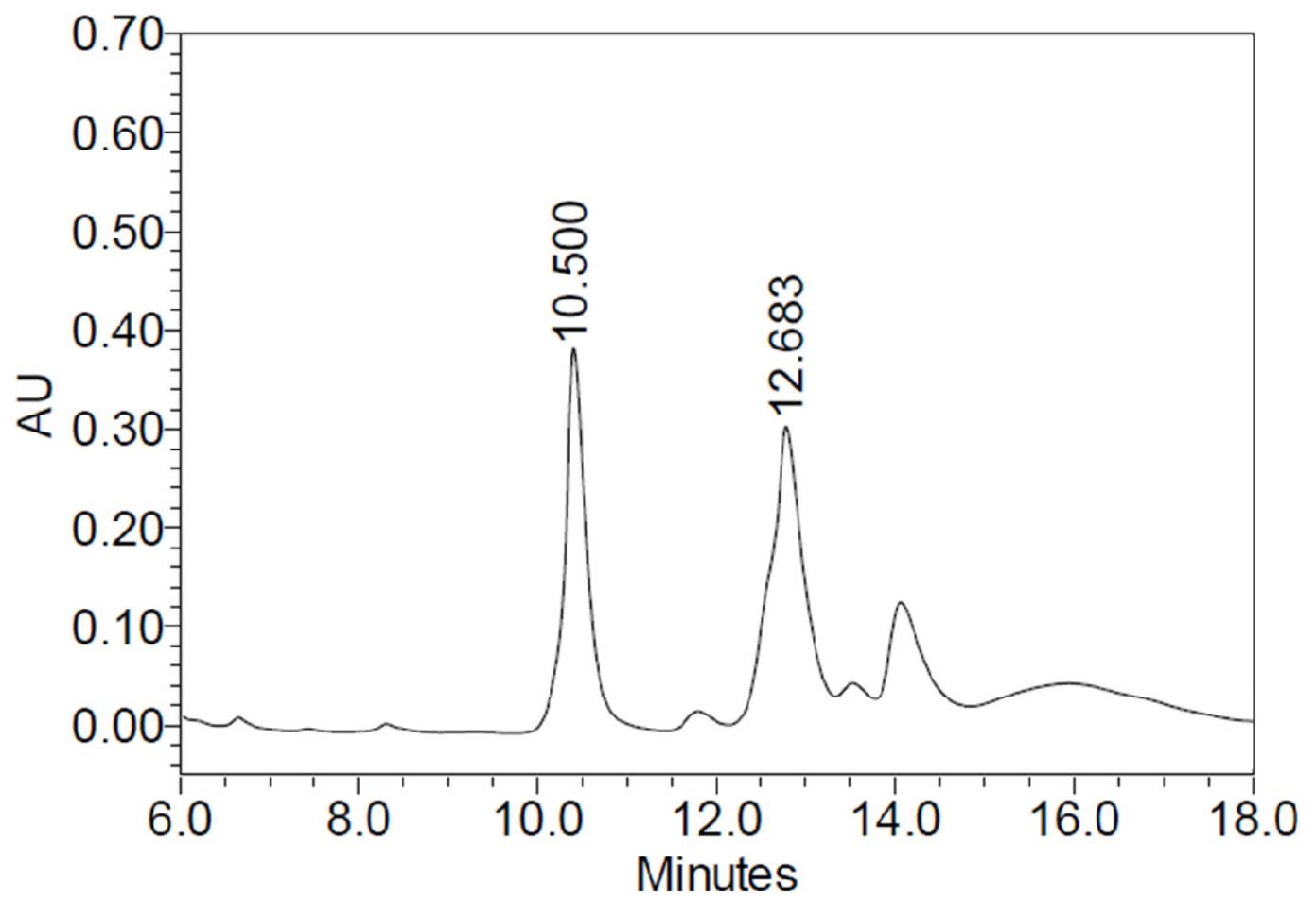

Figure 2.24. Enantioseparation of $\alpha$-methylstyrene oxide catalyzed by F103A spiked with racemic standard on Whelk-O 1 column. Mobile phase, $n$-hexane/ethanol $(99.8 / 0.2, \mathrm{v} / \mathrm{v})$; monitoring wavelength, $208.6 \mathrm{~nm}$; column temperature, $4^{\circ} \mathrm{C}$.

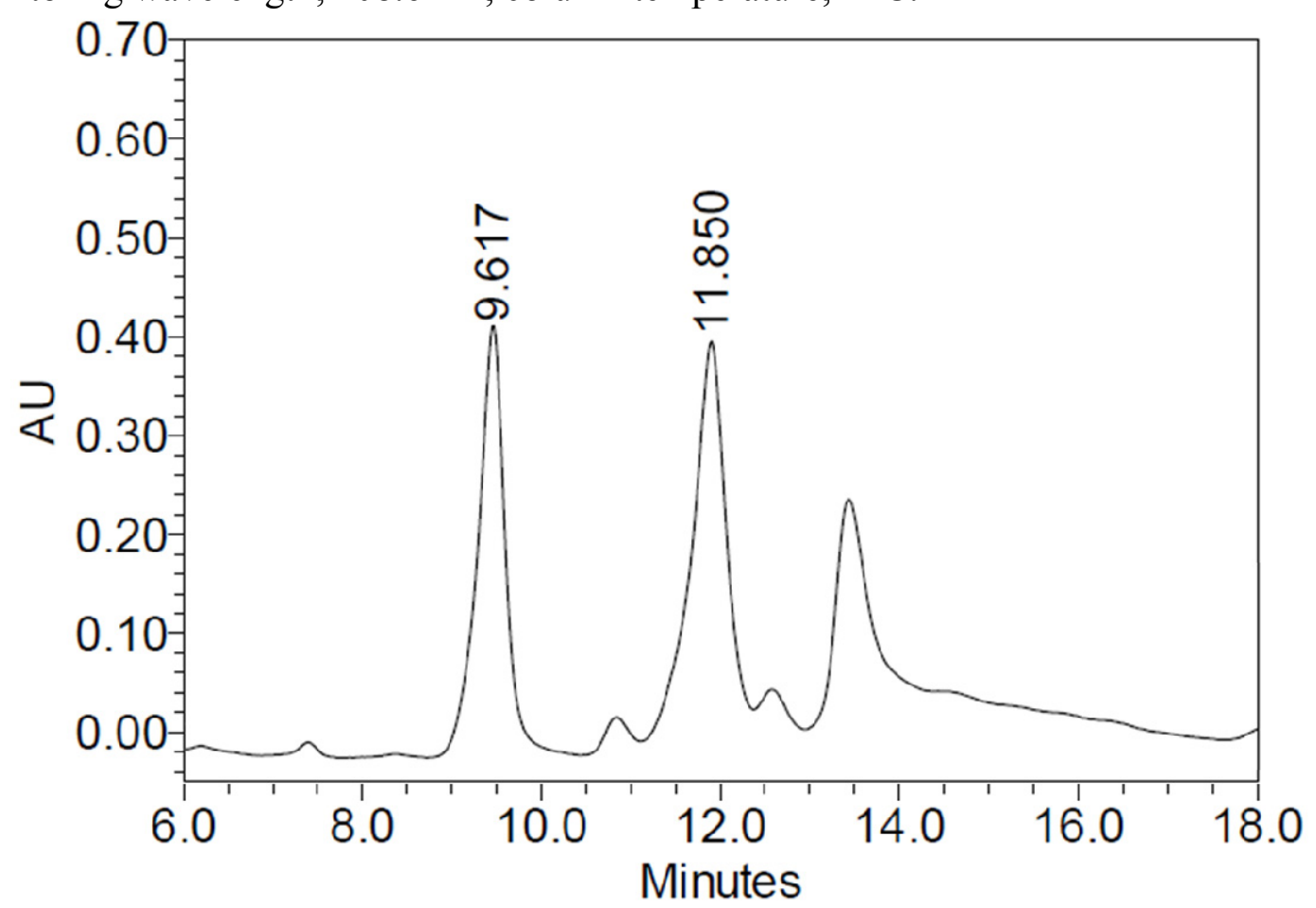

Figure 2.25. Enantioseparation of $\alpha$-methylstyrene oxide catalyzed N74V spiked with racemic standard on Whelk-O 1 column. Mobile phase, $n$-hexane/ethanol $(99.7 / 0.3, \mathrm{v} / \mathrm{v})$; monitoring wavelength, $208.6 \mathrm{~nm}$; column temperature, $4^{\circ} \mathrm{C}$. 


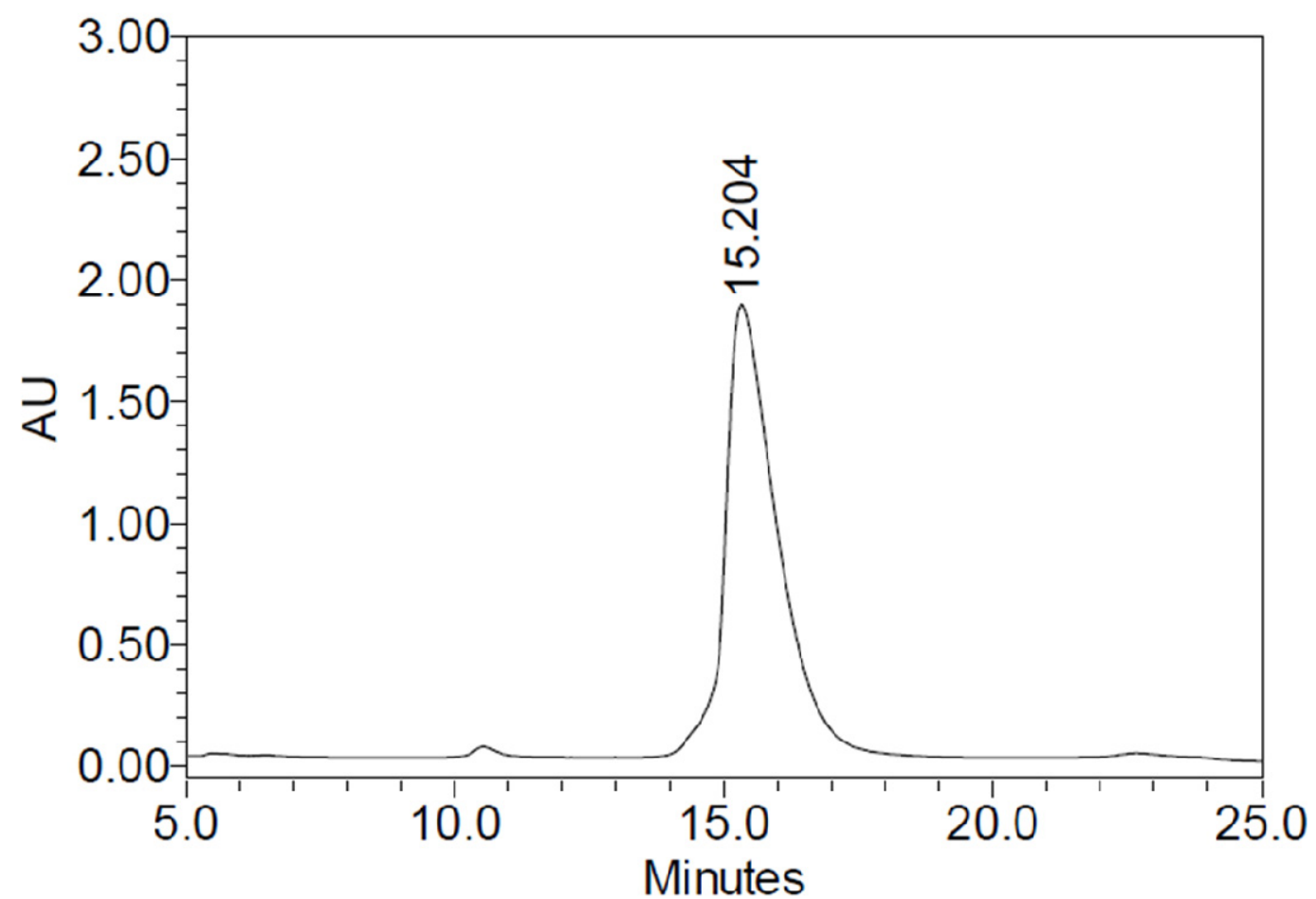

Figure 2.26. Enantioseparation of cis- $\beta$-methylstyrene oxide catalyzed by $\mathrm{CPO}$ on Whelk-O 1 column. Mobile phase, pure $n$-hexane; monitoring wavelength, $215.7 \mathrm{~nm}$.

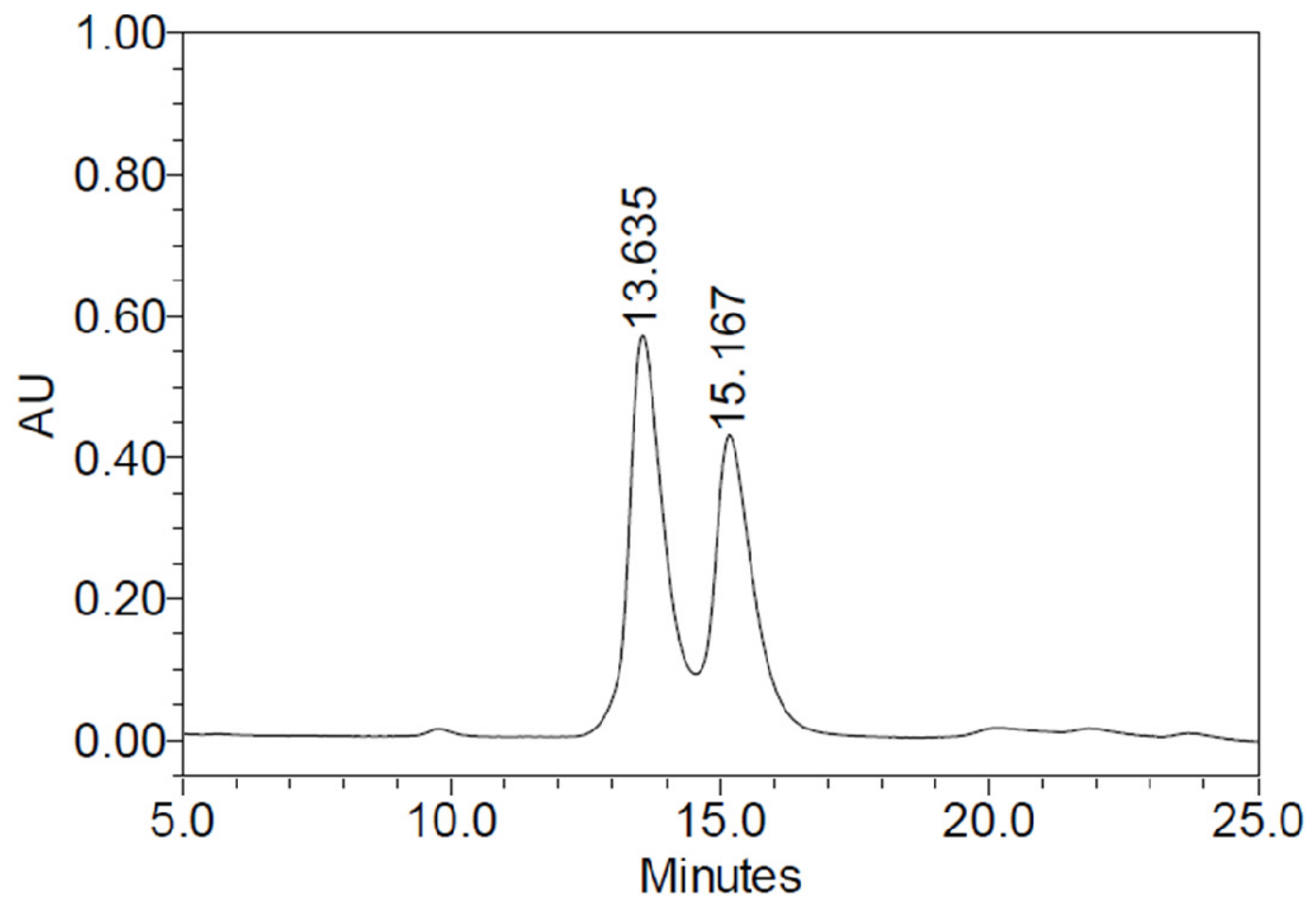

Figure 2.27. Enantioseparation of cis- $\beta$-methylstyrene oxide catalyzed by F103A on Whelk-O 1 column. Mobile phase, pure $n$-hexane; monitoring wavelength, $215.7 \mathrm{~nm}$. 


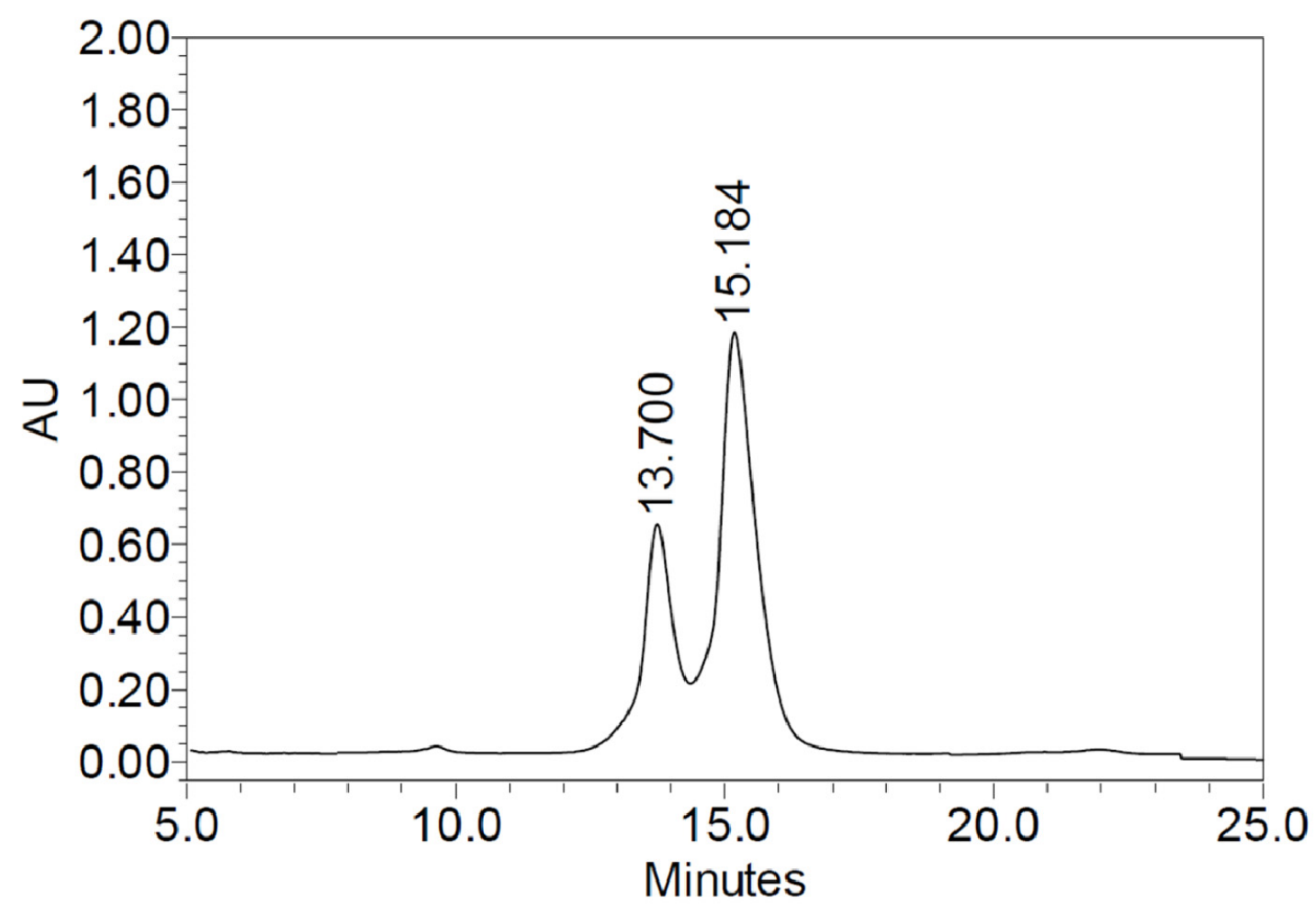

Figure 2.28. Enantioseparation of cis- $\beta$-methylstyrene oxide catalyzed by F103A with $1 S 2 R$ enantiomer on Whelk-O 1 column. Mobile phase, pure $n$-hexane; monitoring wavelength, $215.7 \mathrm{~nm}$.

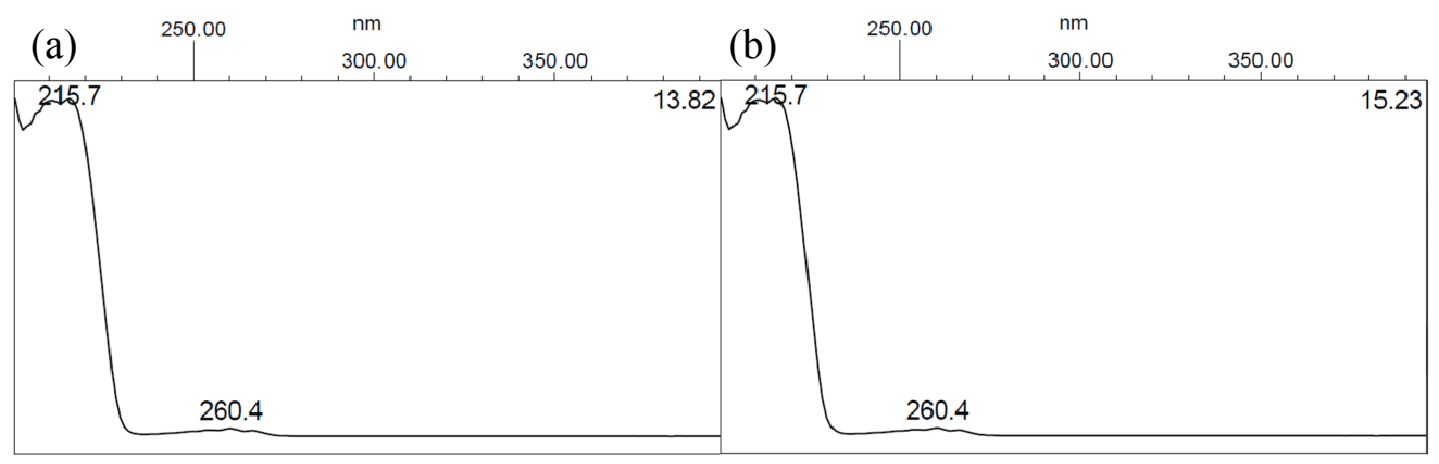

Figure 2.29. UV-vis spectra of (a) (R)-cis- $\beta$-methylstyrene oxide and (b) (S)-cis- $\beta$-methylstyrene oxide. 


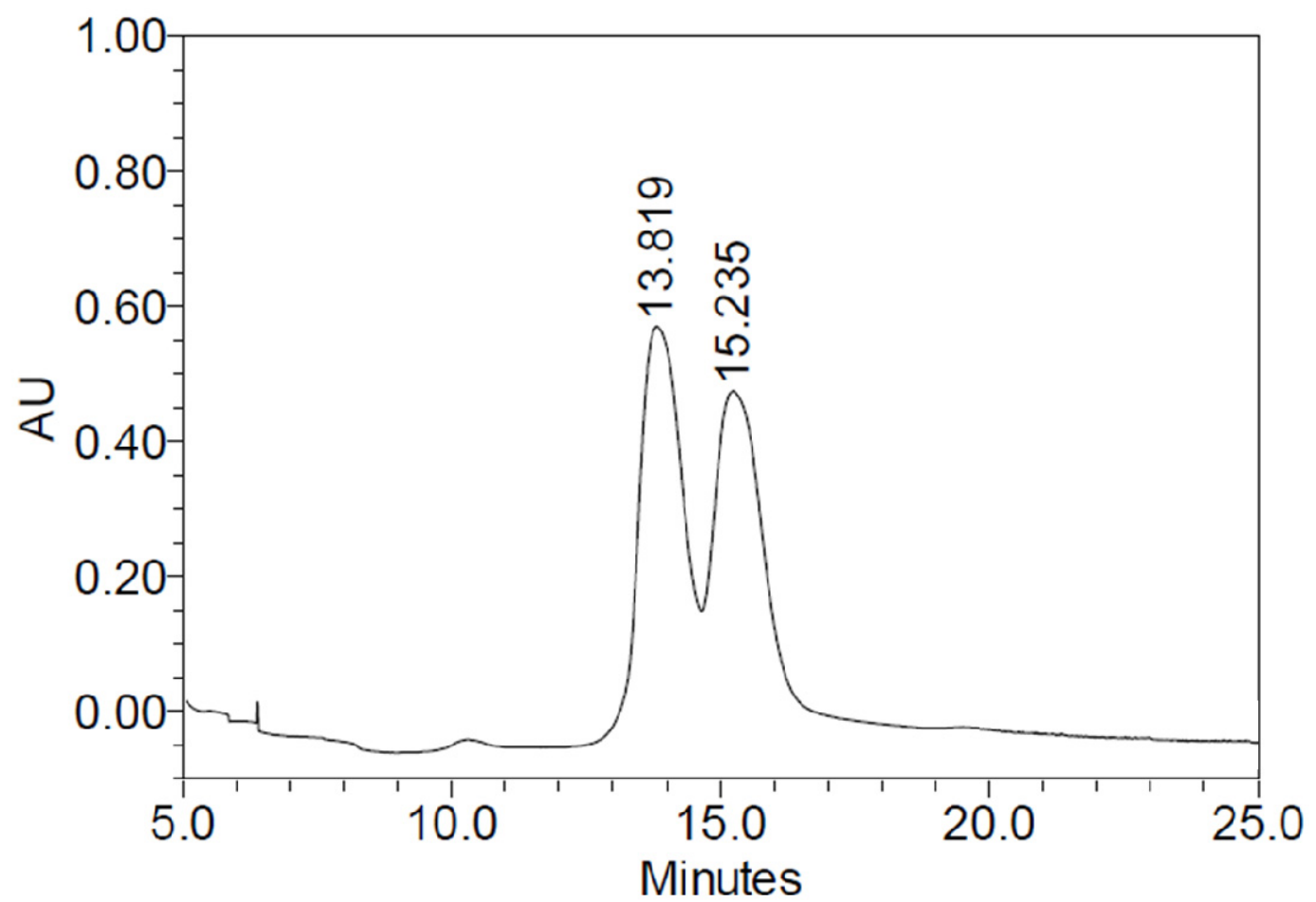

Figure 2.30. Enantioseparation of cis- $\beta$-methylstyrene oxide catalyzed by N74V on Whelk-O 1 column. Mobile phase, pure $n$-hexane; monitoring wavelength, $215.7 \mathrm{~nm}$.

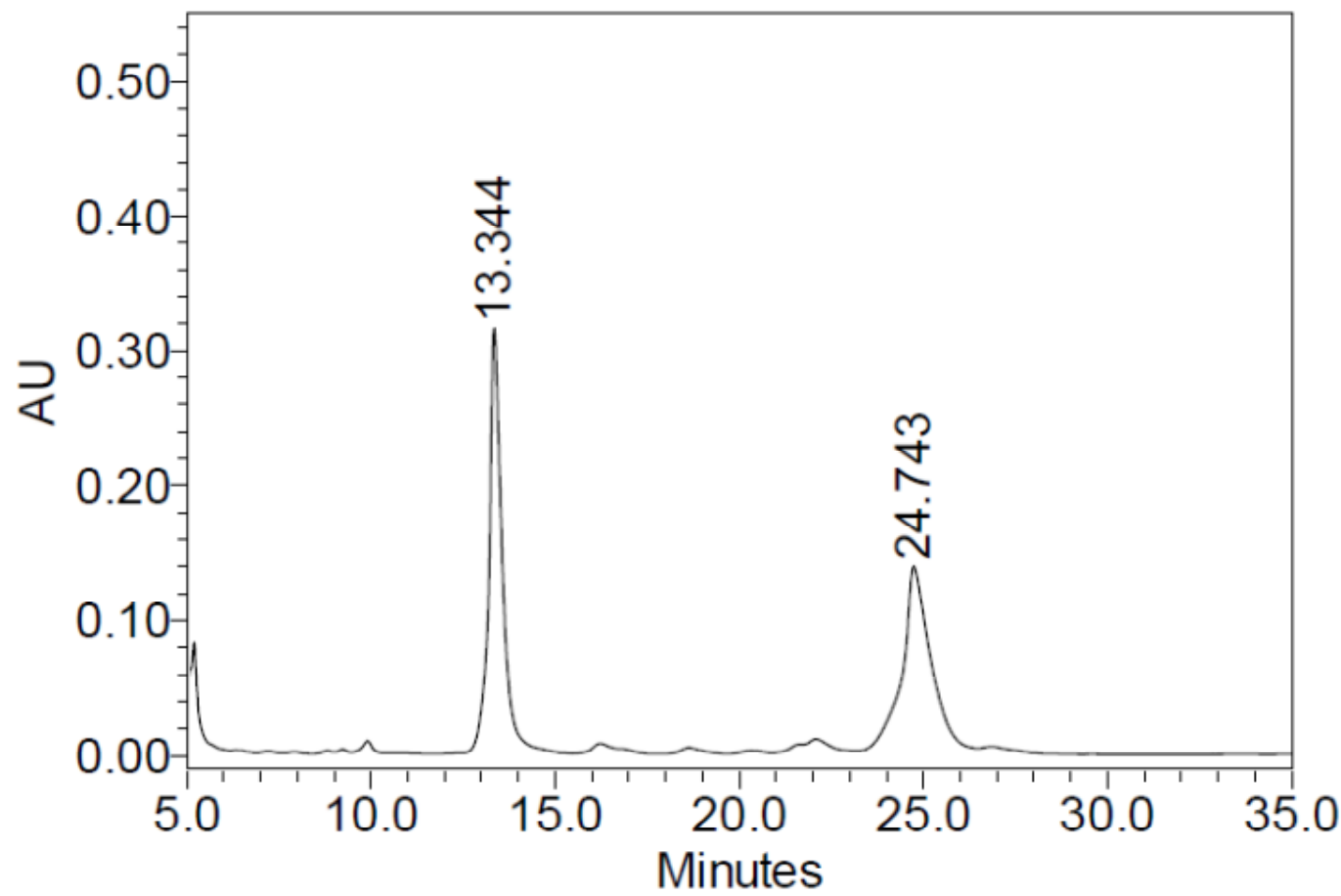

Figure 2.31. Enantioseparation of trans- $\beta$-ethylstyrene oxide catalyzed by $\mathrm{CPO}$ on Whelk-O 1 column. Mobile phase, $n$-hexane/ethanol (99.9/0.1, v/v); monitoring wavelength, $218 \mathrm{~nm}$; column temperature, $4^{\circ} \mathrm{C}$. 


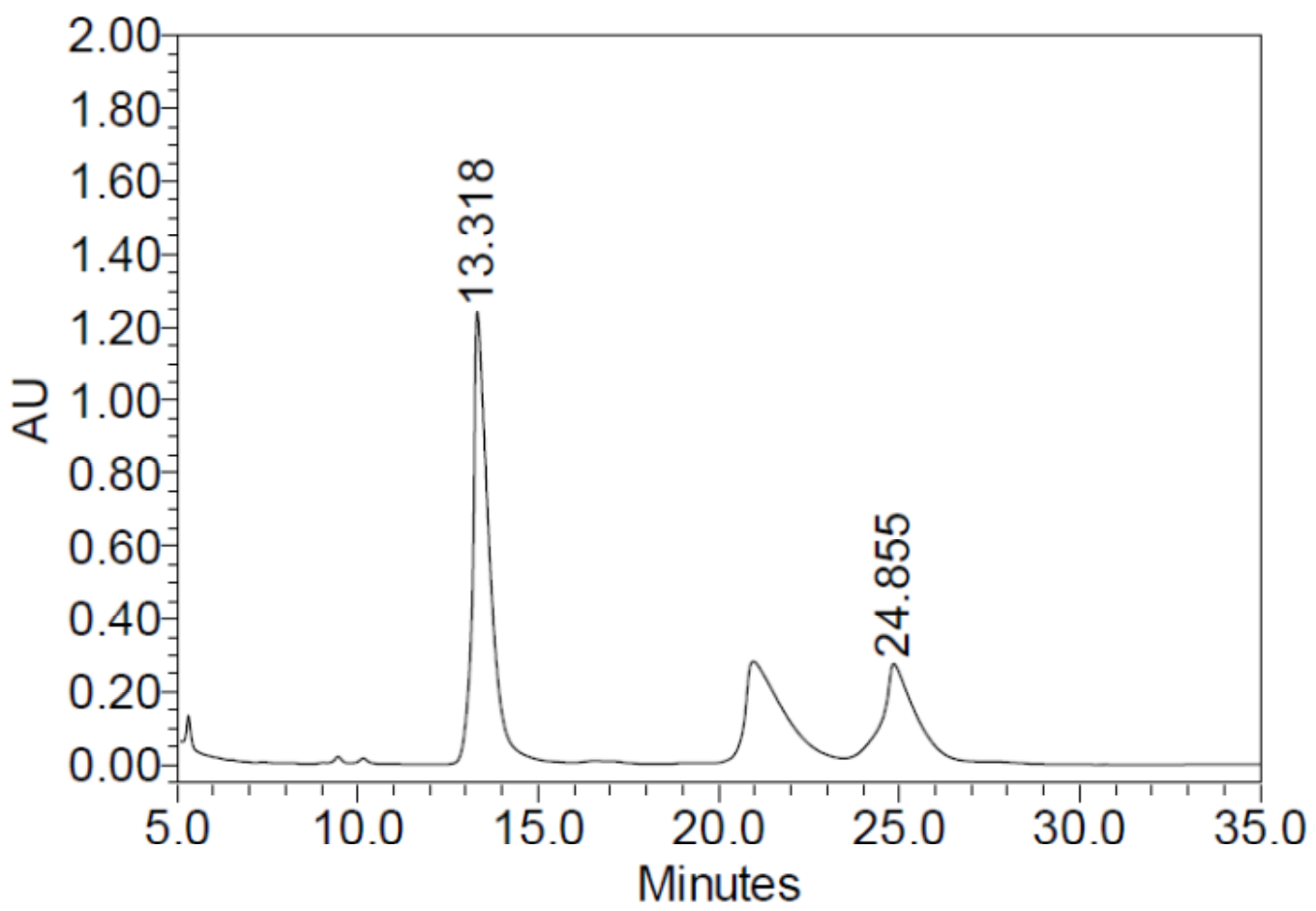

Figure 2.32. Enantioseparation of trans- $\beta$-ethylstyrene oxide catalyzed by F103A on Whelk-O 1 column. Mobile phase, $n$-hexane/ethanol (99.9/0.1, v/v); monitoring wavelength, $218 \mathrm{~nm}$; column temperature, $4^{\circ} \mathrm{C}$.

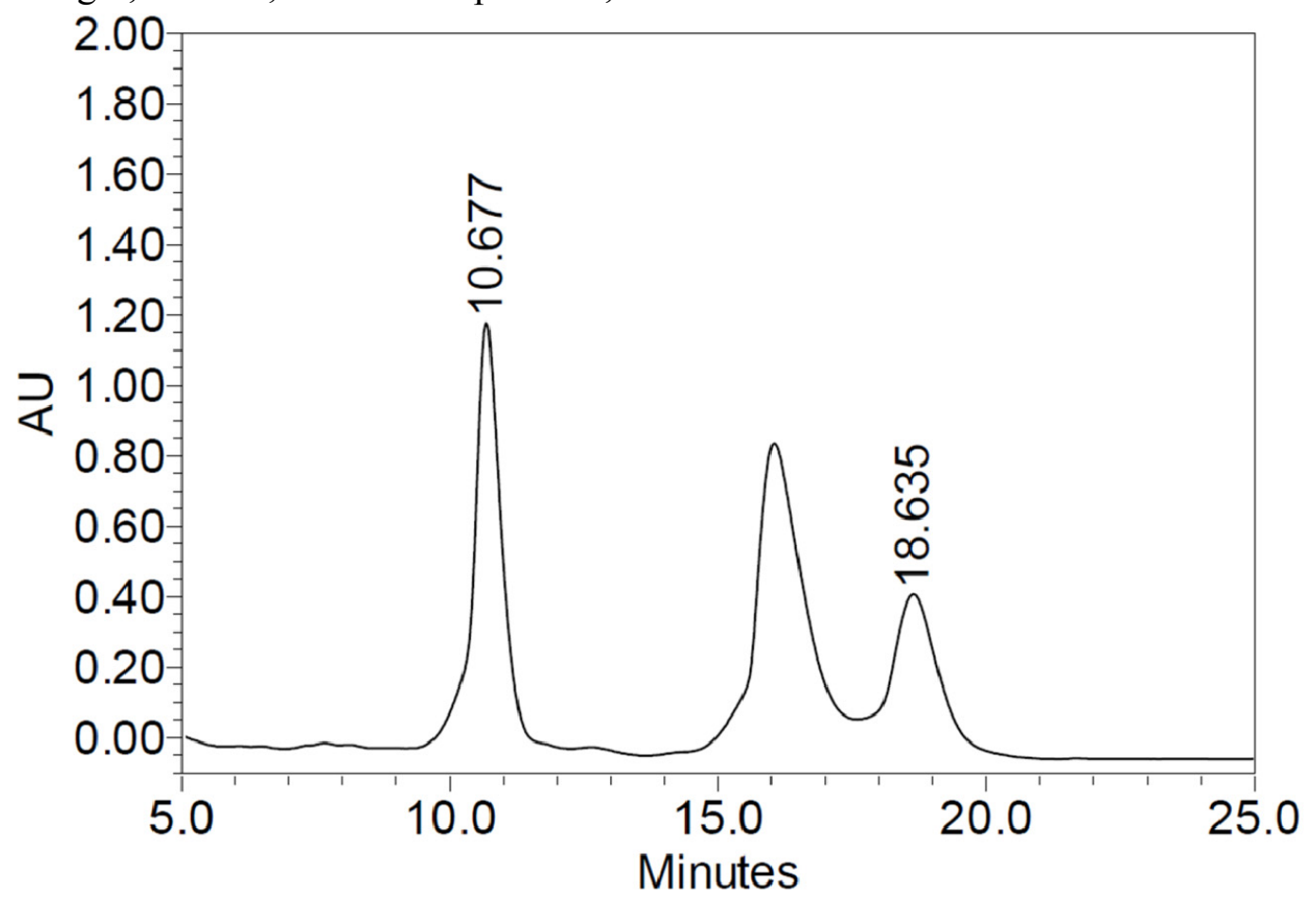

Figure 2.33. Enantioseparation of trans- $\beta$-ethylstyrene oxide catalyzed by $\mathrm{N} 74 \mathrm{~V}$ on Whelk-O 1 column. Mobile phase, $n$-hexane/ethanol (99.8/0.2, v/v); monitoring wavelength, $218 \mathrm{~nm}$; column temperature, $4{ }^{\circ} \mathrm{C}$. 


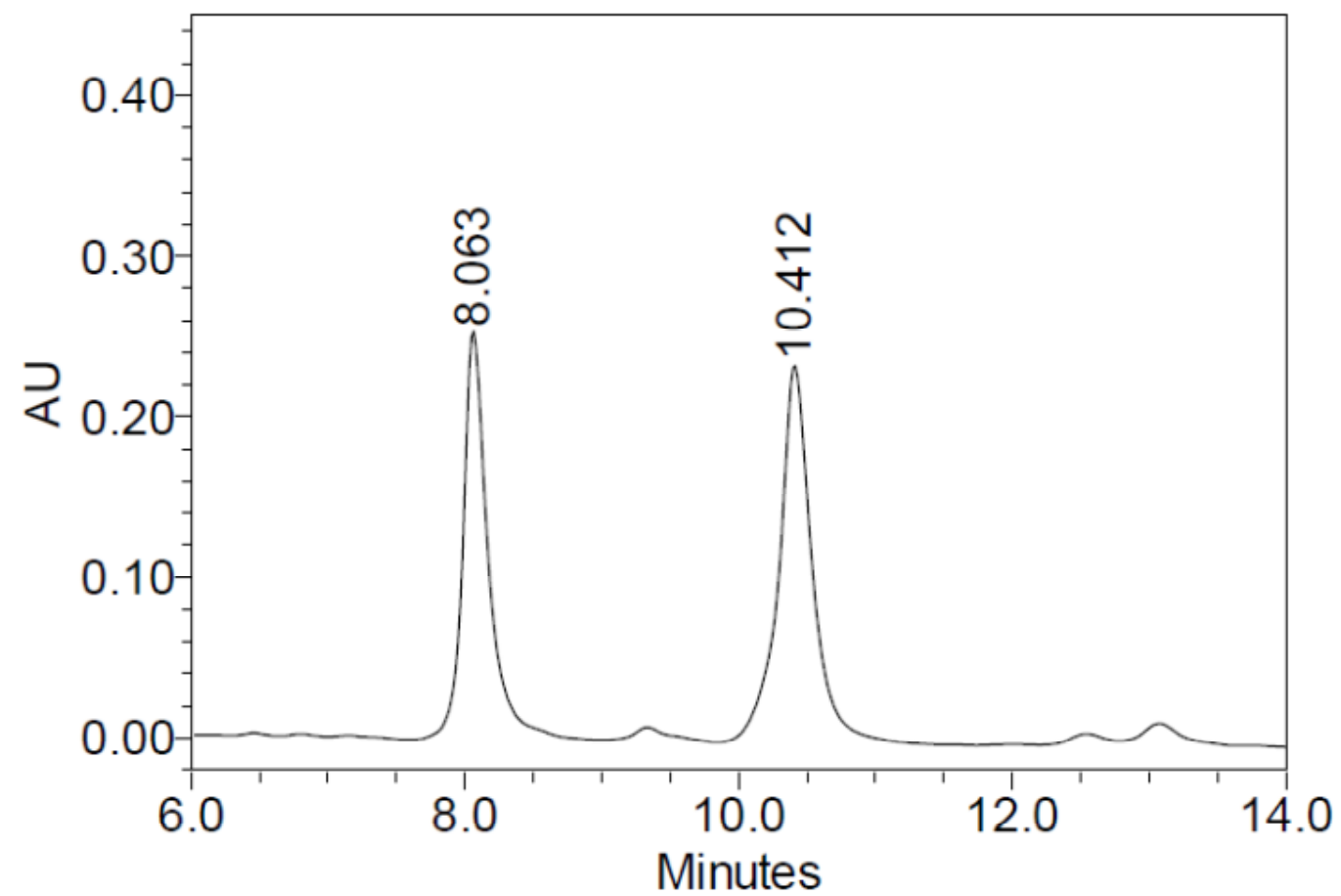

Figure 2.34. Enantioseparation of $\beta$-dimethylstyrene oxide catalyzed by CPO on WhelkO 1 column. Mobile phase, $n$-hexane/ethanol $(99.8 / 0.2, \mathrm{v} / \mathrm{v})$; monitoring wavelength, $216.8 \mathrm{~nm}$.

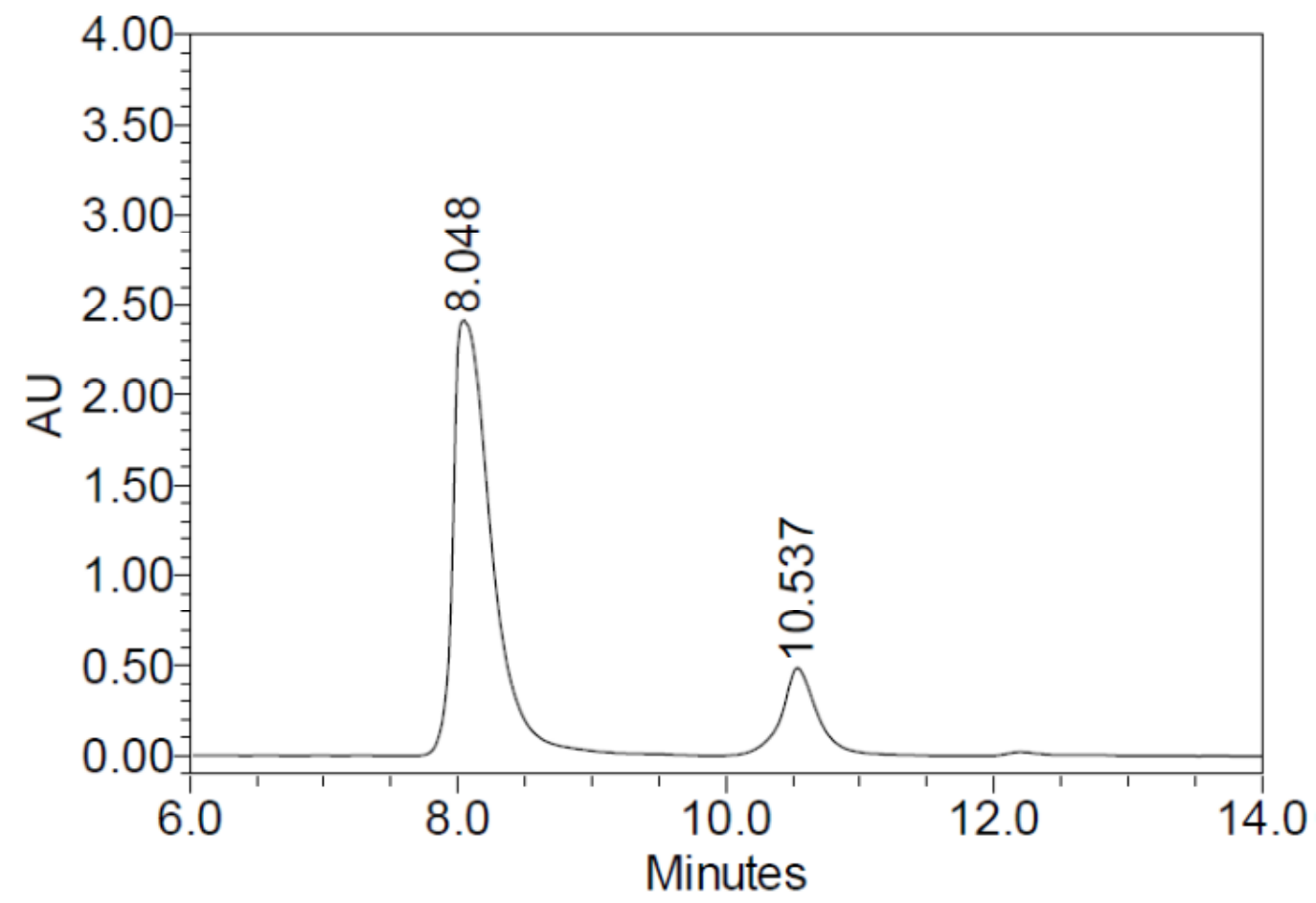

Figure 2.35. Enantioseparation of $\beta$-dimethylstyrene oxide catalyzed by F103A on Whelk-O 1 column. Mobile phase, $n$-hexane/ethanol $(99.8 / 0.2, \mathrm{v} / \mathrm{v})$; monitoring wavelength, $216.8 \mathrm{~nm}$. 


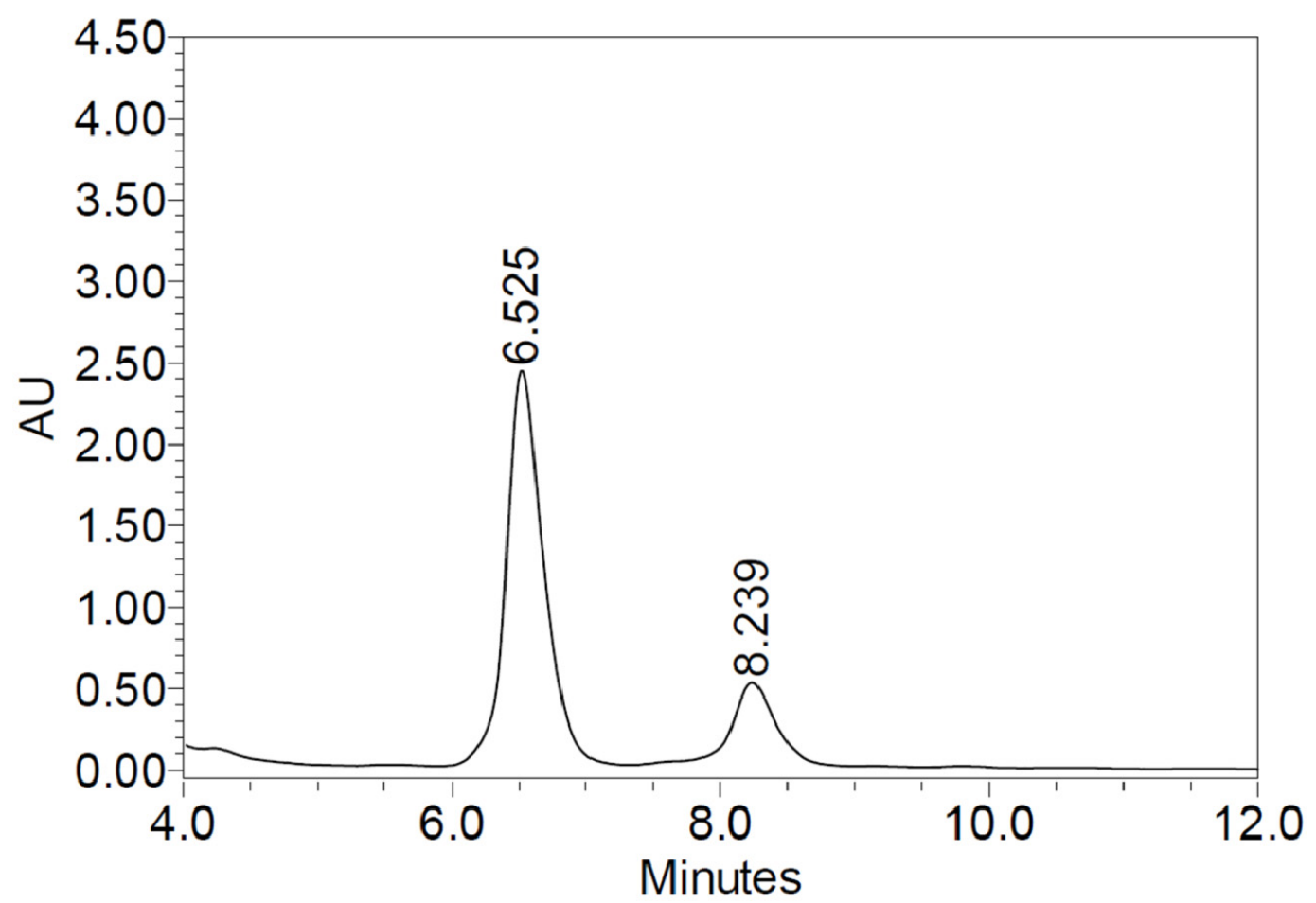

Figure 2.36. Enantioseparation of $\beta$-dimethylstyrene oxide catalyzed by N74V on WhelkO 1 column. Mobile phase, $n$-hexane/ethanol $(99.7 / 0.3, \mathrm{v} / \mathrm{v})$; monitoring wavelength, $216.8 \mathrm{~nm}$.

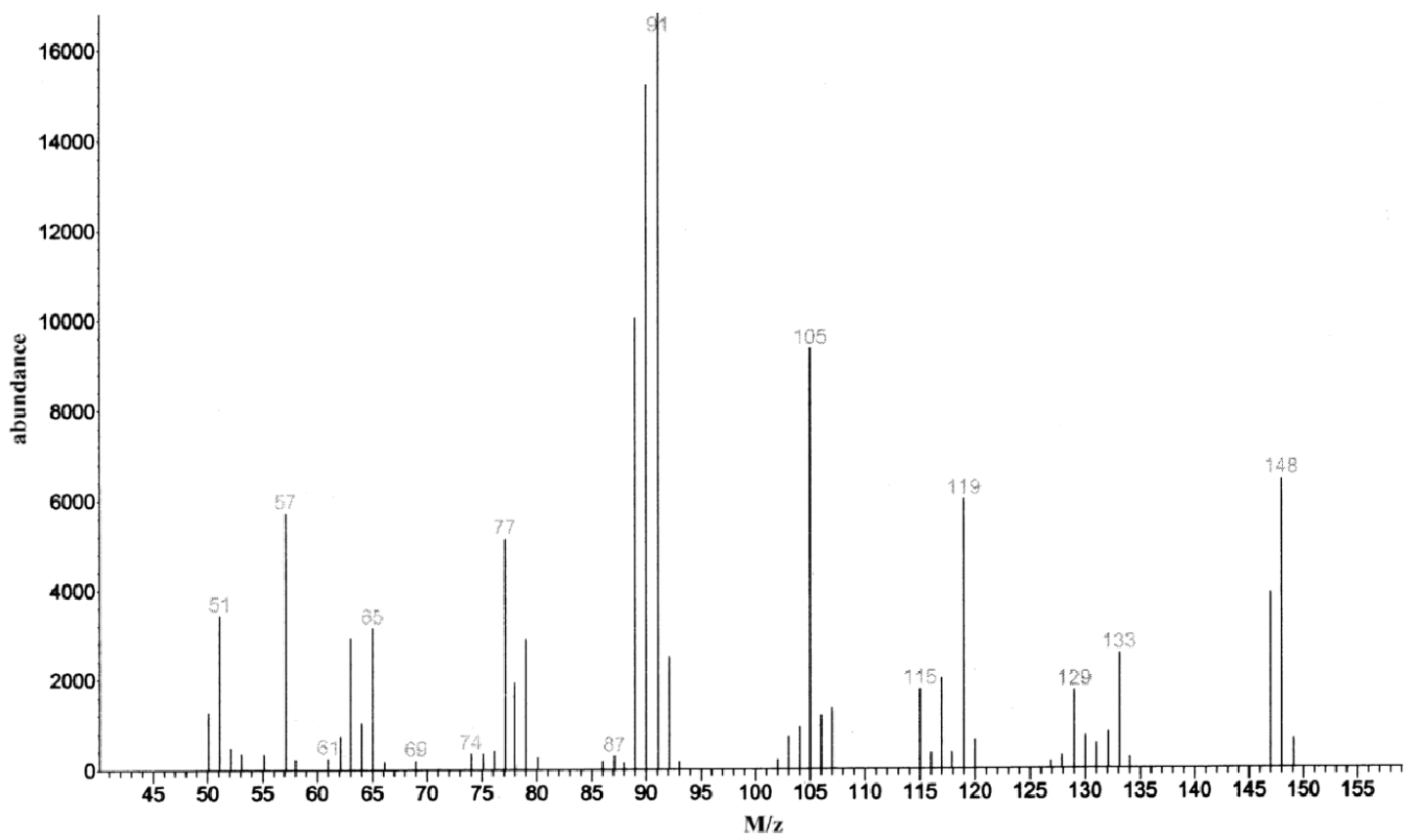

Figure 2.37. Mass spectrum of $(R)$ - trans- $\beta$-ethylstyrene oxide catalyzed by F103A. 


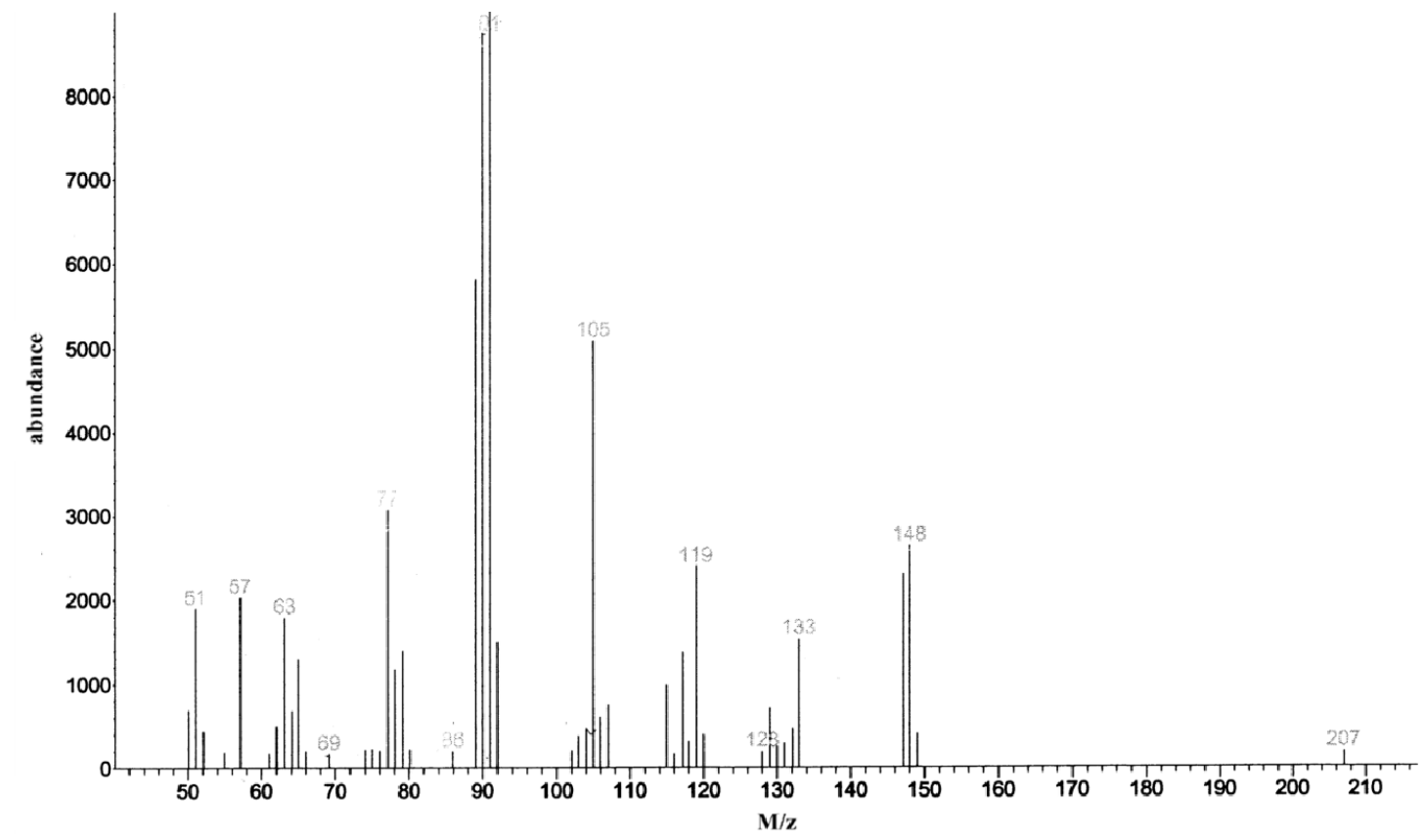

Figure 2.38. Mass spectrum of (S)- trans- $\beta$-ethylstyrene oxide catalyzed by F103A.

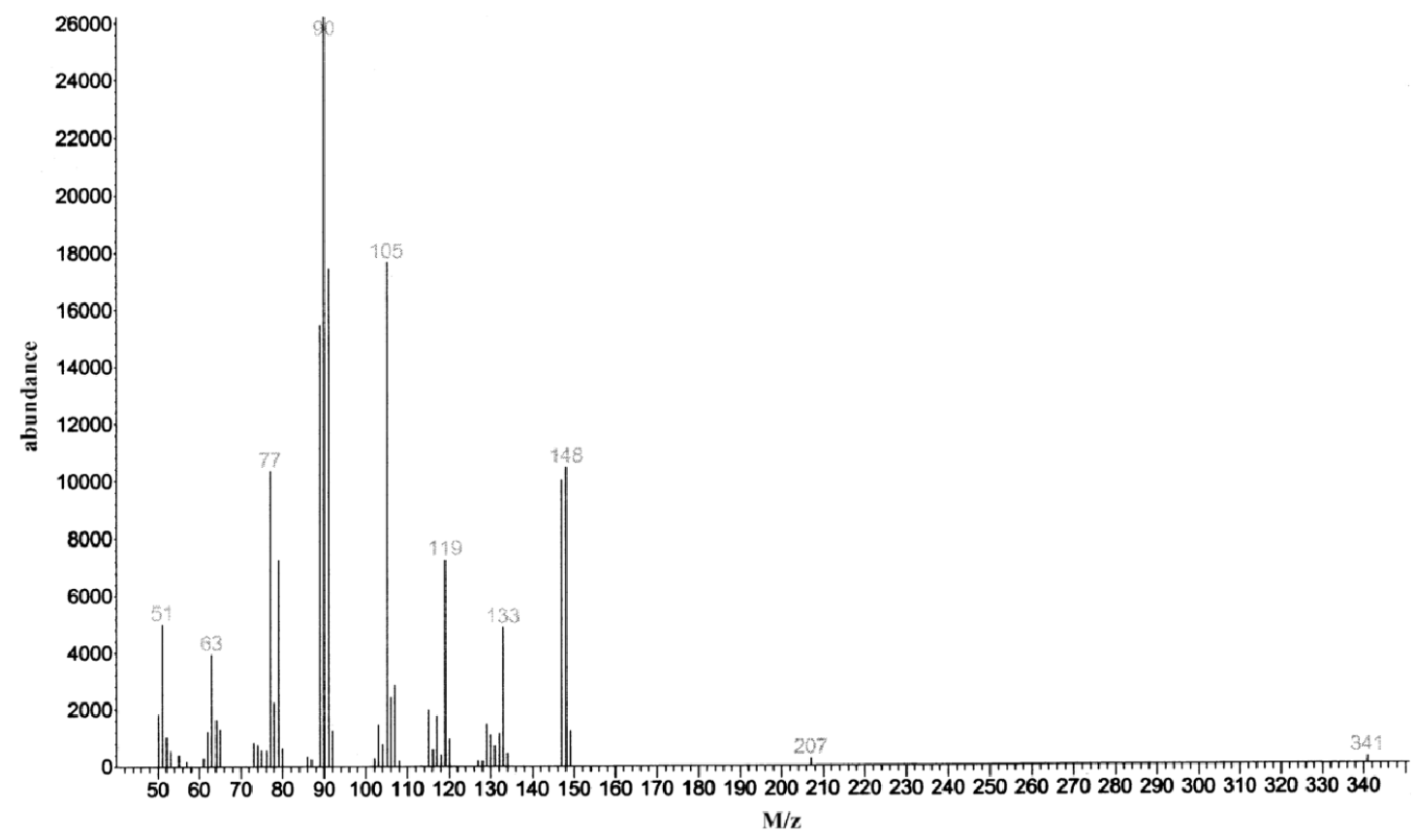

Figure 2.39. Mass spectrum of $(R)$ - $\beta$-dimethylstyrene oxide catalyzed by F103A. 


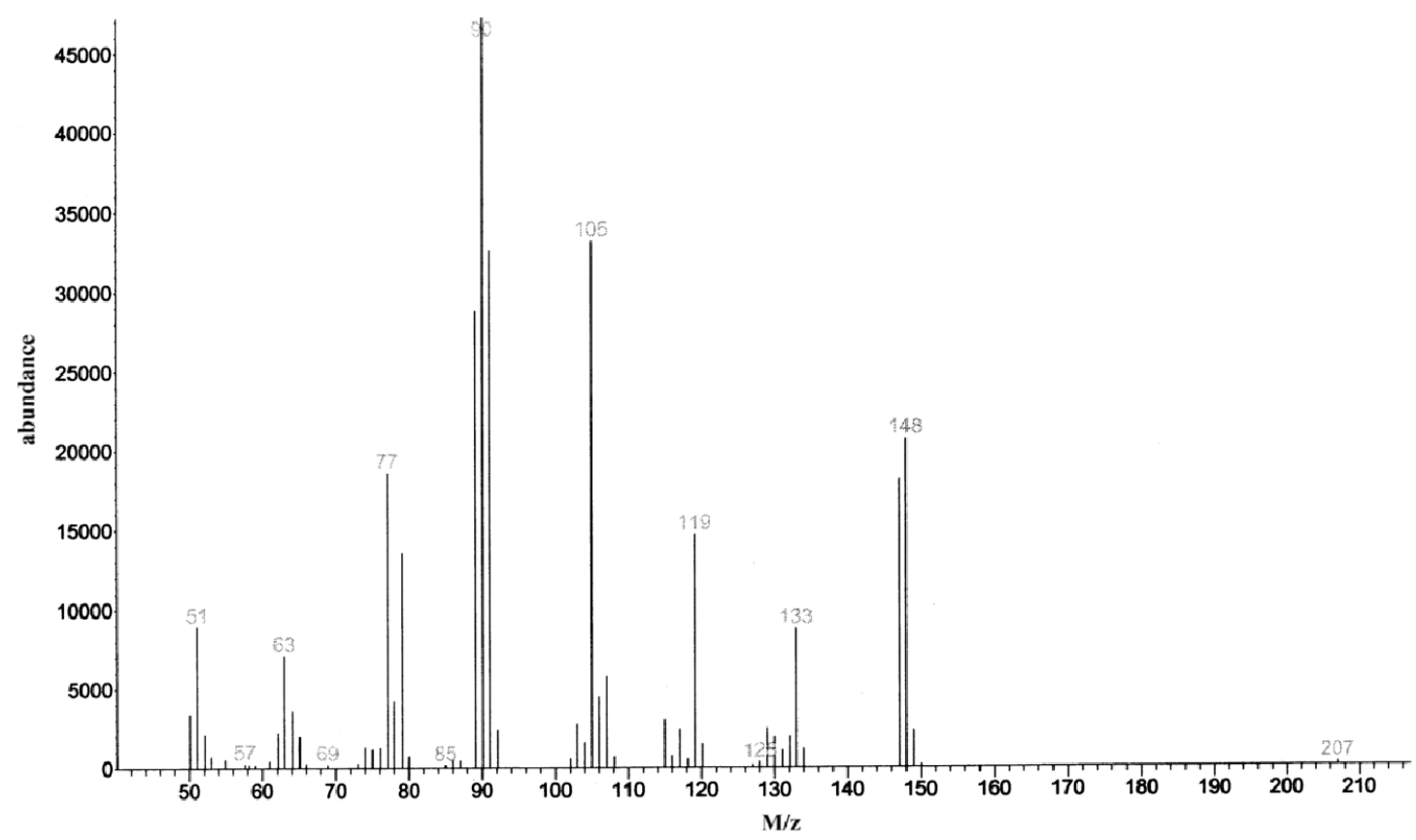

Figure 2.40. Mass spectrum of $(S)$ - $\beta$-dimethylstyrene oxide catalyzed by F103A.

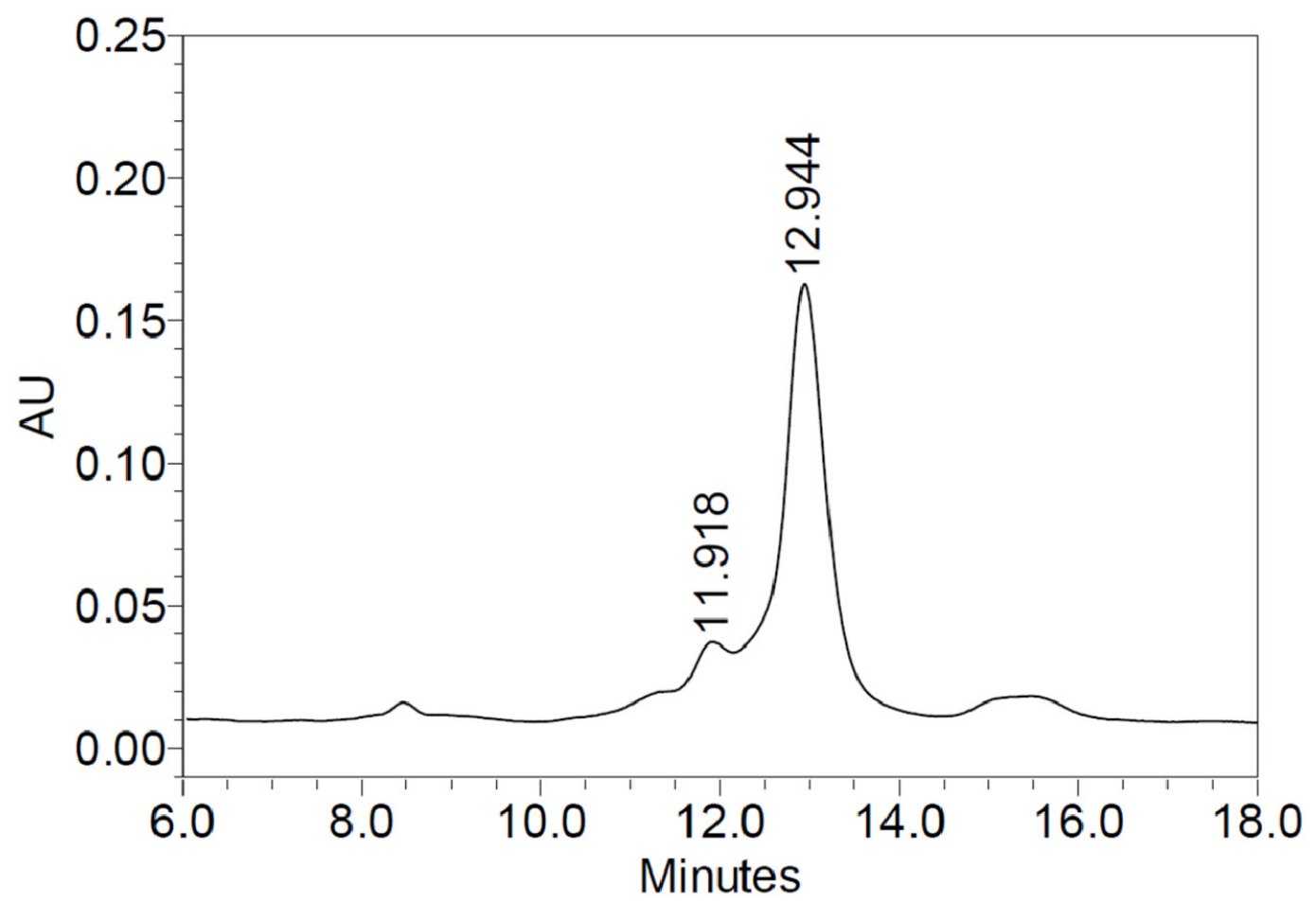

Figure 2.41. Enantioseparation of $\alpha$-ethylstyrene oxide catalyzed by CPO on Whelk-O 1 column. Mobile phase, $n$-hexane/ethanol (99.9/0.1, v/v); monitoring wavelength, 208.6 $\mathrm{nm}$; column temperature, $4{ }^{\circ} \mathrm{C}$. 


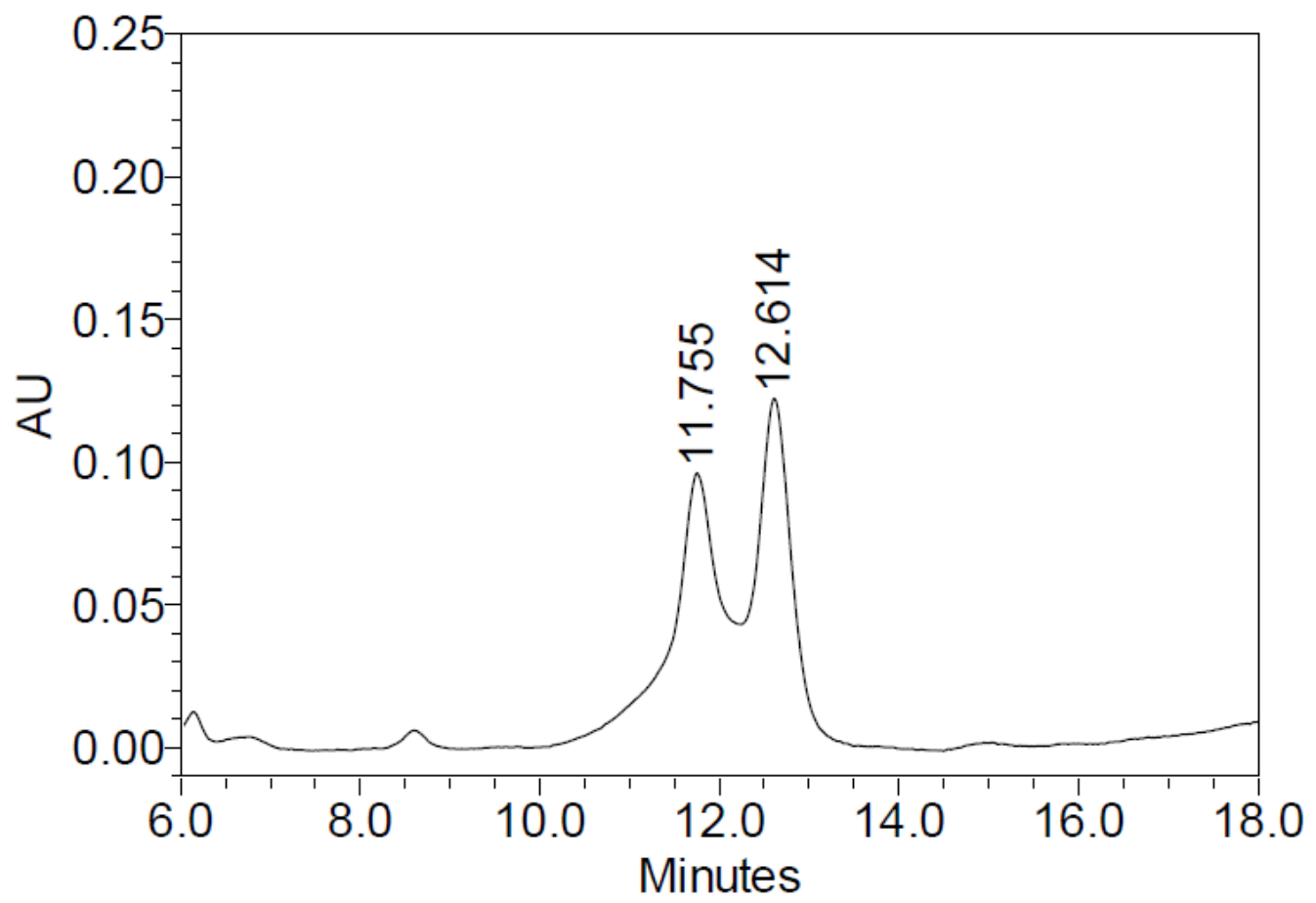

Figure 2.42. Enantioseparation of $\alpha$-ethylstyrene oxide catalyzed by F103A on Whelk-O 1 column. Mobile phase, $n$-hexane/ethanol $(99.9 / 0.1, \mathrm{v} / \mathrm{v}) ;$ monitoring wavelength, 208.6 $\mathrm{nm}$; column temperature, $4^{\circ} \mathrm{C}$.

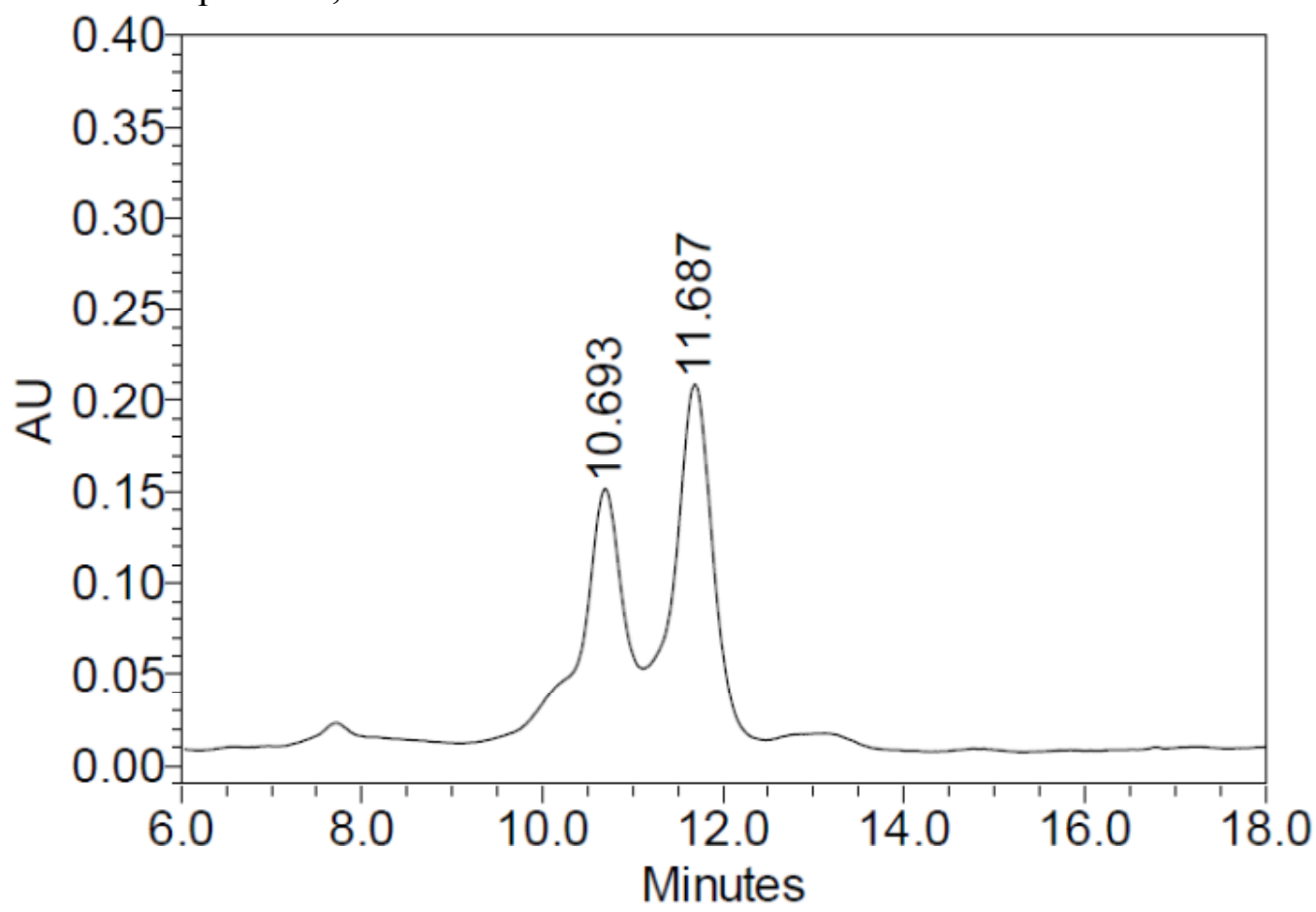

Figure 2.43. Enantioseparation of $\alpha$-ethylstyrene oxide catalyzed by N74V on Whelk-O 1 column. Mobile phase, $n$-hexane/ethanol $(99.8 / 0.2, \mathrm{v} / \mathrm{v})$; monitoring wavelength, 208.6 $\mathrm{nm}$; column temperature, $4^{\circ} \mathrm{C}$. 


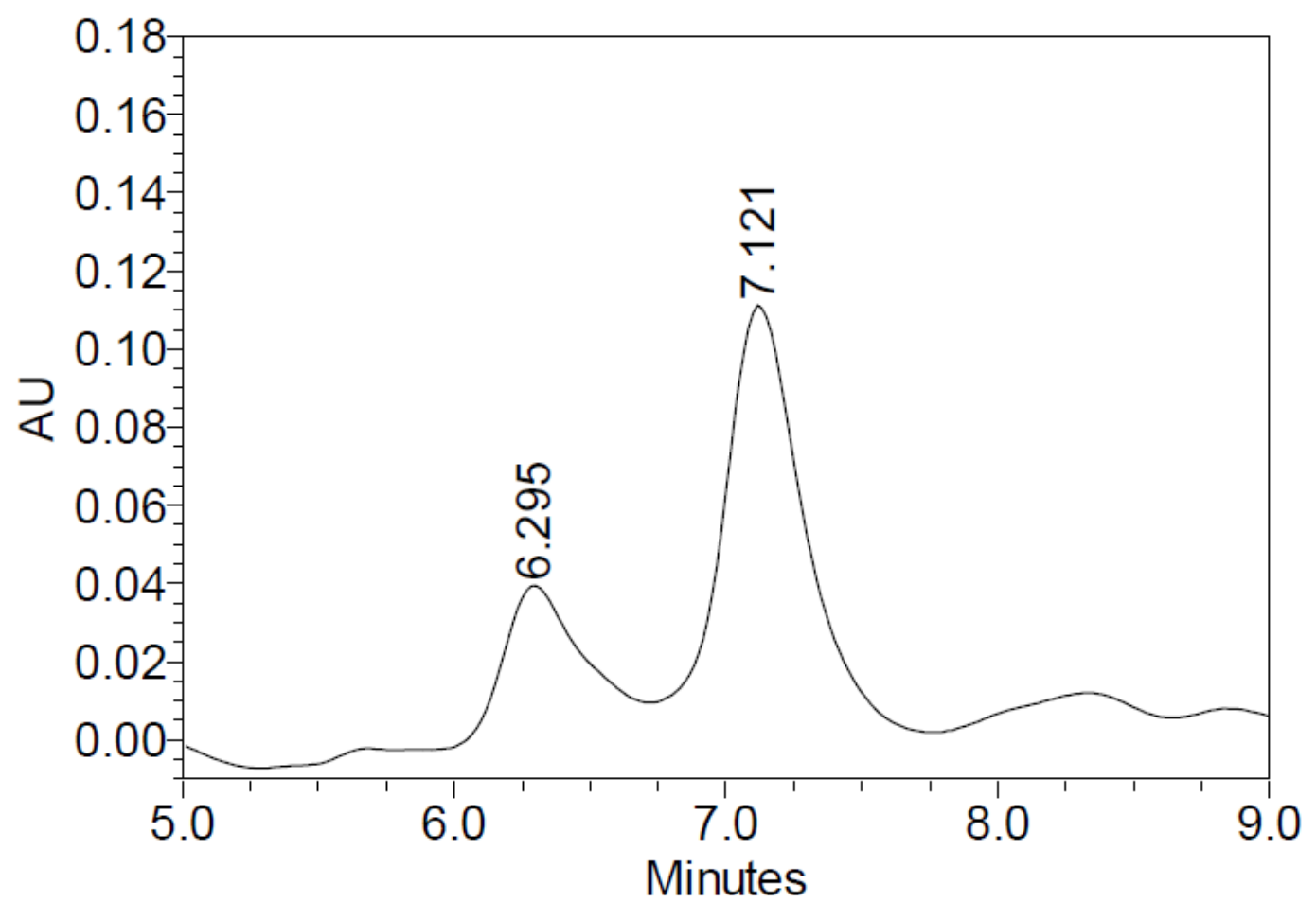

Figure 2.44. Enantioseparation of $\alpha$-propylstyrene oxide catalyzed by CPO on Whelk-O 1 column. Mobile phase, $n$-hexane/ethanol $(99.8 / 0.2, \mathrm{v} / \mathrm{v})$; monitoring wavelength, 208.6 $\mathrm{nm}$; column temperature, $4{ }^{\circ} \mathrm{C}$.

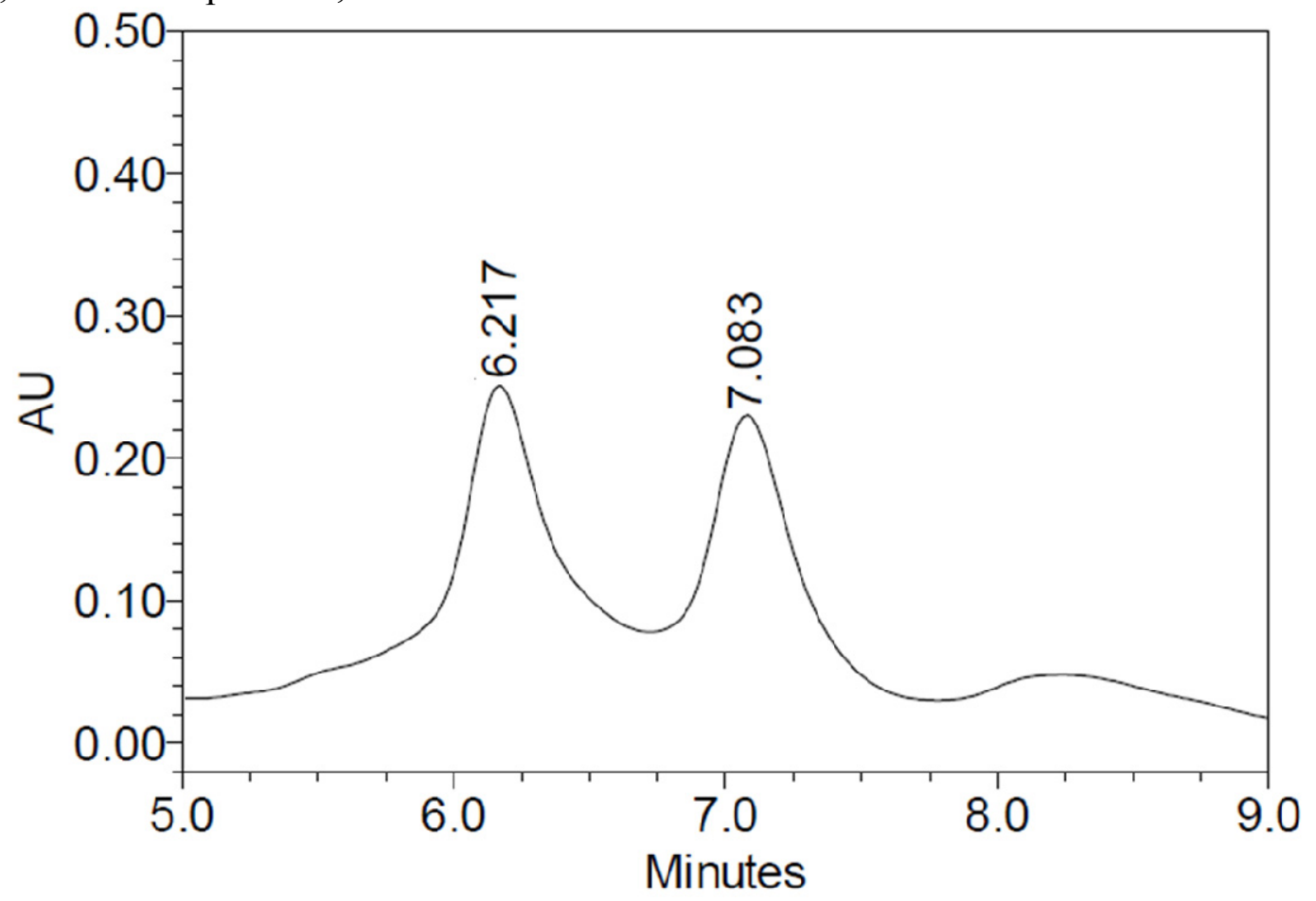

Figure 2.45. Enantioseparation of $\alpha$-propylstyrene oxide catalyzed by F103A on WhelkO 1 column. Mobile phase, $n$-hexane/ethanol $(99.8 / 0.2, \mathrm{v} / \mathrm{v})$; monitoring wavelength, $208.6 \mathrm{~nm}$; column temperature, $4^{\circ} \mathrm{C}$. 


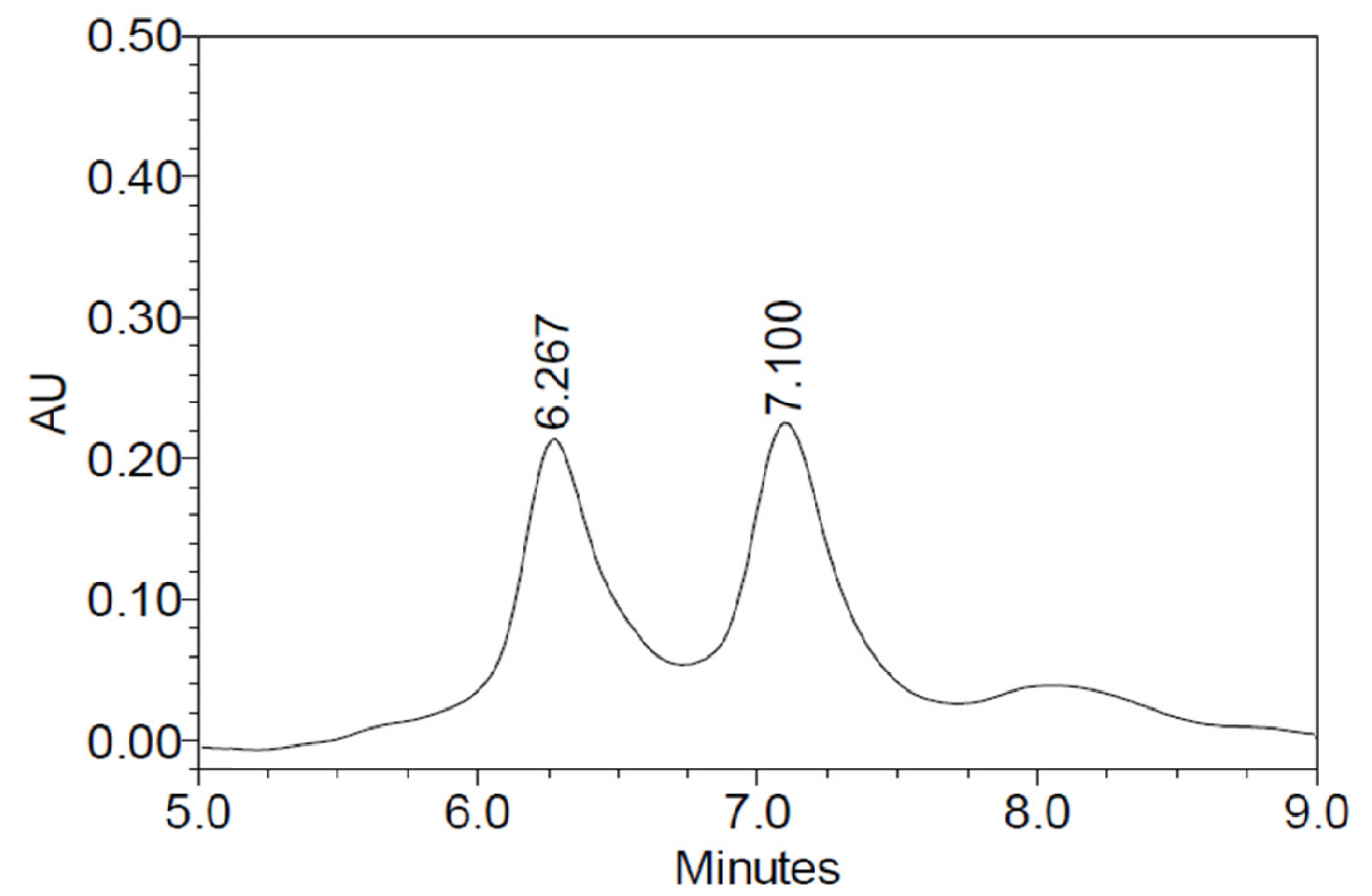

Figure 2.46. Enantioseparation of $\alpha$-propylstyrene oxide catalyzed by N74V on Whelk-O 1 column. Mobile phase, $n$-hexane/ethanol (99.8/0.2, v/v); monitoring wavelength, 208.6 nm; column temperature, $4{ }^{\circ} \mathrm{C}$.

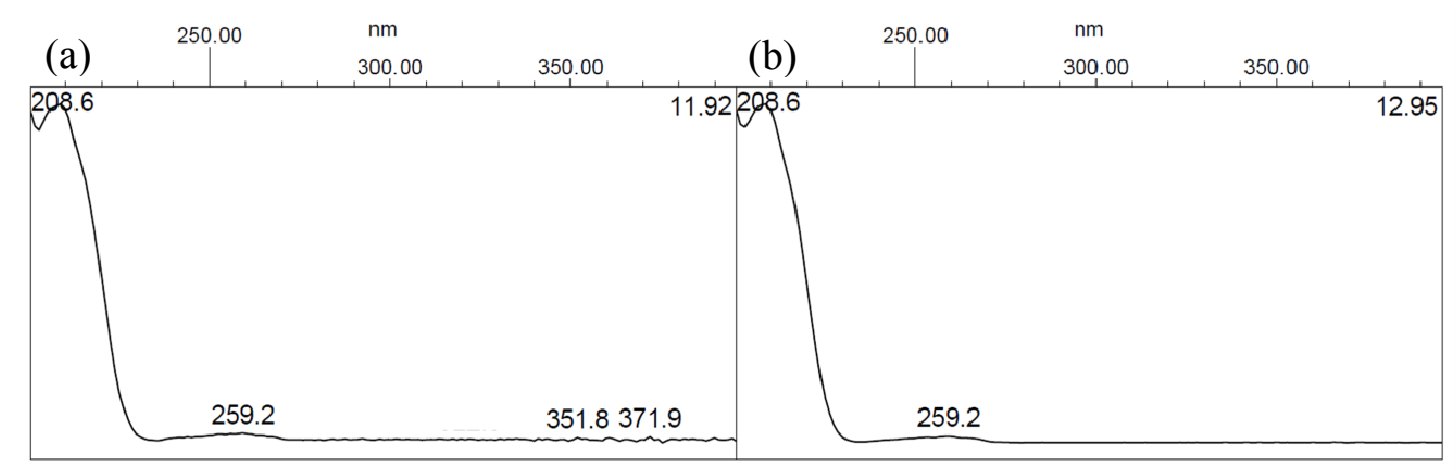

Figure 2.47. UV-vis spectra of (a) (R)- $\alpha$-ethylstyrene oxide and (b) (S)- $\alpha$-ethylstyrene oxide.

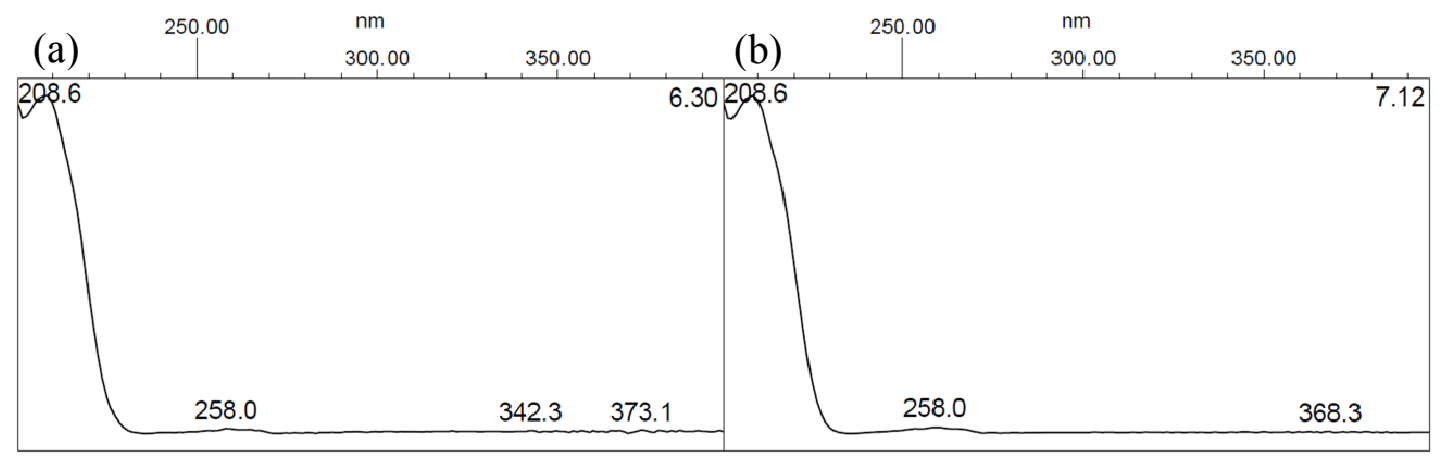

Figure 2.48. UV-vis spectra of (a) (R)- $\alpha$-propylstyrene oxide and (b) (S)- $\alpha$-propylstyrene oxide. 
Table 2.3. The optimized HPLC conditions for the enantioseparation of styrene and its derivatives epoxidation products. ${ }^{a}$

\begin{tabular}{lccc}
\hline Substrate & Mobile phase $n$-hexane:ethanol(v/v) & $\mathrm{T}\left({ }^{\circ} \mathrm{C}\right)$ & Wavelength $(\mathrm{nm})$ \\
\hline Styrene & pure $n$-hexane & ambient & 215.7 \\
$\alpha$-methylstyrene & $99.8 / 0.2$ & 4 & 208.6 \\
$\alpha$-ethylstyrene & $99.9 / 0.1$ & 4 & 208.6 \\
$\alpha$-propylstyrene & $99.9 / 0.1$ & 4 & 208.6 \\
Cis- $\beta$-methylstyrene & 100 & ambient & 215.7 \\
Trans- $\beta$-methylstyrene & $99.8 / 0.2$ & ambient & 216.8 \\
Trans- $\beta$-ethylstyrene & $99.9 / 0.1$ & 4 & 218 \\
$\beta$-dimethylstyrene & $99.9 / 0.1$ & ambient & 216.8 \\
\hline
\end{tabular}

${ }^{a}$ Chromatographic conditions: column: Whelk-O 1 column; flow rate: $1.0 \mathrm{~mL} / \mathrm{min}$.

Table 2.4. Enantioselective epoxidation results of styrene and its derivatives catalyzed by CPO, F103A and N74V.

\begin{tabular}{|c|c|c|c|c|c|c|c|c|c|c|c|c|c|c|c|c|c|c|}
\hline \multirow[b]{2}{*}{ Substrate } & \multicolumn{6}{|c|}{$\mathrm{CPO}$} & \multicolumn{6}{|c|}{ F103A } & \multicolumn{6}{|c|}{$\mathrm{N}_{74 \mathrm{~V}^{\mathrm{a}}}$} \\
\hline & $\mathrm{k} 1$ & $\mathrm{k} 2$ & $\alpha$ & Rs & ee & $\begin{array}{c}\text { yield } \\
(\%)\end{array}$ & $\mathrm{k} 1$ & $\mathrm{k} 2$, & $\alpha$ & Rs & ee & $\begin{array}{c}\text { yield } \\
(\%)\end{array}$ & $\mathrm{k} 1$ & $\mathrm{k} 2$ ' & $\alpha$ & Rs & ee & $\begin{array}{c}\text { yield } \\
(\%)\end{array}$ \\
\hline$\alpha$-methylstyrene & 2.01 & 2.61 & 1.30 & 2.32 & 79 & 58 & 2.01 & 2.63 & 1.31 & 2.39 & 75 & 39 & 1.76 & 2.39 & 1.36 & 2.45 & 70 & 42 \\
\hline$\alpha$-ethylstyrene & 2.41 & 2.70 & 1.12 & 0.87 & 84 & 3 & 2.36 & 2.60 & 1.10 & 0.86 & 7 & 5 & 2.06 & 2.34 & 1.14 & 0.92 & 9 & 6 \\
\hline$\alpha$-propylstyrene & 0.80 & 1.03 & 1.29 & 0.99 & 41 & 2 & 0.78 & 1.02 & 1.31 & 0.86 & 1 & 3 & 0.79 & 1.03 & 1.30 & 0.85 & 1 & 3 \\
\hline Cis- $\beta$-methylstyrene & --- & 3.34 & --- & --- & 96 & 95 & 2.90 & 3.33 & 1.15 & 0.76 & 7 & 50 & 2.95 & 3.35 & 1.14 & 0.70 & 5 & 56 \\
\hline Trans- $\beta$-methylstyrene & 1.16 & 2.28 & 1.97 & 5.35 & 2 & 7 & 1.16 & 2.28 & 1.97 & 4.20 & 51 & 40 & 1.05 & 2.20 & 2.10 & 2.30 & 44 & 47 \\
\hline Trans- $\beta$-ethylstyrene & 2.81 & 6.07 & 2.16 & 5.20 & 2 & 6 & 2.81 & 6.10 & 2.17 & 3.46 & 48 & 34 & 2.05 & 4.32 & 2.11 & 2.90 & 43 & 37 \\
\hline$\beta$-dimethylstyrene & 1.30 & 1.97 & 1.52 & 3.28 & 8 & 4 & 1.30 & 2.01 & 1.55 & 2.35 & 69 & 38 & 0.86 & 1.35 & 1.57 & 1.11 & 62 & 41 \\
\hline
\end{tabular}

${ }^{a}$ For N74V mutant, different separation conditions were developed due to the influence of byproducts, as stated in Figures 2.16, 2.19, 2.22, 2.33, and 2.43. 
with ethanol as the modifier than 2-propanol. The decrease of retention was caused by the increase in eluting capability as the mobile phase modifier changed from 2-propanol to ethanol, which results in ethanol as a stronger solvent compared to 2-propanol. In addition, the $\alpha$ and Rs factors were both higher while using ethanol. The better enantioseparation may be because ethanol participates more in altering the CSP conformation, which leads to an improved fit of enantiomers into the chiral selectors. ${ }^{76}$

The influences of modifier concentration at $0.1 \%, 0.2 \%, 0.3 \%$ and $0.5 \%$ in $n$-hexane are shown in Table 2.2. It clearly shows that with the decrease in ethanol concentration, the retention became stronger. This effect was because the lower ethanol concentration diminished its competition with solutes at the binding sites of CSP, which resulted in stronger retention of solutes. The separation factors were almost the same at different modifier concentrations, indicating that the modifier concentration is not so significantly involved in the chiral recognition process. Nevertheless, the adding of modifier can increase the column efficiency, leading to increased resolution. However, increasing the modifier concentration will not further improve the resolution because of the much shortened interaction time between analytes and the CSP.

The effect of varying column temperature shown in Table 2.2 reveals that the retention was significantly increased at $4{ }^{\circ} \mathrm{C}$ compared to that at the ambient temperature. Moreover, the separation factor and resolution were both improved, but the separated peaks were broadened at the same time due to the decrease in column efficiency at lower temperature.

\subsubsection{Elution order of styrene oxide and its derivatives}

It is suggested that the Whelk-O 1 column can keep the same elution order for 
similar enantiomers under all conditions, and normally the retention time of $(R)$ enantiomer is shorter than $(S)$-enantiomer. ${ }^{77}$ The elution order of styrene oxide was verified by using $(R)$-styrene oxide and $(S)$-styrene oxide standards. The results (Figures 2.1, 2.4 and 2.5) reveal that $(R)$-styrene oxide has a shorter retention time compared with $(S)$-styrene oxide, which is consistent with the above prediction. In addition, the $(R)-\alpha-$ methylstyrene oxide, which was reported to have a higher abundance than the $(S)-\alpha-$ methylstyrene oxide in the $\mathrm{CPO}$ catalyzed epoxidation products, ${ }^{14}$ also has a shorter retention time (Figure 2.20).

The elution order of epoxidation products with two chiral centers were studied with $(1 R, 2 R)$ and $(1 S, 2 S)$-trans- $\beta$-methylstyrene oxide standards. It was found that the $(1 R$, $2 R)$-enantiomer preceded the $(1 S, 2 S)$-enantiomer, as shown in Figures 2.2, 2.6 and 2.7. Furthermore, $(1 S, 2 R)$-cis- $\beta$-methylstyrene oxide from the CPO catalyzed epoxidation was used as standard and spiked in the solution of the corresponding racemic epoxidation products. It confirmed that the $(1 R, 2 S)$-enantiomer was eluted before the $(1 S, 2 R)$ enantiomer, as shown in Figure 2.28.

Therefore, it is concluded that for the Whelk-O 1 column, the styrene oxide and its derivatives with the $(R)-\alpha$ carbon enantiomers generally have a shorter retention time than the $(S)-\alpha$ carbon enantiomers, no matter whether the $\beta$ carbon is chiral or not. Therefore, the first eluted epoxide enantiomers from the Whelk-O 1 column in our experiments are all considered as the $(R)$ - or $(1 R, 2 X)$-enantiomers.

\subsubsection{Enantioselectivity and yield of CPO catalyzed epoxidation reactions}

As shown in Table 2.4 , the epoxidation of styrene, $\alpha$-methylstyrene, and $\alpha$ ethylstyrene with $\mathrm{CPO}$ has a declining yield and a rising ee value with the size of the 
substituent on $\alpha$ carbon of the double bond increased, which is consistent with the published results. ${ }^{14}$ However, $\alpha$-propylstyrene, which has the largest $\alpha$-substituent in our experiment, revealed the lowest yield of epoxide product, but with only a moderate enantioselectivity. The major epoxidation product of $\alpha$-methylstyrene was the $(R)-\alpha-$ methylstyrene epoxide, which is consistent with the enantioselectivity of styrene epoxidation. It is notable that the enantioselectivity of both $\alpha$-ethylstyrene and $\alpha$ propylstyrene were reversed, resulting in the $(S)$-enantiomers as the major products.

In Table 2.4, it is shown that CPO is a very effective catalyst for the epoxidation of cis- $\beta$-methylstyrene, providing a high yield with high ee value, which is in good agreement with the literature. ${ }^{75}$ However, the epoxidation of trans-disubstituted olefins, such as trans- $\beta$-methylstyrene and trans- $\beta$-ethylstyrene, resulted in much lower yield and enantioselectivity. The low yield and ee values were not evidently affected with the trans substituent group changed from methyl to ethyl. For the epoxidation of the trisubstituted olefins, $\beta$-dimethylstyrene, $\mathrm{CPO}$ also revealed a poor yield and enantioselectivity. All of the $\beta$-substituted styrene derivatives had their corresponding $(R)$-enantiomers as the major epoxidation products, except for the $\beta$-dimethylstyrene which had a $(S)-\beta$ dimethylstyrene epoxide as the major product.

In summary, the substitution at cis position of the styrene can increase both the yield and enantioselectivity of CPO catalyzed epoxidation, but the substitution at trans position will greatly diminish the epoxidation yield and enantioselectivity. If the substitution is on the $\alpha$-carbon, the epoxidation yield will be decreased while the enantioselectivity increased. However, if the $\alpha$-substituted group is too big, it will hinder the enantioselectivity. CPO catalyzed epoxidation of most of the styrene 
derivatives have the same enantioselectivity as styrene, with the $(R)$-enantiomer as the major product, while the epoxidation of $\alpha$-ethylstyrene, $\alpha$-propylstyrene and $\beta$ dimethylstyrene favors the $(S)$-enantiomers.

Our results clearly indicate that in all cases, the substituent's position and length of the styrene derivatives play significant roles in the overall enantioselectivity and yields of the reaction. It appears that the greater steric size caused by the substitution, except the cis- $\beta$ methyl substitution, will limit the access of styrene derivatives to the active site, which results in lower epoxidation yields. This effect can be explained by the restricted size and shape of the active site binding pocket revealed by the CPO crystal structure. ${ }^{25}$ Steric factors from the distal side residues contribute to control both the position and the orientation of the substrate binding. It has been proposed that the epoxidation reaction occurs only when the terminal unsaturated carbon, in this case, the $\beta$-carbon of styrene derivatives, is placed closely to the active oxygen species ${ }^{78-79}$. Therefore, when the styrene or its derivative enters the active site binding pocket, it is restrained by the surrounding residues and forced to adapt a conformation that allows its $\beta$-carbon to be in proximity to the compound I oxygen. The enantioselective oxygen insertion reaction is caused by the favor of one binding conformation over the other, which is determined by the shape of the pocket and the substrate substituent. Therefore, the outstanding yield and enantioselectivity for the epoxidation of cis- $\beta$-methylstyrene is because the size and the position of the substitution fit perfectly with the size and the shape of the binding pocket. The reversed enantioselectivity for $\alpha$-ethylstyrene, $\alpha$-propylstyrene and $\beta$-dimethylstyrene is due to their long or bulky substitutes, which switch their favorite binding orientation and meanwhile increase the difficulty for them to have access to the active site. 


\subsubsection{Enantioselectivity and yield of CPO mutants catalyzed epoxidation reactions}

F103A mutant displays a different epoxidation behavior from chloroperoxidase. As was the case for CPO, the epoxidation of styrene, $\alpha$-methylstyrene, $\alpha$-ethylstyrene and $\alpha$ propylstyrene with F103A mutant had a decreasing yield with increasing substituent size. However, the F103A mutant epoxidation enantioselectivity was greatly reduced for styrene, $\alpha$-ethylstyrene and $\alpha$-propylstyrene, yet the epoxidation of $\alpha$-methylstyrene and a-ethylstyrene revealed high enantioselectivity but with a different conformation preference; the $(S)$-enantiomers was the major products. Unlike CPO, the yield of $c i s-\beta$ methylstyrene epoxidation catalyzed by the F103A mutant was lower compared with the epoxidation of styrene. The enantioselectivity of F103A mutant catalyzed cis- $\beta$ methylstyrene epoxidation was still low, which was in great contrast with the CPO catalyzed reaction. By contrast, the F103A mutant catalyzed epoxidation of trans- $\beta$ methylstyrene, trans- $\beta$-ethylstyrene, and $\beta$-dimethylstyrene showed a dramatic increase in both yield and enantioselectivity compared with CPO. All of the $\beta$-substituted styrene derivatives share the same conformation preference with the styrene epoxidation by having the $(R)$-enantiomers as the major products.

The epoxidation performance of the N74V mutant was very similar to the F103A mutant, generally with a little higher yields but slightly lower ee values, as shown in Table 2.4. However, different side products during the epoxidation reactions were observed for the two mutants (data not shown), indicating that different catalytic factors may be affected by the two mutations.

The above data clearly show that the $\mathrm{F} 103 \rightarrow \mathrm{A}$ and $\mathrm{N} 74 \rightarrow \mathrm{V}$ mutations dramatically change the epoxidation activity and the enantioselectivity of CPO. As mentioned in 
Chapter I, Phe103 can work together with the Phe183 as a clamp to hold the substrate's phenyl group. Therefore, the binding position of styrene or its derivatives will be fixed and the orientation of the double bond will be affected by the surrounding residues, leading to enantioselective oxygen insertion reactions. We hypothesized that the replacement of Phe103 with Ala in our mutant creates a larger opening on the bottom of the wide channel and meanwhile disables the Phe103-Phe186 clamp. The observed new enantioselectivity profile of the F103A mutate is consistent with our hypothesis. The more open wide channel can allow trans- $\beta$-substituted styrene derivatives (trans- $\beta$ methylstyrene, trans- $\beta$-ethylstyrene, and $\beta$-dimethylstyrene) to access the active center easier, resulting in higher epoxidation yields. The decrease of the epoxidation yields of styrene, $\alpha$-substituted and cis- $\beta$-substituted styrene derivatives can also be explained. The opening at the bottom of the wide channel allows not only the double bond moiety of the substrate, but also the phenyl moiety to have access to the active site, which hinders the epoxidation process. In addition, the disabling of the Phe103-Phe186 clamp greatly affected the regulation of the substrate binding orientations, leading to the significantly changed ee values for all the tested substrates.

The greatly changed epoxidation profile caused by the N74 $\rightarrow \mathrm{V}$ mutation suggests that Asn74 also plays an important role in controlling the substrate binding during epoxidation process. The surprising similarity of N74V and F103A mutants' epoxidation results suggests that Phe103 and Asn74 may play a similar role in the epoxidation, or they can cooperate to manage the substrate access to the active site. However, further study of the mechanism of how Asn74 affects CPO epoxidation activity is challenging yet necessary. 


\section{CHAPTER III. CPO CATALYZED REGIOSPECIFIC DEGRADATION OF DMSP}

\subsection{Experimental}

\subsubsection{Materials}

MPA and MSA were ordered from Sigma-Aldrich (St. Louis, MO). CPO and F103A were prepared in our own lab with Rz value over 1.50. All other reagents and materials were purchased from Fisher Scientific (Pittsburgh, PA). Unless otherwise specified, all the chemicals and reagents were used without further purification.

\subsubsection{Instruments}

All UV-visible absorption measurements were determined on a Cary 300 Bio spectrophotometer (Varian, Palo Alto, CA). UV-vis spectroscopy was used to measure the DMSP oxidation activity and characterize the oxidation products. LC-MS and GC MS were used to identify the structures of the DMSP oxidation products. A Finnigan LCQ Deca XP MAX system (ThermoFinnigan, San Jose, CA) with Surveyor autosampler and Surveyor LC Pump was used in the mass spectrometry detection of the analytes. Xcalibur software (ThermoFinnigan) was used for instrument control and data analysis. A Supelcosil C18 column $(5 \mu \mathrm{m}, 250 \mathrm{~mm} \times 4.6 \mathrm{~mm})$ was used for chromatographic separation.

The GC-MS analysis was performed by using a HP-6890 gas chromatograph interfaced with a HP-5973 mass detector (Hewlett- Packard, Palo Alto, CA) equipped with a DB-5MS fused silica capillary column (30 m x $0.25 \mathrm{~mm}$ i.d., film thickness 0.25 $\mu \mathrm{m}$, Agilent Technologies). 


\subsubsection{Oxidation of DMSP catalyzed by WT CPO and F103A}

The $3 \mathrm{~mL}$ reaction mixture contained $5 \mu \mathrm{g}$ of CPO, $2 \mathrm{mM} \mathrm{H}_{2} \mathrm{O}_{2}$, and $300 \mu \mathrm{M}$ DMSP in $10 \mathrm{mM}$ citrate buffer at $\mathrm{pH}$ 3.0. The reaction was initiated by the addition of $\mathrm{H}_{2} \mathrm{O}_{2}$. DMSP oxidation activity was determined by measuring the absorbance at $259 \mathrm{~nm}$ as a function of time under room temperature or $4{ }^{\circ} \mathrm{C}$. After 5 minutes reaction, the UV-vis absorption spectrum of the mixture was measured.

Two negative comparison tests were carried out under the same condition with either no CPO or no DMSP, respectively. F103A mutant was used to measure the DMSP oxidation activity under the same condition as CPO.

\subsubsection{Identification of the products from CPO catalyzed oxidation of DMSP by GC-}

\section{MS and LC-MS}

The reaction products were extracted with $300 \mu$ l of isooctane, dichloromethane $\left(\mathrm{CH}_{2} \mathrm{Cl}_{2}\right)$, or $n$-hexane, respectively. The extracts from organic phase were examined using GC-MS to identify the products.

YM-30 Centricon was used to remove the CPO from the reaction mixture. The filtrate was examined using LC-MS to identify the products.

\subsubsection{UV-vis absorption measurements of DMS, DMSO, MeSH, MPA and MSA}

The possible products, DMS, DMSO, MeSH, MPA and MSA were examined by UV-vis spectroscopy, respectively. They were also tested as the intermediates from the first reaction by reacting with $\mathrm{H}_{2} \mathrm{O}_{2}$ catalyzed by CPO. The kinetic spectra and absorption spectra were obtained as described above for the DMSP oxidation experiments.

\subsection{Results}

The UV-vis absorption spectra of the DMSP oxidation catalyzed by CPO (Figure 3.1) 
shows that a new peak at $259 \mathrm{~nm}$ appeared after the addition of $\mathrm{H}_{2} \mathrm{O}_{2}$, in contrast with the reactions without CPO or without DMSP (data not shown).

The activity assay of DMSP oxidation catalyzed by CPO was monitored at $259 \mathrm{~nm}$ under ambient temperature and $4{ }^{\circ} \mathrm{C}$, respectively. The initial increase at $259 \mathrm{~nm}$ followed by a decrease was observed at $25^{\circ} \mathrm{C}$, while the appearance of a faster rate of the first reaction and higher absorbance was observed at $4{ }^{\circ} \mathrm{C}$. Refer to Figure 3.2 for the activity assay of DMSP oxidation catalyzed by $\mathrm{CPO}$ at $25{ }^{\circ} \mathrm{C}$ and $4{ }^{\circ} \mathrm{C}$. The comparison tests without CPO or DMSP did not show any change during the activity assay (data not shown).

The UV-vis absorption spectrum of the DMSP oxidation catalyzed by F103A mutant also showed that a new peak appeared at $259 \mathrm{~nm}$ after adding $\mathrm{H}_{2} \mathrm{O}_{2}$. Therefore, F103A mutant was also tested with the activity assay of DMSP oxidation. It was found that the initial rate of the oxidation activity of F103A mutant was much slower compared with that of WT CPO. Refer to Figure 3.3 for the activity assay of DMSP oxidation catalyzed by F103A mutant. After 6 minutes, the absorbance at $259 \mathrm{~nm}$ stopped increasing with no observable decrease thereafter (data not shown).

Unfortunately, all of our efforts to identify the DMSP oxidation products failed. The LC-MS spectrum of DMSP oxidation products failed to produce reliable identifications because of too many unknown peaks contained in the spectrum. The isooctane, $\mathrm{CH}_{2} \mathrm{Cl}_{2}$, or $n$-hexane extracts of DMSP oxidation products were examined by GC-MS. However, the GC-MS chromatograms did not show any peak for the extracts, and also no mass signals of the ions were observed, indicating that the products cannot be extracted with none-polar organic solvents. 


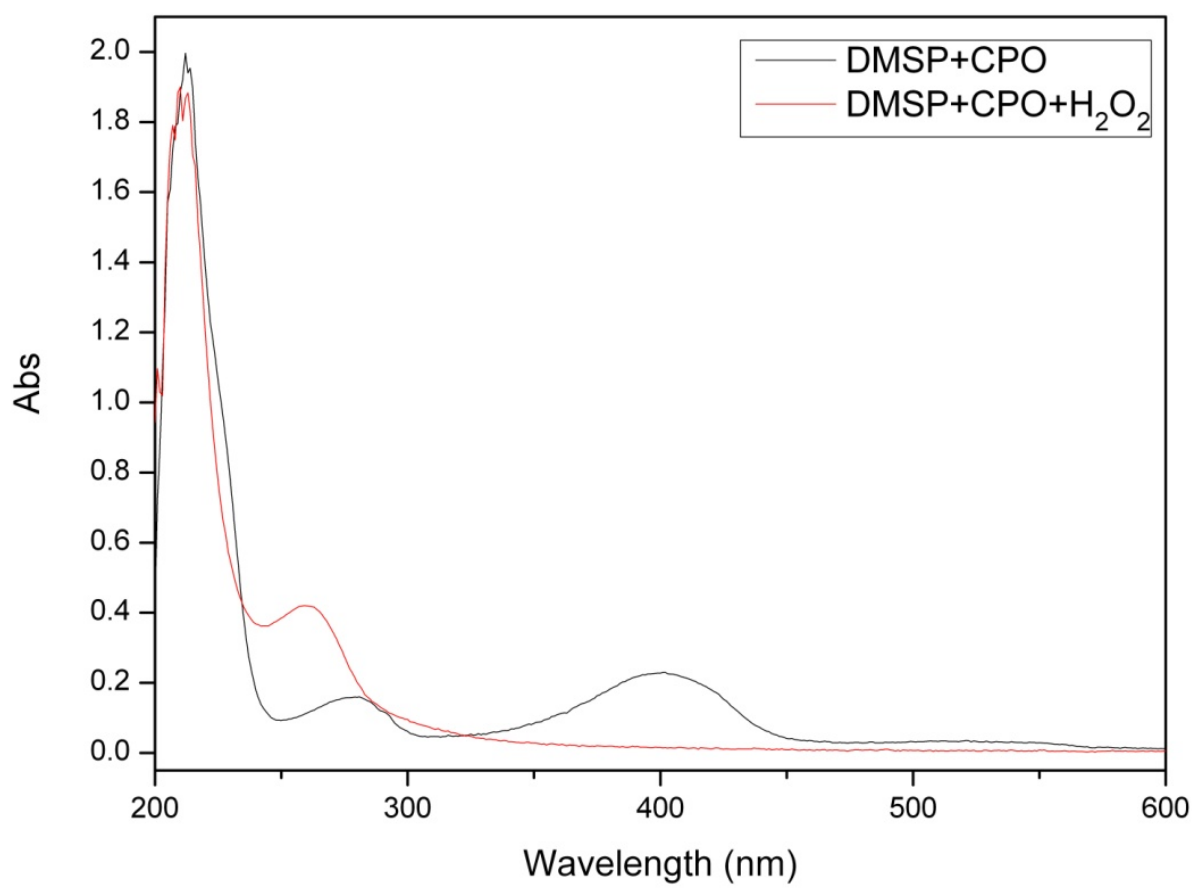

Figure 3.1. UV-vis absorption spectrum of DMSP oxidation products.

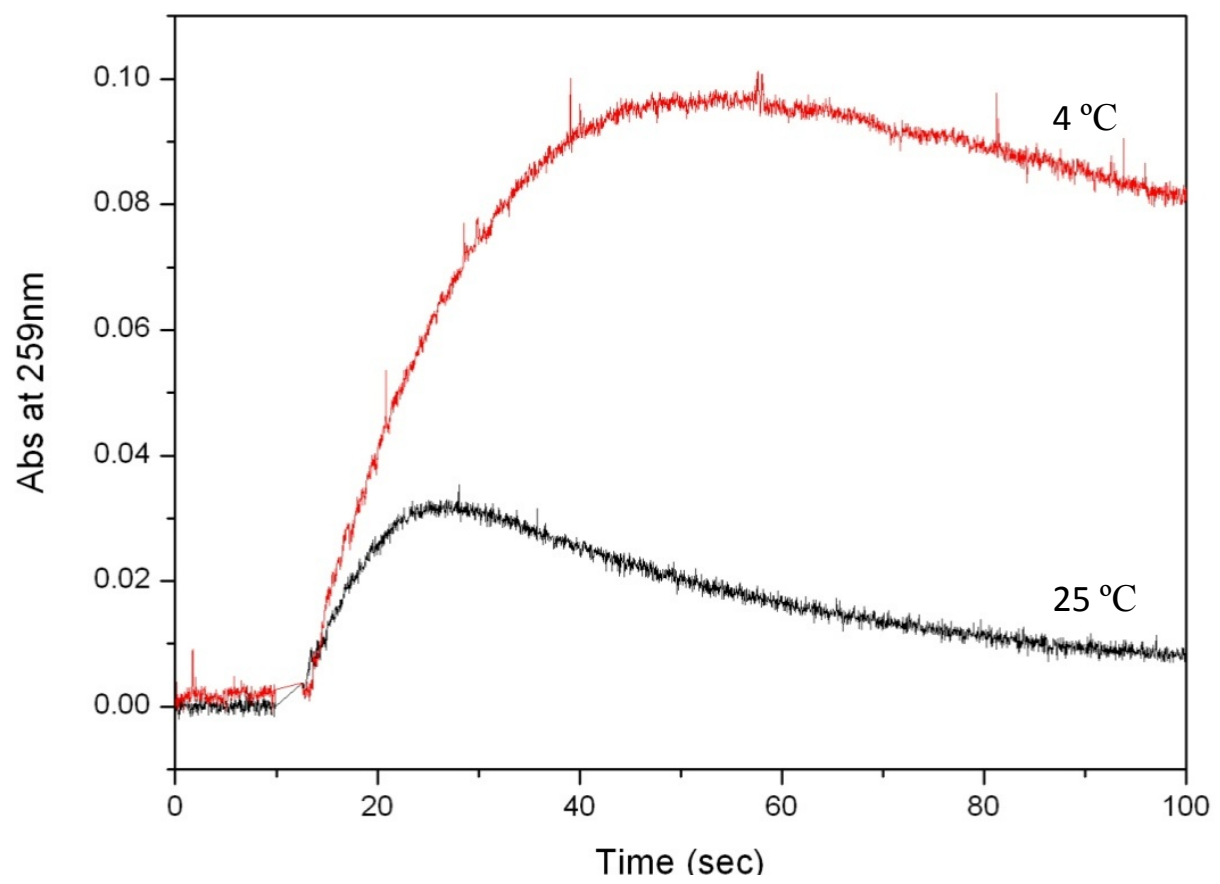

Figure 3.2. Activity assay of DMSP oxidation catalyzed by $\mathrm{CPO}$ at $25^{\circ} \mathrm{C}$ and $4{ }^{\circ} \mathrm{C}$. 


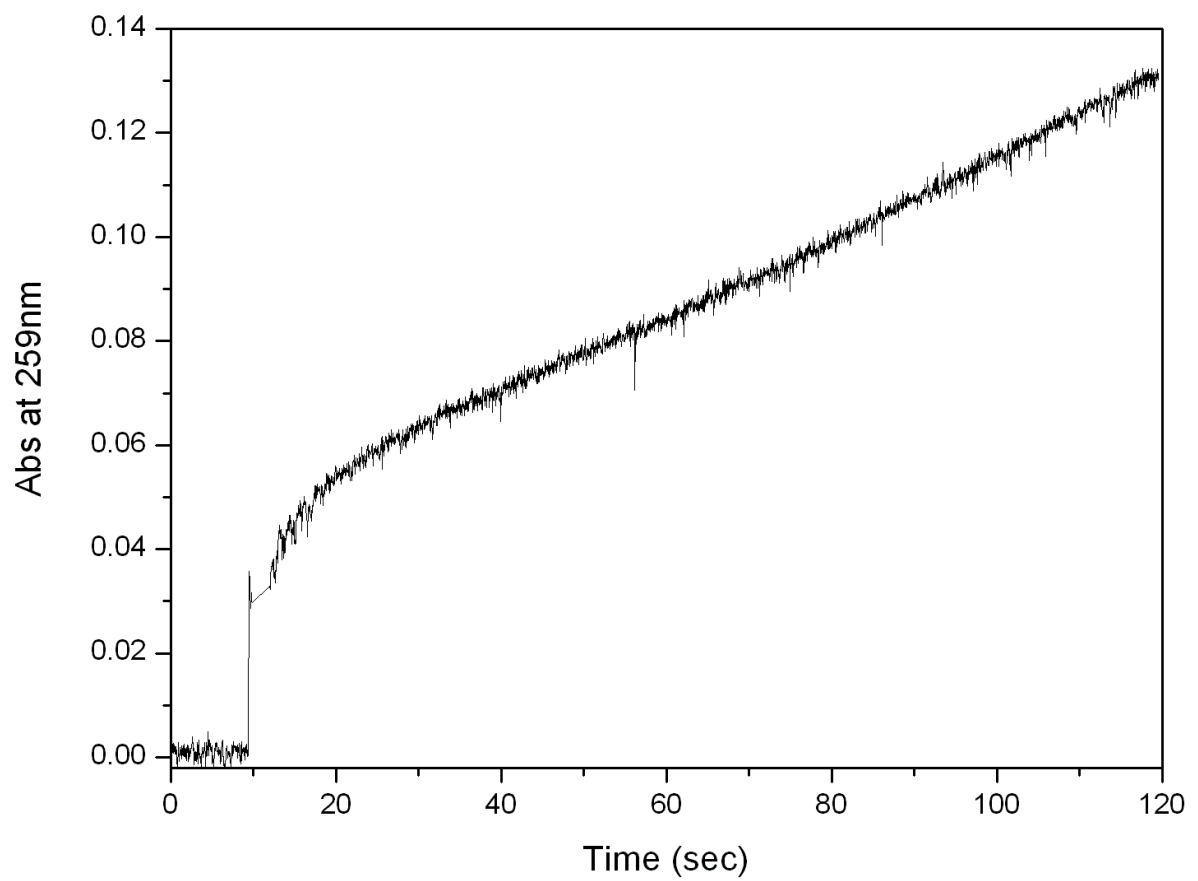

Figure 3.3. Activity assay of DMSP oxidation catalyzed by F103A mutant.

\subsection{Discussion and Conclusions}

As shown in Figure 3.1, the new $259 \mathrm{~nm}$ peak suggested a new product formed, which indicates that CPO can catalyze the oxidation of DMSP with $\mathrm{H}_{2} \mathrm{O}_{2}$ as the oxidant. In the activity assay (Figure 3.2), the appearance of a initial increase followed by a decrease in the absorbance at $259 \mathrm{~nm}$ confirmed that CPO could catalyze a two-step oxidation reaction of DMSP, in which the product of the first step reaction is the reactant of the second step reaction. At $4{ }^{\circ} \mathrm{C}$, the faster rate of the first reaction and the higher absorbance suggests that the rate of the breakdown of the intermediate from the first reaction is dramatically decreased. Therefore, the rate of the second step reaction was affected more severely by temperature. 
The same $259 \mathrm{~nm}$ peak in the UV-vis absorption spectra of DMSP oxidation products catalyzed by F103A confirmed that the F103A mutant can also catalyze the oxidation of DMSP. As shown in Figure 3.3, the continuous increase in absorbance at $259 \mathrm{~nm}$ without observable decrease indicates that F103A could not further catalyze the second step reaction as WT CPO. It also suggests that the second step reaction was not spontaneous, but was catalyzed by WT CPO.

For identification by LC-MS, numerous peaks were shown in the LC-MS spectrum of DMSP oxidation products. It may be for the reason that CPO catalyzed reaction can lead to complicated system, which resulted in the failure of identification.For the identification by GC-MS, no mass signal was observed in the chromatogram. The poor extraction efficiency may lead to the failure of identification on GC-MS.

According to the literature, ${ }^{67} \mathrm{DMS}, \mathrm{DMSO}, \mathrm{MeSH}, \mathrm{MPA}$ and MSA are the common products of DMSP oxidation in nature. However, none of their absorption spectra (data not shown) matched with the UV-vis absorption spectra of DMSP oxidation products catalyzed by CPO. In addition, they cannot be further oxidized by CPO or F103A mutant, which indicates that they are not the first or second step products of the DMSP oxidation catalyzed by CPO. Since another possible natural product, MMPA, was commercially not available, we cannot verify its UV-vis absorption spectrum. Therefore, the product of DMSP oxidation catalyzed by CPO may be MMPA or other substances which are not naturally produced through DMSP oxidation.

As stated in Chapter I, DMSP is a feeding attractant that exists extensively as a metabolite in marine phytoplankton, seaweeds, and some species of aquatic vascular plants, and tends to be released by grazer attack. CPO is naturally secreted by a fungus, $C$. 
fumago, which is also grown in the ocean. Therefore, the role of the DMSP-degradation reaction in the activated defense system may reveal the biological function of CPO. When CPO is secreted by C. fumago, it creates an environment that can degrade any released DMSP and convert it to a toxic or deterrent product against the grazers. As a result, the secreted CPO can act as a protecting shield to inhibit ongoing feeding and consequently protect its host and the adjacent marine plants. Therefore, our results indicate that the natural function of $\mathrm{CPO}$ may be to protect $C$. fumago and its possible symbiotic host plants from being consumed. 


\section{REFERENCES}

(1) Morris, D. R.; Hager, L. P. Journal of Biological Chemistry 1966, 241, 1763.

(2) Beckwith, J. R.; Hager, L. P. Journal of Biological Chemistry 1963, 238, 3091.

(3) Omura, T. Biochemical and Biophysical Research Communications 2005, 338, 404.

(4) Thomas, J. A.; Hager, L. P. Biochemical and Biophysical Research Communications 1968, 32, 770.

(5) Thomas, J. A.; Morris, D. R.; Hager, L. P. Journal of Biological Chemistry 1970, $245,3129$.

(6) Hollenberg, P. F.; Hager, L. P. Journal of Biological Chemistry 1973, 248, 2630.

(7) Hager, L. P. Journal of Biological Chemistry 2010, 285, 14852.

(8) Penner-Hahn, J. E.; Smith Eble, K.; McMurry, T. J.; Renner, M.; Balch, A. L.; Groves, J. T.; Dawson, J. H.; Hodgson, K. O. Journal of the American Chemical Society 1986, 108, 7819.

(9) Hager, L. P.; Doubek, D. L.; Silverstein, R. M.; Hargis, J. H.; Martin, J. C. Journal of the American Chemical Society 1972, 94, 4364.

(10) Kobayashi, S.; Nakano, M.; Kimura, T.; Schaap, A. P. Biochemistry 1987, 26, 5019.

(11) Kim, S. H.; Perera, R.; Hager, L. P.; Dawson, J. H.; Hoffman, B. M. Journal of the American Chemical Society 2006, 128, 5598.

(12) Green, M. T.; Dawson, J. H.; Gray, H. B. Science 2004, 304, 1653.

(13) Nakajima, R.; Yamazaki, I.; Griffin, B. W. Biochemical and Biophysical Research Communications 1985, 128, 1.

(14) Dexter, A. F.; Lakner, F. J.; Campbell, R. A.; Hager, L. P. Journal of the American Chemical Society 1995, 117, 6412.

(15) Wang, B.; Wong, O. A.; Zhao, M.-X.; Shi, Y. The Journal of Organic Chemistry 2008, 73, 9539 .

(16) Jung, D.; Streb, C.; Hartmann, M. Microporous and Mesoporous Materials 2008, 113,523 . 
(17) Yi, X.; Mroczko, M.; Manoj, K. M.; Wang, X.; Hager, L. P. Replacement of the proximal heme thiolate ligand in chloroperoxidase with a histidine residue, 1999; Vol. 96.

(18) Hu, S.; Hager, L. P. ChemInform 1999, 30, no.

(19) Hu, S.; Hager, L. P. Tetrahedron Letters 1999, 40, 1641.

(20) Lin, H.; Liu, Y.; Wu, Z.-L. Tetrahedron: Asymmetry 2011, 22, 134.

(21) Hasemann, C. A.; Kurumbail, R. G.; Boddupalli, S. S.; Peterson, J. A.; Deisenhofer, J. Structure 1995, 3, 41.

(22) Boddupalli, S. S.; Hasemann, C. A.; Ravichandran, K. G.; Lu, J. Y.; Goldsmith, E. J.; Deisenhofer, J.; Peterson, J. A. Proc Natl Acad Sci U SA 1992, 89, 5567.

(23) Sundaramoorthy, M.; Terner, J.; Poulos, T. L. Chem Biol 1998, 5, 461.

(24) Sundaramoorthy, M.; Terner, J.; Poulos, T. L. Structure 1995, 3, 1367.

(25) Kühnel, K.; Blankenfeldt, W.; Terner, J.; Schlichting, I. Journal of Biological Chemistry 2006, 281, 23990.

(26) Sundaramoorthy, M.; Terner, J.; Poulos, T. L. Structure (London, England : 1993) 1995, 3, 1367.

(27) Wang, X.; Tachikawa, H.; Yi, X.; Manoj, K. M.; Hager, L. P. J Biol Chem 2003, 278,7765 .

(28) Kuhnel, K.; Blankenfeldt, W.; Terner, J.; Schlichting, I. J Biol Chem 2006, 281, 23990.

(29) Ettre, L. S. Milestones in the evolution of chromatography; ChromSource, 2002.

(30) Lindsay, S.; Barnes, J.; ACOL High performance liquid chromatography; Published on behalf of Thames Polytechnic, London, by Wiley, 1992.

(31) Miller, J. M. Chromatography: concepts and contrasts; Wiley, 2005.

(32) Reddy, I. K.; Miḥvar, R.; Mehvar, R. Chirality in drug design and development; Marcel Dekker, 2004.

(33) Simplício, A. L.; Matias, P.; Gilmer, J. F.; Clancy, J. M. Journal of Chromatography A 2006, 1120, 89.

(34) Sellers, J. A.; Olsen, B. A.; Owens, P. K.; Gavin, P. F. Journal of Pharmaceutical 
and Biomedical Analysis 2006, 41, 1088.

(35) Driffield, M.; York, U. o. Novel approaches to chiral HPLC: an improved optical rotation detector and dendritic chiral stationary phases; University of York, 2002.

(36) Gübitz, G.; Schmid, M. G. Chiral separations: methods and protocols; Humana Press, 2004.

(37) Toyo'oka, T.; Liu, Y.-M. Journal of Chromatography A 1995, 689, 23.

(38) Lindner, W.; Leitner, C.; Uray, G. Journal of Chromatography A 1984, 316, 605.

(39) Beesley, T. E.; Scott, R. P. W. Chiral chromatography; John Wiley \& Sons, 1998.

(40) Hermansson, J. Journal of Chromatography A 1984, 316, 537.

(41) Gazdag, M.; Szepesi, G.; Huszár, L. Journal of Chromatography A 1988, 436, 31.

(42) Aboul-Enein, H. Y.; Ali, I. Chiral separations by liquid chromatography and related technologies; M. Dekker, Inc., 2003.

(43) Kummer, M.; Palme, H. J.; Werner, G. Journal of Chromatography A 1996, 749, 61.

(44) Kubota, T.; Yamamoto, C.; Okamoto, Y. Journal of the American Chemical Society 2000, 122, 4056.

(45) Aboul-Enein, H. Y.; Ali, I. Journal of Pharmaceutical and Biomedical Analysis 2002, 27, 441 .

(46) Seeman, J. I.; Secor, H. V.; Armstrong, D. W.; Timmons, K. D.; Ward, T. J. Analytical Chemistry 1988, 60, 2120.

(47) Pirkle, W. H.; Mahler, G. S.; Pochapsky, T. C.; Hyun, M. H. Journal of Chromatography A 1987, 388, 307.

(48) Wainer, I. W.; Alembik, M. C. Journal of Chromatography A 1986, 367, 59.

(49) Pirkle, W. H. Journal of Chromatography A 1991, 558, 1.

(50) Ward, T. J.; Oswald, T. M. In Encyclopedia of Analytical Chemistry; John Wiley \& Sons, Ltd: 2006.

(51) Maier, N. M.; Franco, P.; Lindner, W. Journal of Chromatography A 2001, 906, 3.

(52) Davankov, V. A.; Semechkin, A. V. Journal of Chromatography A 1977, 141, 313. 
(53) Zhao, C.; Cann, N. M. Journal of Chromatography A 2007, 1149, 197.

(54) Pirkle, W. H.; Jonathan Brice, L.; Caccamese, S.; Principato, G.; Failla, S. Journal of Chromatography A 1996, 721, 241.

(55) Pirkle, W. H.; Welch, C. J. Tetrahedron: Asymmetry 1994, 5, 777.

(56) Pirkle, W. H.; Pochapsky, T. C. Chemical Reviews 1989, 89, 347.

(57) Welch, C. J. Journal of Chromatography A 1994, 666, 3.

(58) Blum, A. M.; Lynam, K. G.; Nicolas, E. C. Chirality 1994, 6, 302.

(59) Cantoni, G. L.; Anderson, D. G.; Rosenthal, W. t. t. a. o. E. Journal of Biological Chemistry 1956, 222, 171.

(60) Charlson, R. J.; Lovelock, J. E.; Andreae, M. O.; Warren, S. G. Nature 1987, 326, 655.

(61) Dacey, J. W. H.; King, G. M.; Wakeham, S. G. Nature 1987, 330, 643.

(62) Cunningham, G. B.; Strauss, V.; Ryan, P. G. Journal of Experimental Biology 2008, 211, 3123 .

(63) Seymour, J. R.; Simó, R.; Ahmed, T.; Stocker, R. Science 2010, 329, 342.

(64) DeBose, J. L.; Lema, S. C.; Nevitt, G. A. Science 2008, 319, 1356.

(65) Nevitt, G. A. Journal of Experimental Biology 2008, 211, 1706.

(66) Todd, J. D.; Rogers, R.; Li, Y. G.; Wexler, M.; Bond, P. L.; Sun, L.; Curson, A. R. J.; Malin, G.; Steinke, M.; Johnston, A. W. B. Science 2007, 315, 666.

(67) Rafel, S. Trends in Ecology \&amp; Evolution 2001, 16, 287.

(68) Gabric, A.; Gregg, W.; Najjar, R.; Erickson, D.; Matrai, P. Chemosphere - Global Change Science 2001, 3, 377.

(69) Raina, J.-B.; Dinsdale, E. A.; Willis, B. L.; Bourne, D. G. Trends in Microbiology 2010, 18, 101.

(70) Wolfe, G. V.; Steinke, M.; Kirst, G. O. Nature 1997, 387, 894.

(71) Alstyne, K. L. V. Activated defense systems in marine macroalgae: evidence for an ecological role for DMSP cleavage; Inter-Research. 
(72) Suzanne, S.; Gordon, W.; Amy, S.; Sarah, L.; Jennifer, C. Limnol Oceangr 2003, 48,230 .

(73) Paul, V. J.; Van Alstyne, K. L. Journal of Experimental Marine Biology and Ecology 1992, 160, 191.

(74) Morante-Zarcero, S.; del Hierro, I.; Fajardo, M.; Sierra, I. Analytica Chimica Acta $2008,618,102$.

(75) Allain, E. J.; Hager, L. P.; Deng, L.; Jacobsen, E. N. Journal of the American Chemical Society 1993, 115, 4415.

(76) Pan, C.; Shen, B.; Zhang, X.; Zhang, D.; Xu, X. Chinese Journal of Analytical Chemistry 2006, 34, 159.

(77) Magora, A.; Abu-Lafi, S.; Levin, S. Journal of Chromatography A 2000, 866, 183.

(78) Luke, B. T.; Collins, J. R.; Loew, G. H.; McLean, A. D. Journal of the American Chemical Society 1990, 112, 8686.

(79) De Visser, S. P.; Ogliaro, F.; Harris, N.; Shaik, S. Journal of the American Chemical Society 2001, 123, 3037.

\section{APPENDIX A}

Sequences of Chloroperoxidase

\section{General information}

The wild-type chloroperoxidase protein includes 299 amino acids as listed in Figure A.

Figure A. Amino acid sequence of full-length of WT Chloroperoxidase. N74 and F103 are underlined.

1 EPGSGIGYPY DNNTLPYVAP GPTDSRAPCP ALNALANHGY IPHDGRAISR

51 ETLQNAFLNH MGIANSVIEL ALTNNAFVVCE YVTGSDCGDS LVNLTLLAEP

101 HAFEHDHSFS RKDYKQGVAN SNDFIDNRNF DAETFQTSLD VVAGKTHFDY 
151 ADMNEIRLQR ESLSNELDFP GWFTESKPIQ NVESGFIFAL VSDFNLPDND

201 ENPLVRIDWW KYWFTNESFP YHLGWHPPSP AREIEFVTSA SSAVLAASVT 251 STPSSLPSGA IGPGAEAVPL SFASTMTPFL LATNAPYYAQ DPTLGPNDX 